BNL-105287-2014-IR

\title{
Analysis of Loss-of-Coolant Accidents in the NBSR
}

\author{
J-S Baek, L-Y Cheng, D. Diamond
}

May 2014

Nuclear Science \& Technology Department

Brookhaven National Laboratory

\author{
U.S. Department of Energy \\ National Institute of Standards and Technology
}

Notice: This manuscript has been authored by employees of Brookhaven Science Associates, LLC under Contract No. DE-AC02-98CH10886 with the U.S. Department of Energy. The publisher by accepting the manuscript for publication acknowledges that the United States Government retains a non-exclusive, paid-up, irrevocable, world-wide license to publish or reproduce the published form of this manuscript, or allow others to do so, for United States Government purposes. 


\section{DISCLAIMER}

This report was prepared as an account of work sponsored by an agency of the United States Government. Neither the United States Government nor any agency thereof, nor any of their employees, nor any of their contractors, subcontractors, or their employees, makes any warranty, express or implied, or assumes any legal liability or responsibility for the accuracy, completeness, or any third party's use or the results of such use of any information, apparatus, product, or process disclosed, or represents that its use would not infringe privately owned rights. Reference herein to any specific commercial product, process, or service by trade name, trademark, manufacturer, or otherwise, does not necessarily constitute or imply its endorsement, recommendation, or favoring by the United States Government or any agency thereof or its contractors or subcontractors. The views and opinions of authors expressed herein do not necessarily state or reflect those of the United States Government or any agency thereof. 
BNL- 105287-2014-IR

\section{Analysis of Loss-of-Coolant Accidents in the NBSR}

Manuscript Completed:

May 23, 2014

Prepared by:

Joo Seok Baek, Lap-Yan Cheng, and David Diamond Nuclear Science \& Technology Department Brookhaven National Laboratory

Upton, NY 11973

Prepared for:

National Nuclear Security Administration

National Institute of Standards and Technology 



\begin{abstract}
This report documents calculations of the fuel cladding temperature during loss-of-coolant accidents in the NBSR. The probability of a pipe failure is small and procedures exist to minimize the loss of water and assure emergency cooling water flows into the reactor core during such an event. Analysis in the past has shown that the emergency cooling water would provide adequate cooling if the water filled the flow channels within the fuel elements. The present analysis is to determine if there is adequate cooling if the water drains from the flow channels. Based on photographs of how the emergency water flows into the fuel elements from the distribution pan, it can be assumed that this water does not distribute uniformly across the flow channels but rather results in a liquid film flowing downward on the inside of one of the side plates in each fuel element and only wets the edges of the fuel plates. An analysis of guillotine breaks shows the cladding temperature remains below the blister temperature in fuel plates in the upper section of the fuel element. In the lower section, the fuel plates are also cooled by water outside the element that is present due to the hold-up pan and temperatures are lower than in the upper section. For small breaks, the simulation results show that the fuel elements are always cooled on the outside even in the upper section and the cladding temperature cannot be higher than the blister temperature. The above results are predicated on assumptions that are examined in the study to see their influence on fuel temperature.
\end{abstract}




\section{Table of Contents}

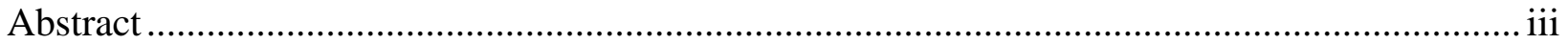

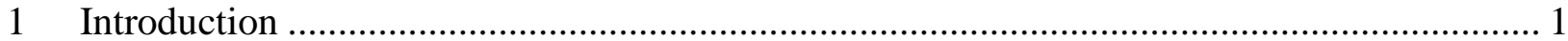

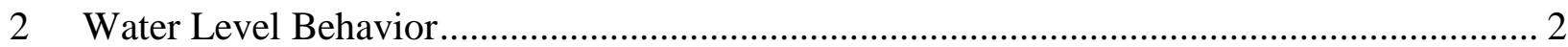

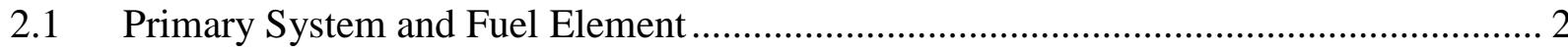

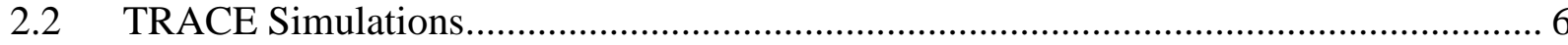

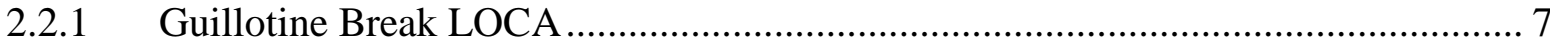

2.2.1.1 Guillotine Break at Vessel Outlet Pipe (Case 1) ............................................ 7

2.2.1.2 Guillotine Break at Outer Plenum Inlet Pipe (Case 2) ................................. 10

2.2.1.3 Guillotine Break at Inner Plenum Inlet Pipe (Case 3) .................................. 13

2.2.1.4 Summary of Guillotine Break LOCA Simulations........................................ 15

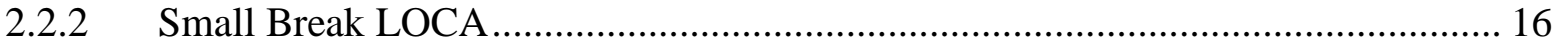

2.2.2.1 Small Break at Vessel Outlet Pipe.............................................................. 16

2.2.2.2 Small Break at Outer Plenum Inlet Pipe (Case 4) ........................................ 17

2.2.2.3 Small Break at Inner Plenum Pipe (Case 5) .............................................. 20

2.2.2.4 Summary of Small Break LOCA Simulations ........................................... 23

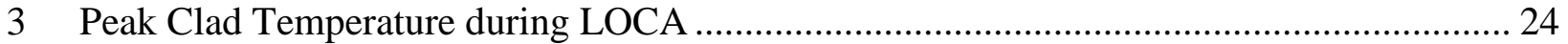

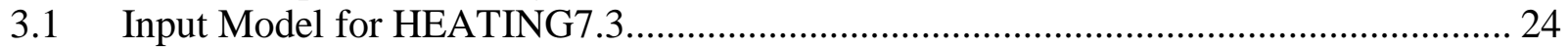

3.1.1 Mesh Regions in Fuel Element for Thin Liquid Film ....................................... 24

3.1.2 Mesh Regions in Fuel Element for Thick Liquid Film....................................... 29

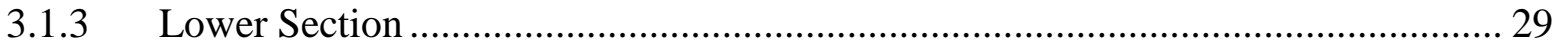

3.1.4 Evaluation of Film Thickness .................................................................... 31

3.1.5 Representation of Joint Between Fuel Plate and Side Plate ............................... 33

3.1.5.1 Thermal Contact between Fuel Plates and Side Plates.................................. 33

3.1.5.2 Conductance for Imperfect Thermal Contact .......................................... 37

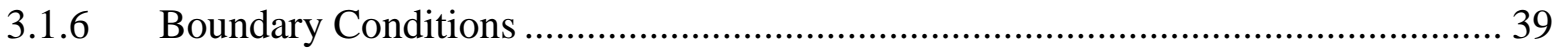

3.1.7 Decay Power and Power Distribution among Fuel Plates .................................. 41

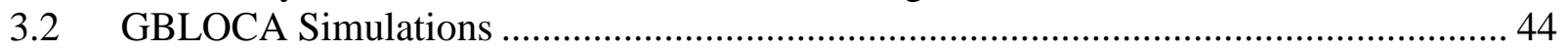

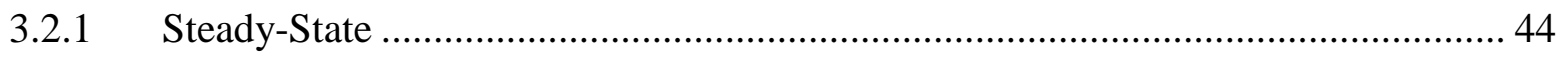

3.2.2 Base Case - Perfect Thermal Contact ........................................................... 45

3.2.2.1 Upper Section of Fuel Element ............................................................ 45

3.2.2.2 Lower Section of Fuel Element ................................................................ 48

3.2.3 Imperfect Thermal Contact .................................................................... 49

3.2.4 Other Considerations ............................................................................ 50

3.2.4.1 Uncertainty in Correlation for Contact Conductance .................................. 50

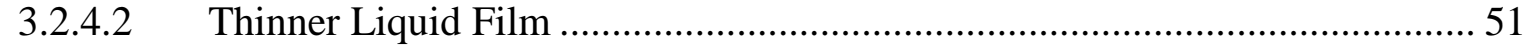

3.2.5 Summary of GBLOCA Simulations ............................................................ 54

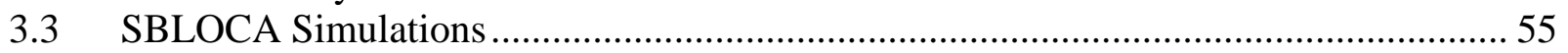

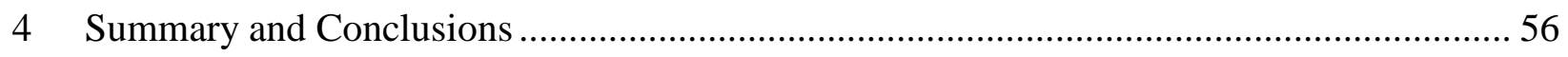

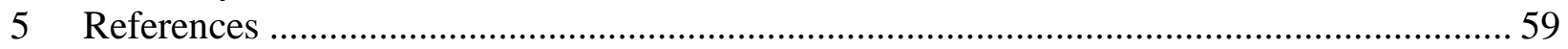




\section{List of Figures}

Figure 2.1 Nodal Diagram of TRACE Model for NBSR ................................................... 3

Figure 2.2 Inner Reserve Tank and Emergency Distribution Pan (NIST, 2010a)..................... 4

Figure 2.3 Emergency Distribution Pan and IRT Water Streams (NIST, 2010a) ...................... 5

Figure 2.4 Fuel Element and Fuel Plates ................................................................... 5

Figure 2.5 Cross Sectional View of Fuel Element........................................................... 6

Figure 2.6 Water Level in Fuel Element after Guillotine Break at Vessel Outlet Pipe (Case 1) . 8

Figure 2.7 End-State of Coolant Distribution inside NBSR Vessel after Guillotine Break ....... 10

Figure 2.8 Water Level in Fuel Element after Guillotine Break at Outer Plenum Inlet Pipe

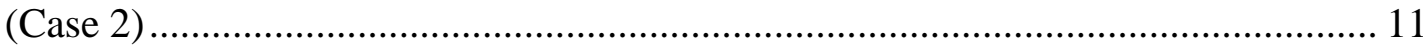

Figure 2.9 Water Level Behavior in Fuel Element after Guillotine Break at Inner Plenum Inlet Pipe (Case 3) ....................................................................................... 13

Figure 2.10 Comparison of Water Level in Upper Fuel Element after Guillotine Breaks ......... 15

Figure 2.11 End-State of Coolant Distribution inside NBSR Vessel after Small Break at

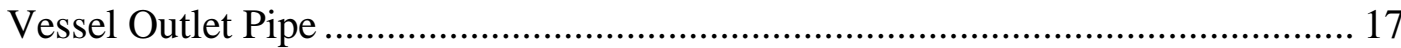

Figure 2.12 Water Level Behavior in Fuel Element after Small Break at Outer Plenum Inlet

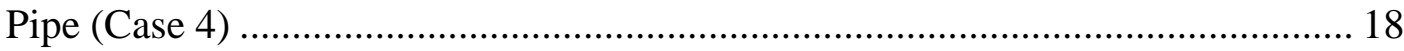

Figure 2.13 End-State of Coolant Distribution inside NBSR Vessel after Small Break at Outer Plenum Inlet Pipe (Case 4) ...................................................................... 20

Figure 2.14 Water Level Behavior in Fuel Element after Small Break at Inner Plenum Inlet Pipe (Case 5) ......................................................................................... 21

Figure 2.15 End-State of Coolant Distribution inside NBSR Vessel after Small Break at Inner Plenum Inlet Pipe (Case 5) .................................................................. 23

Figure 3.1 Fuel Plate and Side Plates (Not to Scale) ........................................................ 25

Figure 3.2 Regions of Fuel Plate and Side Plates in X-Y Plane (Not to Scale)....................... 25

Figure 3.3 Regions of Fuel Plate and Side Plates of Upper Fuel Element in X-Z Plane

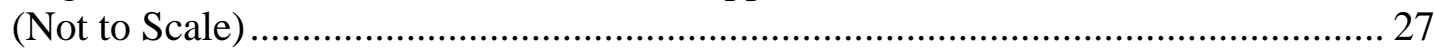

Figure 3.4 Regions of Nine Fuel, Side and Outside Plates in X-Y Plane (Not to Scale) .......... 28

Figure 3.5 Mesh Regions to Simulate Thick Liquid Film in X-Y Plane (Not to Scale)............ 29

Figure 3.6 Regions of Fuel Plate and Side Plates of Lower Fuel Element in X-Z Plane

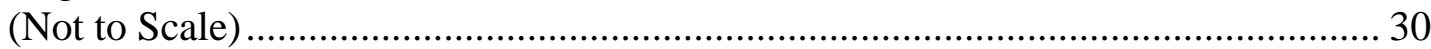

Figure 3-7 Flow in Rectangular Open Channel ................................................................. 31

Figure 3-8 Moody Type Diagram for Open Channels with Impervious Rigid Boundary

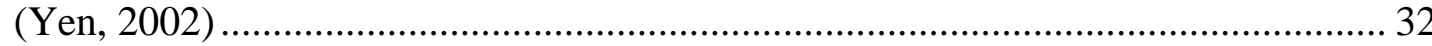

Figure 3.7 Thermal Contact of Two Plates (Dassault, 2014) ................................................ 34

Figure 3.8 Mesh Regions to Simulate Imperfect Thermal Contact with Complete (100\%)

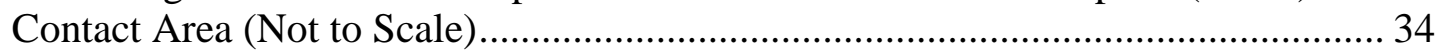

Figure 3.9 Fuel Plates and Side Plate (NIST, 2012) .............................................................. 35

Figure 3.10 Technique Used to Fabricate Roll Swaged Joint for Advance Test Reactor Fuel Element (Adamson, 1968)................................................................................ 36

Figure 3.11 Mesh Regions to Simulate Imperfect Thermal Contact with Incomplete (50\%)

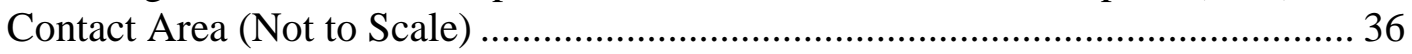

Figure 3.12 Friction and Normal Forces ............................................................................ 38

Figure 3.13 Heat Flux Applied to Outer Surface of Side plate............................................. 40

Figure 3.14 Power Fraction as Function of Time in GBLOCA Simulations............................. 42 
Figure 3.15 Normalized Photon Emission and Absorption Rates in Fuel Element L-3 (Williams, 2014b).

Figure 3.16 Peak Clad Temperature of Upper Fuel Plates with Thin Liquid Film after

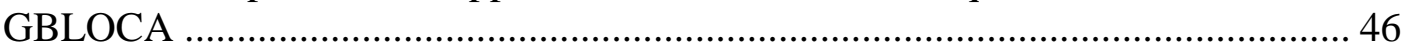

Figure 3.17 Temperature of Surface with Thin Film after GBLOCA ..................................... 47

Figure 3.18 Temperature of Surface with Thick Film after GBLOCA .................................. 48

Figure 3.19 PCT in Lower Fuel Plates with Thin Liquid Film after GBLOCA ...................... 49

Figure 3.22 Effect of Thermal Contact and Contact Area on PCT .......................................... 50

Figure 3.21 Effect of Smaller Contact Conductance on PCT ............................................... 51

Figure 3.23 Water Impingement in Mockup Test with Upper Part of Fuel Element ................. 52

Figure 3.24 PCT Behavior with Smaller Mass Flowrates ................................................... 53

Figure 3.25 Effect of the $9^{\text {th }}$ Plate Being Cooled by Dripping Water...................................... 54

Figure 3.25 PCT in Upper Plates under Extreme SBLOCA Conditions ................................. 56

\section{List of Tables}

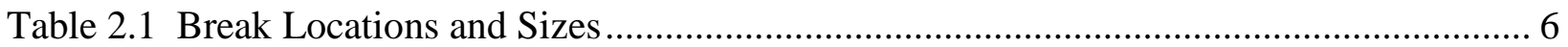

Table 2.2 Sequence of Events after Guillotine Break at Vessel Outlet Pipe ............................... 9

Table 2.3 Sequence of Events after Guillotine Break at Outer Plenum Inlet Pipe ..................... 12

Table 2.4 Sequence of Events after Guillotine Break at Inner Plenum Inlet Pipe...................... 14

Table 2.5 Comparison of Sequence of Events after Guillotine Breaks ................................... 15

Table 2.6 Sequence of Events after Small Break at Outer Plenum Inlet Pipe........................... 19

Table 2.7 Sequence of Events after Small Break at Inner Plenum Inlet Pipe............................ 22

Table 3.1 Regions in X-Y and X-Z Plane for Thin (and Thick) Liquid Film........................... 25

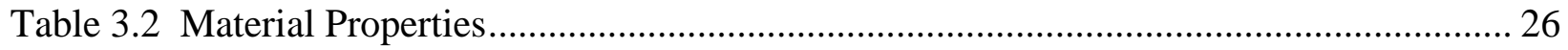

Table 3.3 Thermal and Surface Properties of Al 6061 (Yovanovich, 2014) ............................. 37

Table 3.4 Power Densities in Fuel Element L-3 ................................................................... 43

Table 3.5 Steady-State Average Temperatures in Upper and Lower Sections........................... 45

Table 3.7 Maximum PCTs after Guillotine Break............................................................. 54 


\section{Introduction}

The licensing analysis of the loss-of-coolant accident (LOCA) in the NIST research reactor (NBSR) is found in the Safety Analysis Report (SAR) (NIST, 2010a). Chapter 6 of the SAR discusses the emergency cooling system (ECS), and Chapter 13 discusses the low probability of a significant pipe break: "the main piping is located in protected areas, system pressures are low, and flow rates are small so that wear is not an issue." The probability of a large break (LB), including a double-ended guillotine break, is, therefore, extremely low. For smaller breaks where the operator has time to take action, procedures are in place (NIST, 2011) to mitigate a loss of water by tripping pumps and closing valves after the falling water level in the vessel is detected by instrumentation, and to assure that emergency cooling water continues to flow for as long as needed.

Chapter 13 also refers to an analysis (Cheng, 2004) of why the ECS should provide sufficient water to cool the fuel elements in a LOCA if the coolant channels remain filled with water. That analysis is based on assuming the emergency water would flow from the distribution pan above the fuel elements into all the coolant channels completely wetting the fuel plates. However, a recent examination of photographs of this flow pattern shows that the water will fall only along the inner surface of one of the side plates in the fuel elements. The current study was undertaken to understand what would happen in those cases where this was the only cooling available and what LOCA scenarios would result in this situation.

The effect of a large (guillotine) break is considered at different locations and with the assumption that if the water is drained from the coolant channels, the water from the inner reserve tank (IRT, part of the ECS) creates a film on the inside of one of the two side plates in each fuel element. Small break LOCAs (SBLOCAs) are also analyzed with an arbitrarily small size break of $6.8 \mathrm{~cm}^{2}$ to understand the difference from a LBLOCA.

The analysis is based on two types of calculations. The first (in Section 2) examines how the water would drain from the primary system following a break and the potential for the loss of coolant within the fuel plate channels. The second (in Section 3) looks at the fuel clad temperature as a function of time given that the water has drained from the fuel element. The latter takes into consideration that the outside of the bottom section of the fuel elements would still be cooled by quiescent water due to the presence of the hold-up pan.

An acceptance criterion for the clad temperature given by the U.S. Nuclear Regulatory Commission (NRC) is that there should be no loss of fuel integrity [Chapter 13 in (NRC, 1996)]. A clad temperature of $582^{\circ} \mathrm{C}$, the solidus temperature, is the point at which fission product release is expected (Stahl, 1982) and the NRC accepts $530^{\circ} \mathrm{C}$ as a clad temperature limit not to be exceeded under any conditions [Chapter 14 in (NRC, 1996)]. In the present study the Technical Specification Safety Limit, which is $450^{\circ} \mathrm{C}$, the minimum blister temperature for the aluminum clad (NIST, 2010b) is used as a conservative surrogate to preclude the release of fission products and act as the acceptance criterion. This applies to all break sizes although in reality, the double-ended guillotine break is of such a low probability that it could be considered hypothetical and similar to the accident analyzed in the SAR wherein it is assumed that there is 
complete flow blockage of one fuel element; the so-called "maximum hypothetical accident." Events in this latter category are only analyzed to see if radiation dose limits are exceeded.

\section{Water Level Behavior}

Based on a review of the piping for the NBSR, it was decided that there were three locations that would cover the important locations for pipe breaks: (1) the 18-inch pipe between the reactor vessel outlet ( $\mathrm{D}_{2} \mathrm{O}$ outlet) and the control valve DWV-19; (2) the 14-inch pipe between the control valve DWV-1 and the outer plenum; and (3) the 10-inch pipe between the control valve DWV-2 and the inner plenum. The first pipe is upstream of the primary (main $\mathrm{D}_{2} \mathrm{O}$ ) and shutdown pumps and the others are downstream of the pumps.

The TRACE computer code (NRC, 2010) is used to calculate the water level inside the reactor vessel after a LOCA. The model is based on the RELAP5 input model developed for other safety analyses (Baek, 2013). That original model was converted to a TRACE model because of difficulties applying RELAP5 at atmospheric pressure and with non-condensable gas.

The geometries and the characteristics (such as the pumps' homologous curves) of the hydrodynamic components are exactly the same as those of the RELAP5 model. The logic of the control systems is identical to that in the RELAP5 input deck as well.

\subsection{Primary System and Fuel Element}

Figure 2.1 shows the nodal diagram of the TRACE model for the NBSR. The NBSR consists of the reactor vessel, primary piping from vessel outlet to inlet, upper plenum, inner reserve tank, distribution pan, holdup pan, primary and shutdown cooling pumps, heat exchanger, fuel elements (FEs) and coolant channels. The right and left parts of the figure represent the inner core and outer core, respectively. The inner and outer cores include 6 and 24 fuel elements, respectively. The nodes with red color represent the fuel plates even though they are not thermally modeled in the TRACE simulations. As discussed in Section 3, the responses of the clad and fuel are simulated using HEATING7.3 in order to be able to evaluate three-dimensional heat conduction and temperature distribution in the fuel element in the detail needed for LOCA conditions.

Figure 2.1 also shows "VALVE” components with arrows to simulate different pipe breaks through which the coolant is discharged into the Process Room. LOCAs are simulated by opening these valve components and, if necessary, closing the valves connecting the two adjacent pipes to model guillotine breaks. VALVE-51 and VALVE-70 are also separately used to represent the actual DWV-1 and DWV-2 valves at the NBSR in the SBLOCA simulations. A description of them is presented in Section 2.2.2. 


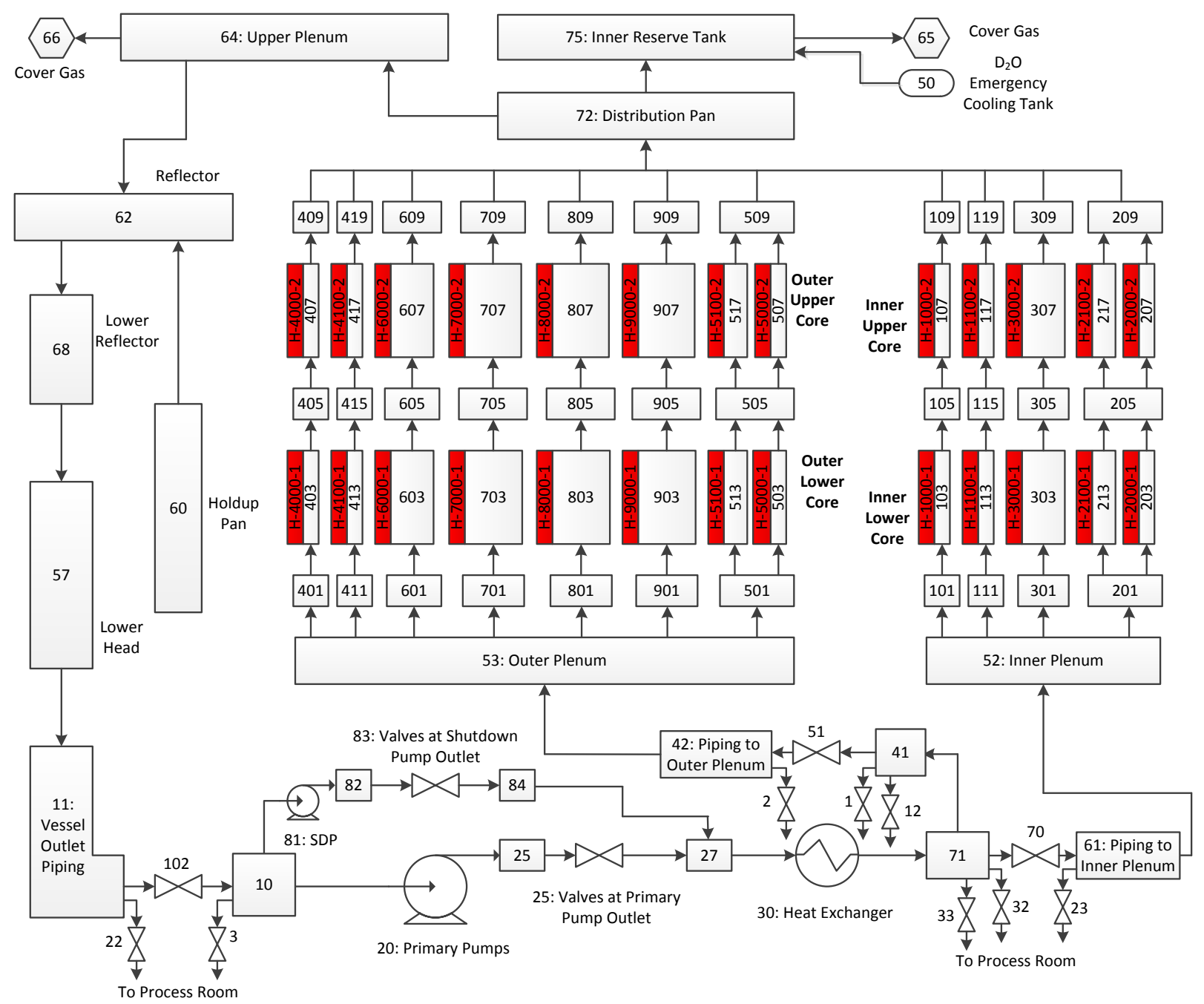

Figure 2.1 Nodal Diagram of TRACE Model for NBSR

Three break locations are considered. VALVEs-3, -22, and -102 represent the guillotine break at the 18-inch pipe between the reactor vessel outlet and the control valve DWV-19. The guillotine break at the 14-inch pipe between the control valve DWV-1 and the outer plenum is modeled using VALVEs-1, -2, and -51. VALVE-12 is used to simulate a SBLOCA in the outer plenum inlet pipe. The guillotine break of the 10 -inch pipe between the control valve DWV-2 and the inner plenum is simulated by opening VALVEs-23 and -32 and closing VALVE-70. A small break at the inner plenum inlet pipe is modeled using VALVE-33.

The inner reserve tank is mounted above the emergency cooling distribution pan. Figure 2.2 shows the IRT (the perimeter annular tank) and the distribution pan. The empty center region is the upper plenum. 


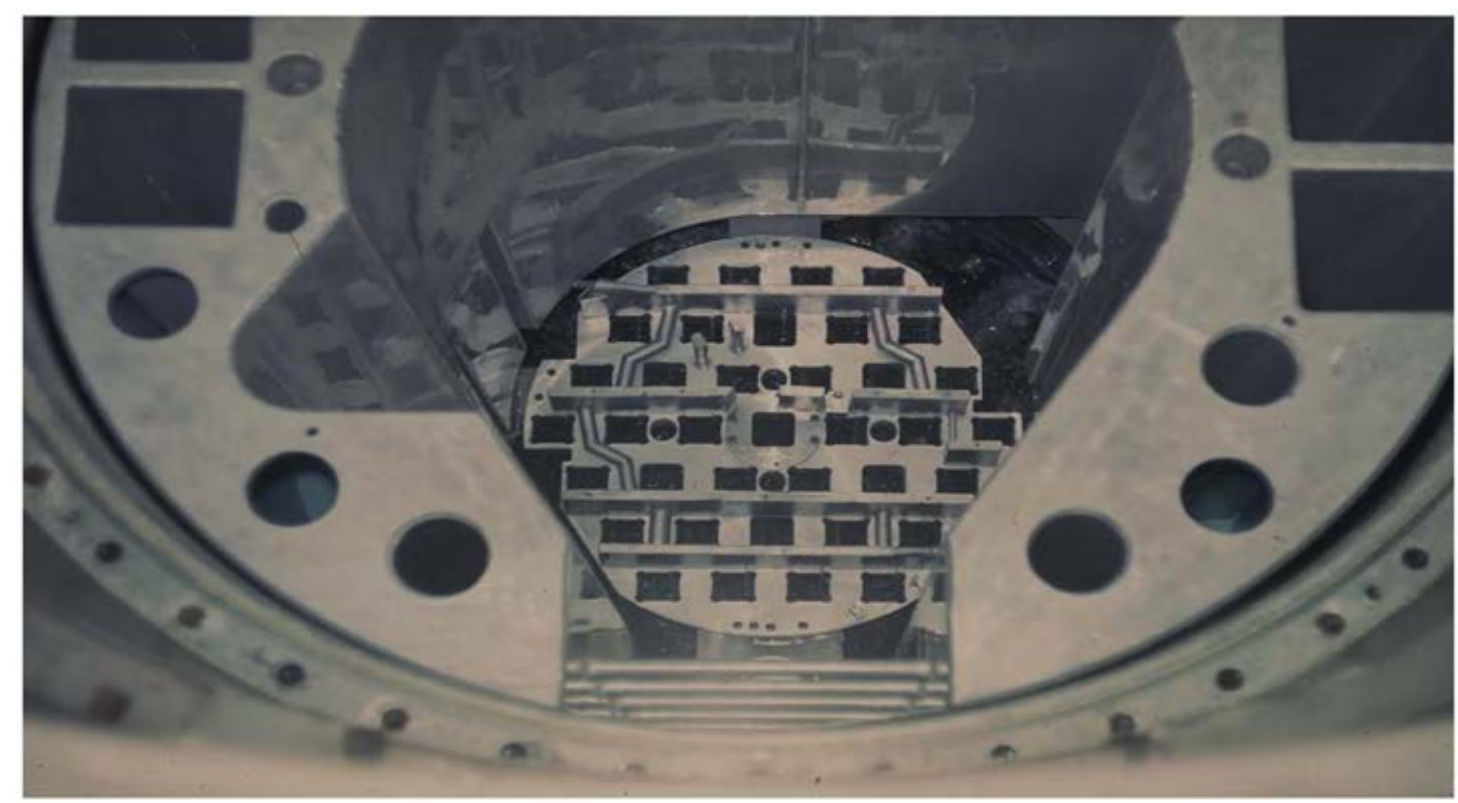

Figure 2.2 Inner Reserve Tank and Emergency Distribution Pan (NIST, 2010a)

When the upper part of the NBSR is uncovered, the water from the IRT flows into the distribution pan and forms 37 water streams flowing into each of the thirty fuel element as shown in Figure 2.3 and seven other locations. As the water drains below the level of the nozzles in the distribution pan, the flow hits the side of the upper end adaptor (the top part of the fuel element) and forms a film flowing downward. This film is spread horizontally on the surface until the momentum is balanced with surface tension and flows down the side plate of the element. When it reaches the elevation of the fuel plates, the liquid film is distributed over the 18 flow channels (at the elevation where the fuel plates begin), and flows further down inside the fuel element. Figure 2.4 and Figure 2.5 show the fuel element with upper and lower fuel plates and the cross sectional view of the fuel element, respectively. 


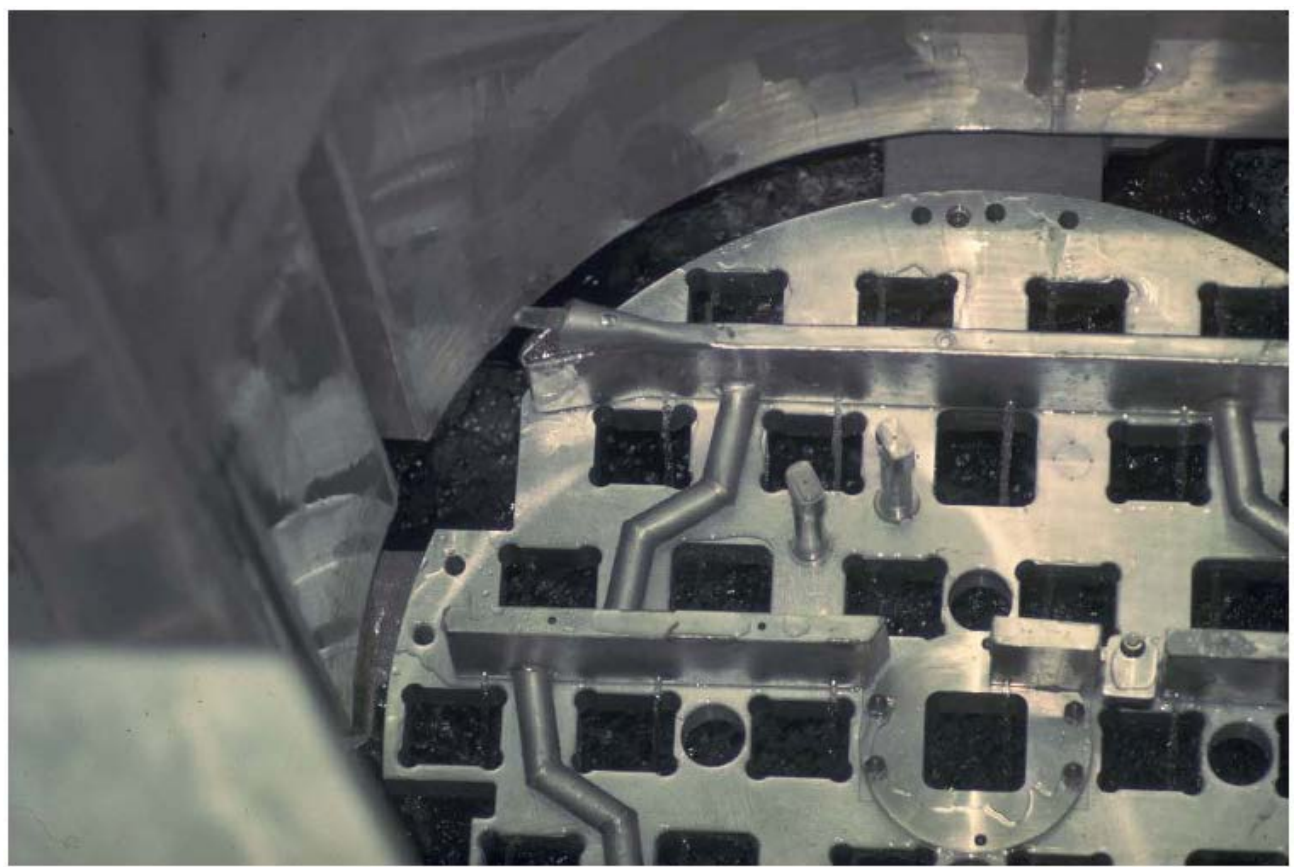

Figure 2.3 Emergency Distribution Pan and IRT Water Streams (NIST, 2010a)

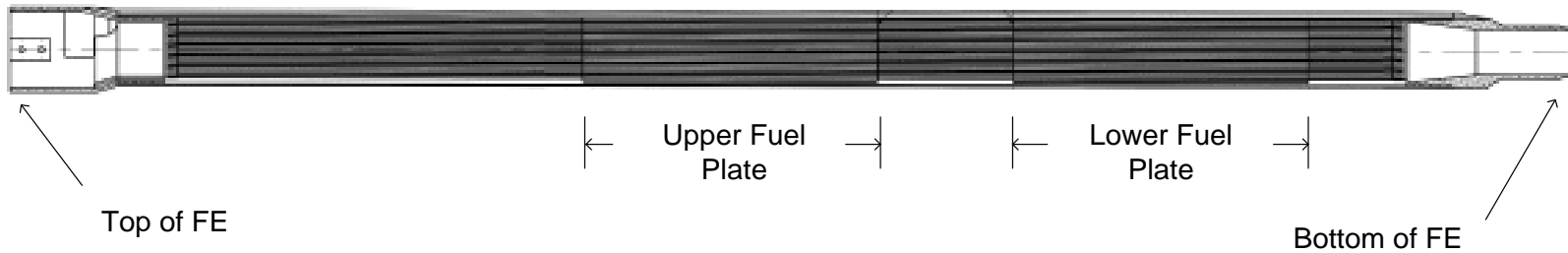

Figure 2.4 Fuel Element and Fuel Plates 


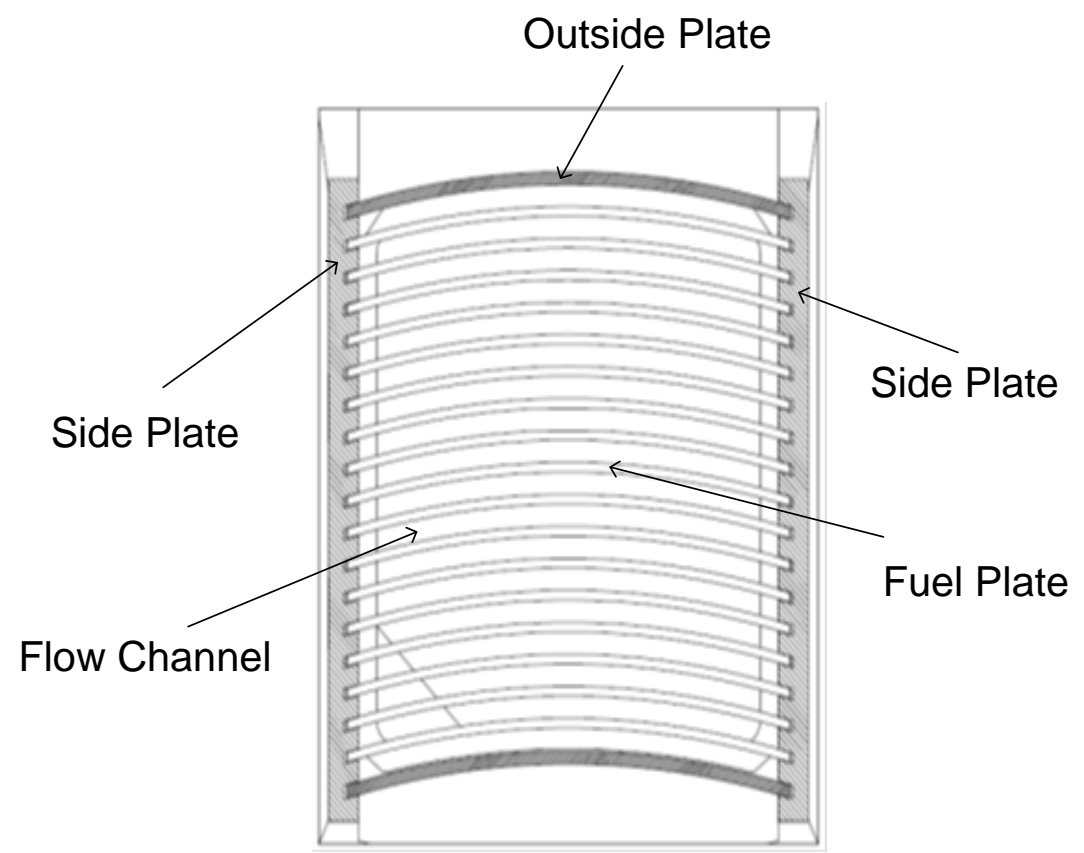

Figure 2.5 Cross Sectional View of Fuel Element

\subsection{TRACE Simulations}

Pipe breaks at three locations (defined above) and of two sizes, guillotine break and small break, were considered. TRACE simulations show the transient water level as the coolant drained from the vessel and the fuel elements. Table 2.1 shows the break locations and sizes with the case identification number. For SBLOCA, an arbitrary break size of $6.8 \mathrm{~cm}^{2}$ has been considered in the analysis.

\section{Table 2.1 Break Locations and Sizes}

\begin{tabular}{|c|c|c|}
\hline Case No. & Location & Size or Remark \\
\hline \multicolumn{3}{|c|}{$\begin{array}{r}\text { Guillotine Break (Double Ended) } \\
\end{array}$} \\
\hline 1 & $\begin{array}{l}\text { 18-inch pipe between the reactor vessel } \\
\text { outlet and the control valve DWV-19 }\end{array}$ & $2 \times 0.1508 \mathrm{~m}^{2}$ \\
\hline 2 & $\begin{array}{l}\text { 14-inch pipe between the control valve } \\
\text { DWV-1 and the outer plenum }\end{array}$ & $2 \times 0.089 \mathrm{~m}^{2}$ \\
\hline 3 & $\begin{array}{l}\text { 10-inch pipe between the control valve } \\
\text { DWV-2 and the inner plenum }\end{array}$ & $2 \times 0.0509 \mathrm{~m}^{2}$ \\
\hline \multicolumn{3}{|c|}{ Small Break } \\
\hline NA & $\begin{array}{l}\text { 18-inch pipe between the reactor vessel } \\
\text { outlet and the control valve DWV-19 }\end{array}$ & $\begin{array}{c}\text { Not simulated } \\
\text { (see Section 2.2.2.1) }\end{array}$ \\
\hline 4 & $\begin{array}{l}\text { 14-inch pipe between the control valve } \\
\text { DWV-1 and the outer plenum }\end{array}$ & $6.8 \mathrm{~cm}^{2}$ \\
\hline 5 & $\begin{array}{l}\text { 10-inch pipe between the control valve } \\
\text { DWV-2 and the inner plenum }\end{array}$ & $6.8 \mathrm{~cm}^{2}$ \\
\hline
\end{tabular}




\subsubsection{Guillotine Break LOCA}

\subsubsection{Guillotine Break at Vessel Outlet Pipe (Case 1)}

A GBLOCA is simulated by closing VALVE-102 between the vessel outlet and the main $\mathrm{D}_{2} \mathrm{O}$ pumps and opening VALVE-3 and VALVE-22 near VALVE-102, with flow areas the same as the pipe flow area of $0.1508 \mathrm{~m}^{2}$. The water level in the upper plenum drops very rapidly from its normal operating level of $4.04 \mathrm{~m}$ (159 in) as the coolant is discharged from the vessel through the break. The water from the IRT flows into the vessel via the distribution pan at time zero when the water level starts to drop in the vessel. The IRT is a passive system, and its flowrate is determined by the difference between the water level in the upper plenum and the level inside the tank. When the vessel water level is below the bottom of the IRT, the IRT flowrate is dependent only on the water level in the tank.

The first reactor scram signal is generated due to low total primary flow at $1.1 \mathrm{~s}$ after the break occurs. When the water level reaches the setpoint of reactor scram on low level $(3.56 \mathrm{~m}=140$ in), another reactor scram signal is generated at $2.3 \mathrm{~s} \mathrm{(without} \mathrm{considering} \mathrm{any} \mathrm{time} \mathrm{delay).} \mathrm{This}$ scram signal is defined as "LOCA signal" in this report. The main $\mathrm{D}_{2} \mathrm{O}$ pumps (PUMP-20 in Figure 2.1) are tripped and a shutdown pump (SDP, PUMP-81 in Figure 2.1) starts running automatically on this LOCA signal. Until the operator stops the SDP and closes the control valves (DWV-1, DWV-2, and DWV-19) in the primary system on the LOCA signal, the coolant continues to drain from the vessel and the water level keeps decreasing. VALVE-51, VALVE70, and VALVE-102 can be considered to be the control valves DWV-1, DWV-2, and DWV-19, respectively, even though, as shown in Figure 2.1, they are actually used to simulate pipe breaks.

Figure 2.6 shows the predicted water level in the fuel element. In the legend of the figure 'sv183' and 'sv-184' stand for the collapsed water level in the fuel plate channels of the lower section (Node-403) and the upper section (Node-407), respectively, in the outer core. As shown in Figure 2.6, the fuel plates start uncovering in the upper and lower sections, at $8.6 \mathrm{~s}$ and $9.2 \mathrm{~s}$, respectively. In other words, it takes only $6.3 \mathrm{~s}$ or $6.9 \mathrm{~s}$ after the LOCA signal for the top of the fuel plates to become uncovered. The fuel plates are completely drained very quickly; in $0.7 \mathrm{~s}$ after their tops start uncovering. A steady collapsed water level of about $0.04 \mathrm{~m}$ after around 10 $\mathrm{s}$ is due to the water coming from the IRT (in reality, it will be the falling liquid film on the inside of one side plate). 


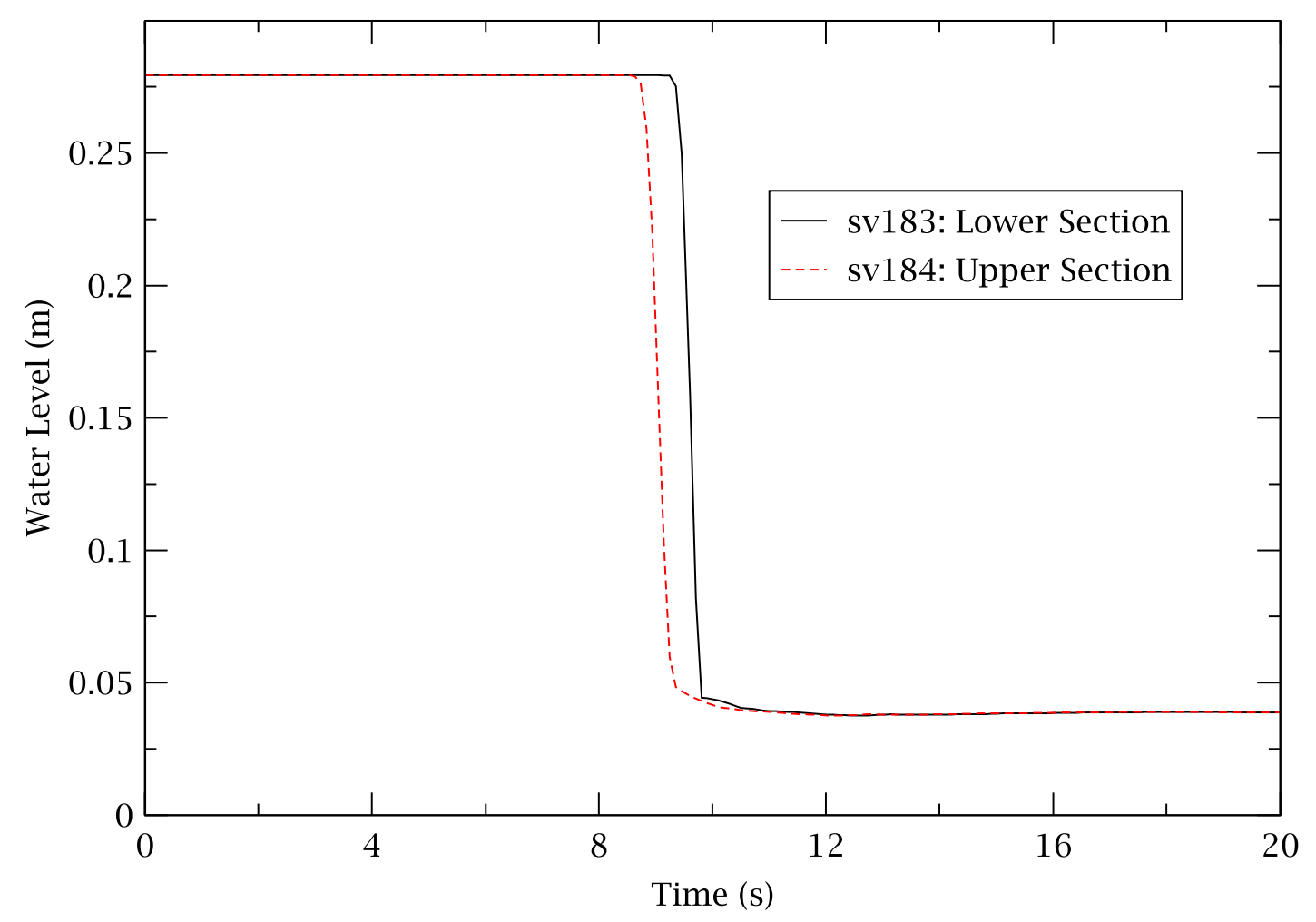

Figure 2.6 Water Level in Fuel Element after Guillotine Break at Vessel Outlet Pipe (Case 1)

Table 2.2 presents the sequence of important events after the guillotine break occurs at the vessel outlet pipe (Case 1). The times in the parentheses are relative to the time of the LOCA signal. As shown in the table, the upper fuel plates are completely uncovered in $7.0 \mathrm{~s}$ after the LOCA signal. This time can be assumed to be too short for the operators to recognize the occurrence of the LOCA and take necessary action to turn off the shutdown pump and shut the control valves in the primary system. Another operator action expected after the LOCA signal, important for the long term (and not modeled for GBLOCAs), is to open control valves (DWV-32 and DWV33) to supply heavy water to the IRT from the $\mathrm{D}_{2} \mathrm{O}$ emergency cooling tank.

As shown in the table, when the fuel plate starts to be uncovered, the water level outside of the side plate is already lower than the level inside the fuel element. If it is assumed that it takes the operator more than eight seconds after the LOCA signal to close the control valves in the primary system, the end-state of water distribution in the NBSR vessel will be like the one shown in Figure 2.7. The grey color indicates the available heavy water. The upper sections of the fuel elements are exposed to gas (air and/or helium ${ }^{\mathrm{a}}$ ). The outside of the lower sections are submerged in the water of the hold-up pan. Because the end fittings of the fuel elements and any other tubes inserted into the lower grid plate are conical, leakage of water down through the fuel

\footnotetext{
${ }^{a}$ The Helium Sweep Gas System supplies additional gas when the pressure drops due to the break and there is the possibility of air entering through the break.
} 
element seats is minimized (NIST, 2010a). Liquid film is flowing downward on the inside of one side plate.

Table 2.2 Sequence of Events after Guillotine Break at Vessel Outlet Pipe

\begin{tabular}{|c|c|}
\hline Time (s) & $\begin{array}{l}\text { Event (Case 1) } \\
\end{array}$ \\
\hline 0.0 & $\begin{array}{l}\text { - Guillotine break occurs at the 18-inch (flow area of } 0.1508 \mathrm{~m}^{2} \text { ) pipe } \\
\text { between the vessel outlet and DWV-19. } \\
\text { - Water level drops in the upper plenum. } \\
\text { - Water flows into the vessel from the IRT via the distribution pan. }\end{array}$ \\
\hline 0.7 & $\begin{array}{l}\text { - Flowrate at the vessel outlet pipe decreases to the setpoint of low total } \\
\text { primary flow ( } \leq 5,900 \text { gpm). }\end{array}$ \\
\hline 1.1 & - First reactor scram signal is generated due to low total primary flow. \\
\hline 2.3 & $\begin{array}{l}\text { - } \quad \text { LOCA signal is generated due to low level }(\leq 3.56 \mathrm{~m}) \\
\text { - } \quad \text { Main } \mathrm{D}_{2} \mathrm{O} \text { pumps are tripped. } \\
\text { - } \quad \text { Shutdown pump starts running. }\end{array}$ \\
\hline $8.4(6.1)$ & $\begin{array}{l}\text { - Water level outside the fuel elements reaches the elevation of the top of the } \\
\text { upper fuel plate. }\end{array}$ \\
\hline $8.6(6.3)$ & $\begin{array}{l}\text { - The fuel plate starts to be uncovered in the upper section of the FE (Node- } \\
\text { 407). }\end{array}$ \\
\hline 9.2 (6.9) & $\begin{array}{l}\text { - The fuel plate starts to be uncovered in the lower section of the FE (Node- } \\
\text { 403). }\end{array}$ \\
\hline$\sim 9.3(\sim 7.0)$ & $\begin{array}{l}\text { - The fuel plate is completely uncovered in the upper section of the FE (Node- } \\
\text { 407). }\end{array}$ \\
\hline $9.6(7.3)$ & $\begin{array}{l}\text { - Water level outside the FEs reaches the elevation of the bottom of the upper } \\
\text { fuel plate. }\end{array}$ \\
\hline$\sim 9.8(\sim 7.5)$ & $\begin{array}{l}\text { - The fuel plate is completely uncovered in the lower section of the FE (Node- } \\
\text { 403). }\end{array}$ \\
\hline 30.0 & - $\quad$ Simulation ends. \\
\hline
\end{tabular}




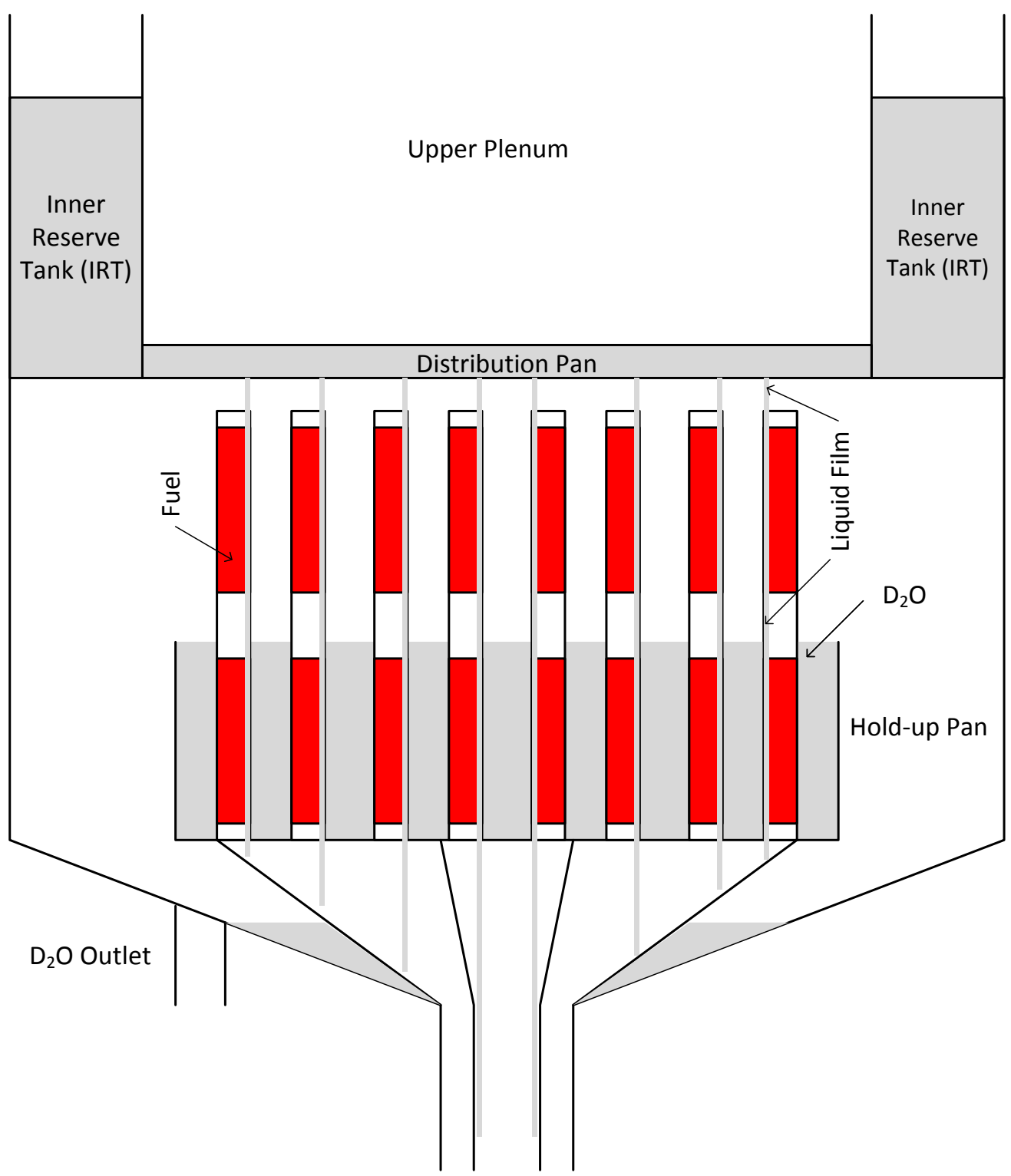

Figure 2.7 End-State of Coolant Distribution inside NBSR Vessel after Guillotine Break

\subsubsection{Guillotine Break at Outer Plenum Inlet Pipe (Case 2)}

As done in Case 1, a guillotine break LOCA is simulated by closing VALVE-51 at the outer plenum inlet pipe and opening VALVE-1 and VALVE-2 near VALVE-51. The flow areas of those valves are the same as the pipe flow area of $0.089 \mathrm{~m}^{2}$.

For this break scenario the general response of the NBSR is similar to that of Case 1. Figure 2.8 and Table 2.3 show the predicted water level and sequence of important events, respectively, after a guillotine break at the outer plenum inlet pipe (Case 2). 


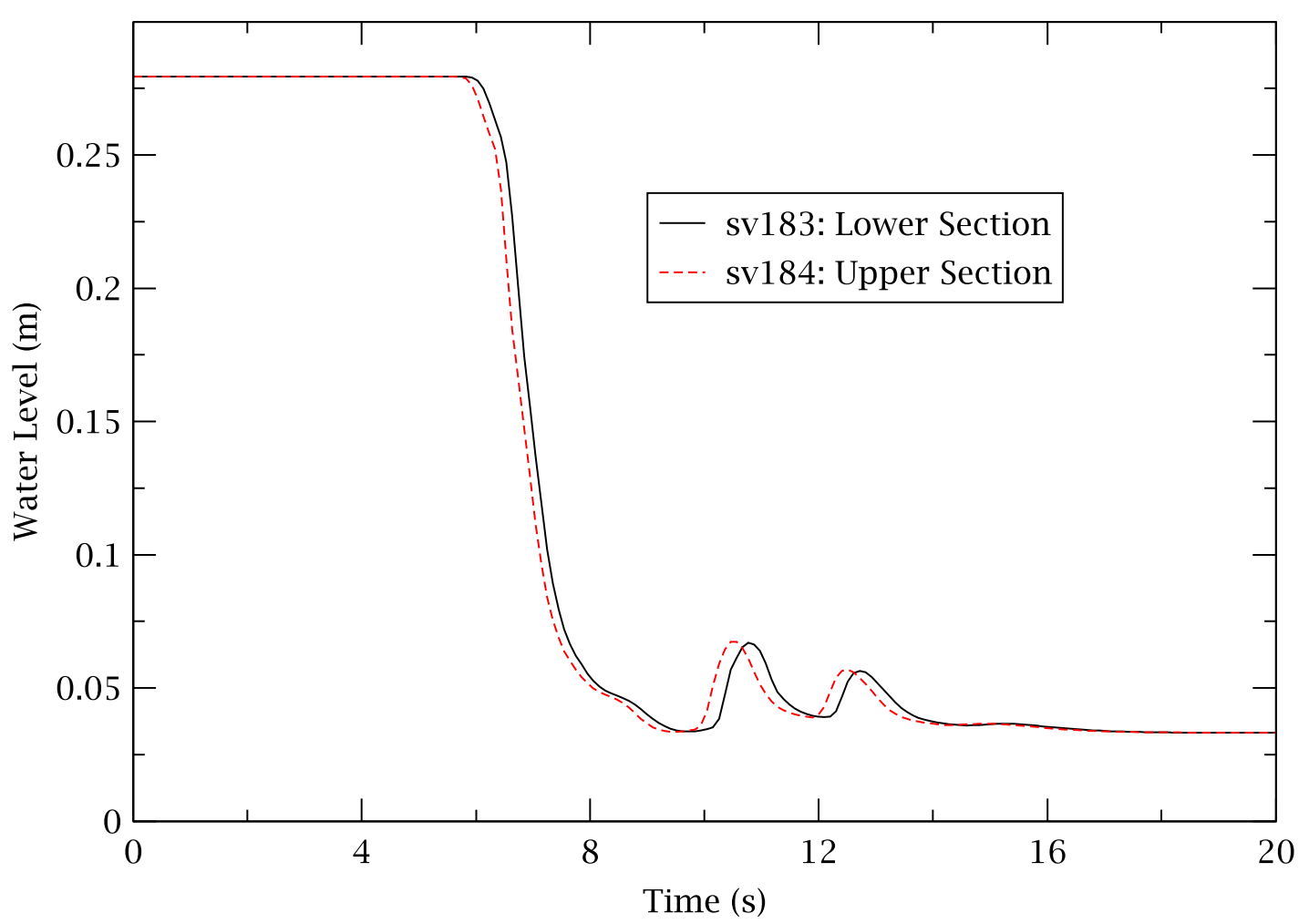

Figure 2.8 Water Level in Fuel Element after Guillotine Break at Outer Plenum Inlet Pipe (Case 2)

The first reactor scram signal is generated earlier in this case relative to Case 1. This is due to the fact that the flowrate measuring point is downstream of the break in the simulation, so the coolant flows in reverse at that point after the break occurs. The LOCA signal is also created earlier in this accident. The coolant is discharged through both ends of the break in this case. However, in Case 1 (vessel outlet pipe break) the main $\mathrm{D}_{2} \mathrm{O}$ pumps will continue to function until they are tripped, delivering to the vessel the remaining water in the broken pipe attached to them. This fact explains the water level dropping faster in Case 2 than in Case 1 at the early stage of the blowdown even though the break areas are smaller in Case 2.

The upper fuel plate starts uncovering at $5.8 \mathrm{~s}$ in Case 2, while it starts at $8.6 \mathrm{~s}$ in Case 1 . This difference is also due to the main $\mathrm{D}_{2} \mathrm{O}$ pumps becoming less effective in pumping water to the vessel at an early stage in this case as compared to Case 1. As shown in Figure 2.8 and Table 2.3, the heated sections are completely uncovered in about $2.2 \mathrm{~s}$ after the water level reaches the top of the fuel plate inside the fuel element. 
Table 2.3 Sequence of Events after Guillotine Break at Outer Plenum Inlet Pipe

\begin{tabular}{|c|c|}
\hline Time (s) & Event (Case 2) \\
\hline 0.0 & $\begin{array}{l}\text { - Guillotine break takes place at the } 14 \text {-inch pipe (flow area of } 0.089 \mathrm{~m}^{2} \text { ) } \\
\text { between the control valve DWV-1 and the outer plenum. } \\
\text { - Water level drops in the upper plenum. } \\
\text { - Water flows into the vessel from the IRT via the distribution pan. }\end{array}$ \\
\hline 0.03 & $\begin{array}{l}\text { - Flowrate at the outer plenum inlet pipe decreases to the setpoint of low outer } \\
\text { plenum flow ( } \leq 4,700 \text { gpm). }\end{array}$ \\
\hline 0.4 & - First reactor scram signal is generated due to low outer plenum flow. \\
\hline 1.3 & $\begin{array}{l}\text { - } \quad \text { LOCA signal is generated due to low level }(\leq 3.56 \mathrm{~m}) \text {. } \\
\text { - } \quad \text { Main } \mathrm{D}_{2} \mathrm{O} \text { pumps are tripped. } \\
\text { - } \quad \text { Shutdown pump starts running. }\end{array}$ \\
\hline $5.8(4.5)$ & $\begin{array}{l}\text { - The fuel plate starts to be uncovered in the upper section of the FE (Node- } \\
\text { 407). }\end{array}$ \\
\hline $6.0(4.7)$ & $\begin{array}{l}\text { - The fuel plate starts to be uncovered in the lower section of the FE (Node- } \\
\text { 403). }\end{array}$ \\
\hline$\sim 8.0(\sim 6.7)$ & $\begin{array}{l}\text { - The fuel plate is completely uncovered in the upper section of the FE (Node- } \\
\text { 407). }\end{array}$ \\
\hline 8.1 ( 6.8) & $\begin{array}{l}\text { - The fuel plate is completely uncovered in the lower section of the FE (Node- } \\
\text { 403). }\end{array}$ \\
\hline $13.3(12.0)$ & $\begin{array}{l}\text { - Water level outside the fuel elements reaches the elevation of the top of the } \\
\text { upper fuel plate. }\end{array}$ \\
\hline $16.3(15.0)$ & $\begin{array}{l}\text { - Water level outside the fuel elements reaches the elevation of the bottom of } \\
\text { the upper fuel plate. }\end{array}$ \\
\hline 30.0 & - Simulation ends. \\
\hline
\end{tabular}

The water level outside of the fuel element is at the top elevation of the upper fuel plate at $13.3 \mathrm{~s}$. This happens $4.9 \mathrm{~s}$ later as compared to Case 1 . This is because in Case 1 , as the discharge of the coolant into the vessel decreases due to reduction of the available water upstream of the main $\mathrm{D}_{2} \mathrm{O}$ pumps (and/or the shutdown pump after $2.3 \mathrm{~s}$ ) the flow downstream of the pumps eventually becomes negative (the coolant flows from the outer and inner plena to the pumps and the break) starting at $4.5 \mathrm{~s}$. With additional flow from the inlet plena, the total break flowrate increases and the rate of decrease of the water level becomes larger in Case 1 . On the other hand, the break flow, which is relatively small, continues being discharged without significant change in Case 2.

If the operator actions to stop the shutdown pump and close the control valves in the primary system are not taken for at least 15 seconds after the LOCA signal, this accident will also lead to the end-state shown in Figure 2.7. 


\subsubsection{Guillotine Break at Inner Plenum Inlet Pipe (Case 3)}

In this scenario a guillotine break is assumed to occur at the pipe between the control valve DWV-2 and the inner plenum. The break areas are the same as the pipe flow area of $0.0509 \mathrm{~m}^{2}$. This accident is simulated by closing VALVE-70 at the inner plenum inlet pipe and opening nearby VALVE-23 and VALVE-32.

The NBSR response to this accident is similar to Case 2, but the events occur a little later because of the smaller break areas. The water level behavior is shown in Figure 2.9 and the sequence of important events is illustrated in Table 2.4.

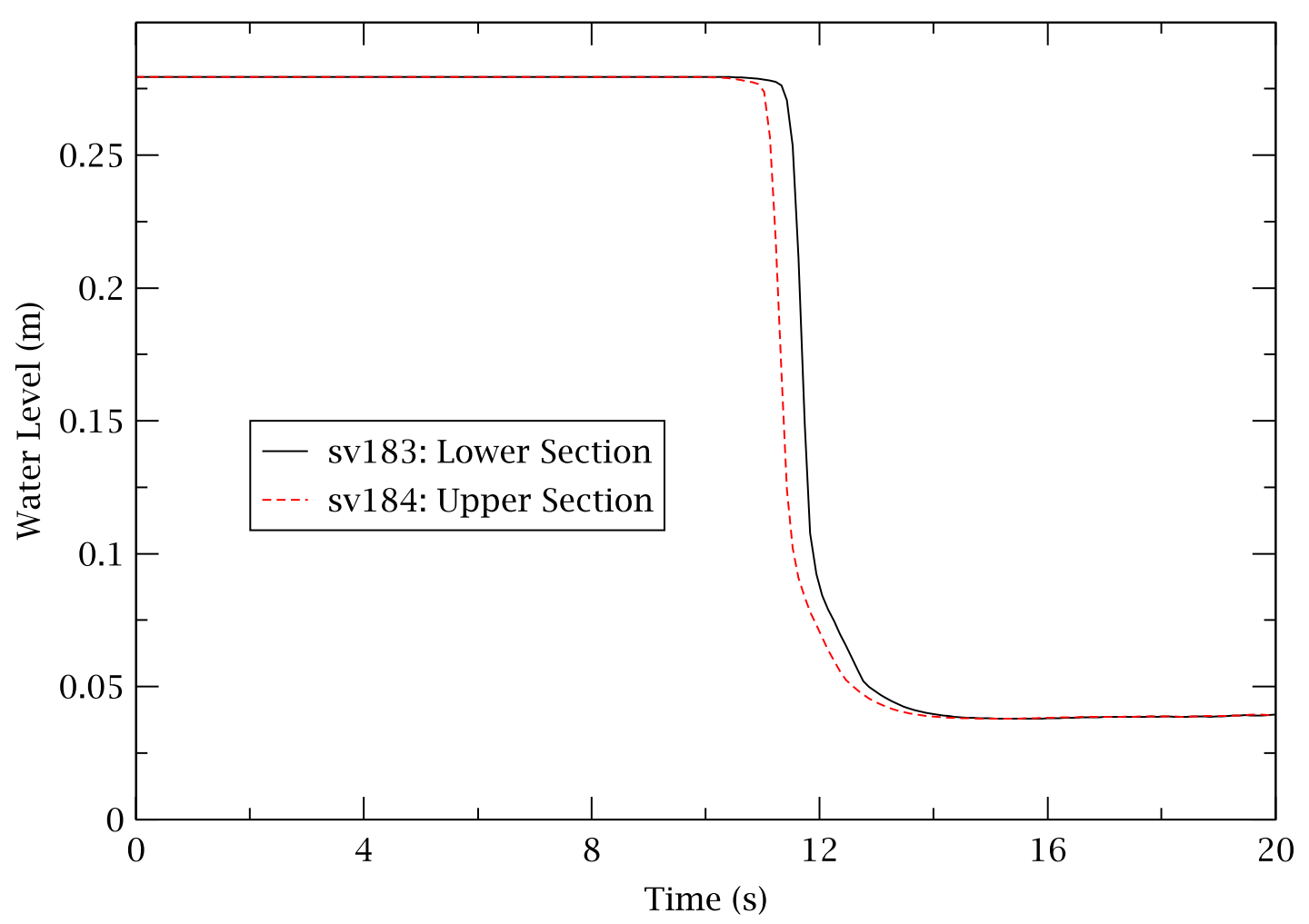

Figure 2.9 Water Level Behavior in Fuel Element after Guillotine Break at Inner Plenum Inlet Pipe (Case 3) 
Table 2.4 Sequence of Events after Guillotine Break at Inner Plenum Inlet Pipe

\begin{tabular}{|c|c|}
\hline Time (s) & Event (Case 3) \\
\hline 0.0 & $\begin{array}{l}\text { - Guillotine break occurs at the } 10 \text {-inch pipe (flow area of } 0.0509 \mathrm{~m}^{2} \text { ) } \\
\text { between the control valve DWV-2 and the inner plenum. } \\
\text { - Water level drops in the upper plenum. } \\
\text { - Water flows into the vessel from the IRT via the distribution pan. }\end{array}$ \\
\hline 0.06 & $\begin{array}{l}\text { - Flowrate at the inner plenum inlet pipe decreases to the setpoint of low inner } \\
\text { plenum flow ( } \leq 1,200 \text { gpm). }\end{array}$ \\
\hline 0.5 & - $\quad$ First reactor scram signal is generated due to low inner plenum flow. \\
\hline 1.9 & $\begin{array}{l}\text { - } \quad \text { LOCA signal is generated due to low level }(\leq 3.56 \mathrm{~m}) \text {. } \\
\text { - } \quad \text { Main } \mathrm{D}_{2} \mathrm{O} \text { pumps are tripped. } \\
\text { - } \quad \text { Shutdown pump starts running. }\end{array}$ \\
\hline $10.9(9.0)$ & $\begin{array}{l}\text { - The fuel plate starts to be uncovered in the upper section of the FE (Node- } \\
\text { 407). }\end{array}$ \\
\hline $11.2(9.3)$ & $\begin{array}{l}\text { - The fuel plate starts to be uncovered in the lower section of the FE (Node- } \\
\text { 403). }\end{array}$ \\
\hline$\sim 12.4(\sim 10.5)$ & $\begin{array}{l}\text { - The fuel plate is completely uncovered in the upper section of the FE (Node- } \\
\text { 407). }\end{array}$ \\
\hline 12.8 ( 10.9) & $\begin{array}{l}\text { - The fuel plate is completely uncovered in the lower section of the FE (Node- } \\
\text { 403). }\end{array}$ \\
\hline $20.6(18.7)$ & $\begin{array}{l}\text { - Water level outside the fuel elements reaches the elevation of the top of the } \\
\text { upper fuel plate. }\end{array}$ \\
\hline $24.2(22.3)$ & $\begin{array}{l}\text { - Water level outside the fuel elements reaches the elevation of the bottom of } \\
\text { the upper fuel plate. }\end{array}$ \\
\hline 30.0 & - Simulation ends. \\
\hline
\end{tabular}

It takes less than $1.5 \mathrm{~s}$ in this case to completely drain water from the upper fuel plate channels while it takes $2.2 \mathrm{~s}$ in Case 2. This is contrary to what might be expected for a smaller break area. The simulation results for Case 2 show that the upper fuel plate starts to be uncovered (5.8 $\mathrm{s}$ after the break) before the water level in the vessel has dropped to the top of the fuel elements (6.2 s after the break). However, the situation is different in Case 3. In Case 3 the water level has already dropped below the top of the fuel elements (9.9 s after the break) before the upper fuel plate starts to be uncovered (10.9 s after the break). A relatively large amount of water continues to flow into the flow channel from the vessel for an additional $0.4 \mathrm{~s}$ in Case 2 while only a small amount of water is supplied from the IRT in Case 3. This fact causes the fuel plate channel to take more time to be completely drained in Case 2 than in Case 3.

Assuming no operator actions to stop the shutdown pump and close the control valves in the primary system for some period (about $22 \mathrm{~s}$ after the LOCA signal), the end-state of water distribution inside the NBSR will be very similar to the one shown in Figure 2.7. 


\subsubsection{Summary of Guillotine Break LOCA Simulations}

Figure 2.10 compares the water level behavior inside the upper section of the fuel elements in all GBLOCAs (Case 1, Case 2, and Case 3). Table 2.5 compares the sequence of some important events. The water level inside the fuel elements reaches the top of the upper fuel plates from 4.5 $\mathrm{s}$ to $9 \mathrm{~s}$ after a LOCA signal is generated. It takes only $0.7 \mathrm{~s}$ to $2.2 \mathrm{~s}$ from that point for the upper fuel plate channels to be completely drained. The times in the parentheses are relative to the time of the LOCA signal.

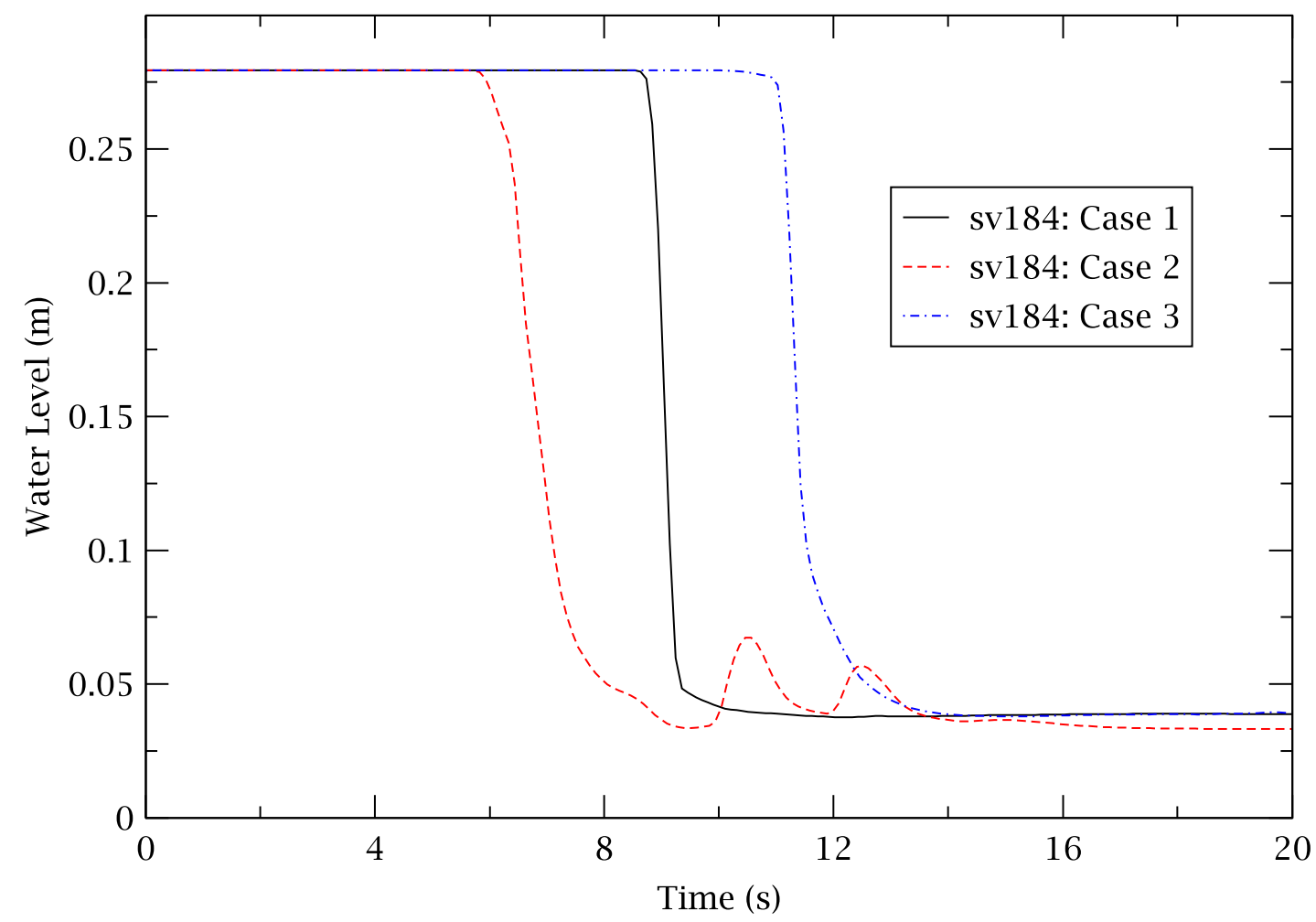

Figure 2.10 Comparison of Water Level in Upper Fuel Element after Guillotine Breaks

Table 2.5 Comparison of Sequence of Events after Guillotine Breaks

\begin{tabular}{|l|c|c|c|}
\hline \multirow{2}{*}{ Event } & \multicolumn{3}{c|}{ Time (s) } \\
\cline { 2 - 4 } & Case 1 & Case 2 & Case 3 \\
\hline First reactor scram on low flow & 1.1 & 0.4 & 0.5 \\
\hline LOCA signal on low level & 2.3 & 1.3 & 1.9 \\
\hline Upper fuel plate starting to be uncovered & $8.6(6.3)$ & $5.8(4.5)$ & $10.9(9.0)$ \\
\hline Upper fuel plate being completely drained & $\sim 9.3(\sim 7.0)$ & $\sim 8.0(\sim 6.7)$ & $\sim 12.4(\sim 10.5)$ \\
\hline $\begin{array}{l}\text { Water level outside fuel element reaching top } \\
\text { elevation of the upper fuel plate }\end{array}$ & $8.4(6.1)$ & $13.3(12.0)$ & $20.6(18.7)$ \\
\hline
\end{tabular}




\subsubsection{Small Break LOCA}

SBLOCAs have been simulated by running TRACE with the input model shown in Figure 2.1. An arbitrary break size of $6.8 \mathrm{~cm}^{2}$ is considered in the analysis. This break is chosen because it is about $1 \%$ of the flow areas of the inlet plenum pipes to both the outer and inner cores. Contrary to the GBLOCA cases, the reactor does not trip on low flow, and operator actions can be credited because it takes a long time (more than 1,700 s) after the LOCA signal for the top of the upper fuel plate starts to be uncovered.

For simplicity it is assumed that the operator stops the shutdown cooling pump (i.e., the SDP is not running) and shuts the control valves DWV-1 and DWV-2 when the LOCA signal occurs. The flow path in the vessel outlet pipe is shut when the valves (three of DWV-3 through DWV6 ) at the outlet of the main $\mathrm{D}_{2} \mathrm{O}$ pumps are completely closed $3 \mathrm{~s}$ after the pumps are tripped. Control valves DWV-32 and DWV-33, connected to the emergency cooling tank, are assumed to be opened by the operator after the LOCA signal. This means that heavy water is supplied to the IRT at a flowrate of $1.74 \mathrm{~kg} / \mathrm{s}(25 \mathrm{gpm})$.

DWV-1 and DWV-2 are not modeled explicitly. However, VALVE-51 and VALVE-70 play the role of these two control valves in the SBLOCA simulations. When a SBLOCA at the outer plenum inlet pipe is simulated, VALVE-70 (DWV-2) is closed on the LOCA signal while the other one (VALVE-51) is still open. On the other hand, VALVE-51 (DWV-1) is closed and VALVE-70 is open with a SBLOCA at the inner plenum inlet pipe. In both cases VALVE-25 at the outlet of the main $\mathrm{D}_{2} \mathrm{O}$ pumps closes in $3 \mathrm{~s}$ after the LOCA signal while VALVE-83 at the shutdown pump outlet remains closed. This valve manipulation scheme accurately simulates the operator action of closing the control valves DWV-1, DWV-2, and DWV-19 on the LOCA signal.

\subsubsection{Small Break at Vessel Outlet Pipe}

If a small break occurs at the vessel outlet pipe and the operator has enough time to turn off the shutdown cooling pump as well as close the control valves (DWV-1, DWV-2, and DWV-19) in the primary system before the fuel elements are drained, the fuel plates are expected not to be uncovered (i.e., they are always covered) while the water level continues dropping outside of the fuel elements. In this type of small break the expected end-state of water distribution inside the NBSR is shown in Figure 2.11.

Chapter 13 of the SAR (NIST, 2010a) explains that the fuel plates are adequately cooled as long as the inside of the fuel elements are filled with the coolant. Therefore, this accident is excluded from the simulations and analysis because the fuel plate channels are always filled with the coolant. 


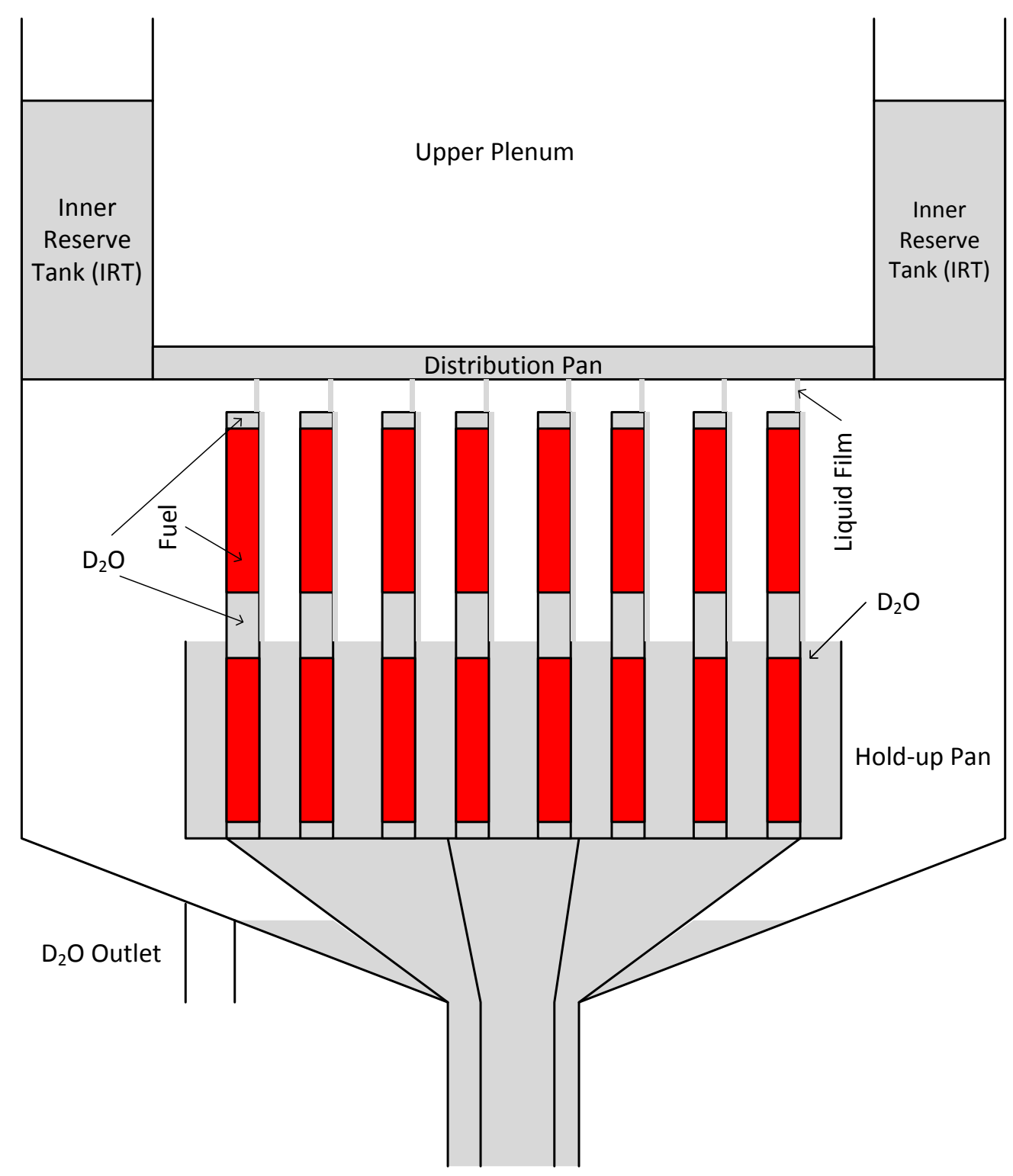

Figure 2.11 End-State of Coolant Distribution inside NBSR Vessel after Small Break at Vessel Outlet Pipe

\subsubsection{Small Break at Outer Plenum Inlet Pipe (Case 4)}

A small break occurring between the control valve DWV-1 and the outer plenum is simulated by opening VALVE-12 at the outer plenum inlet pipe (flow area $=0.089 \mathrm{~m}^{2}$ ). A break size of $0.76 \%\left(6.77 \mathrm{~cm}^{2}\right)$ is considered in the simulation. Figure 2.12 shows the water level behavior inside the fuel element. 


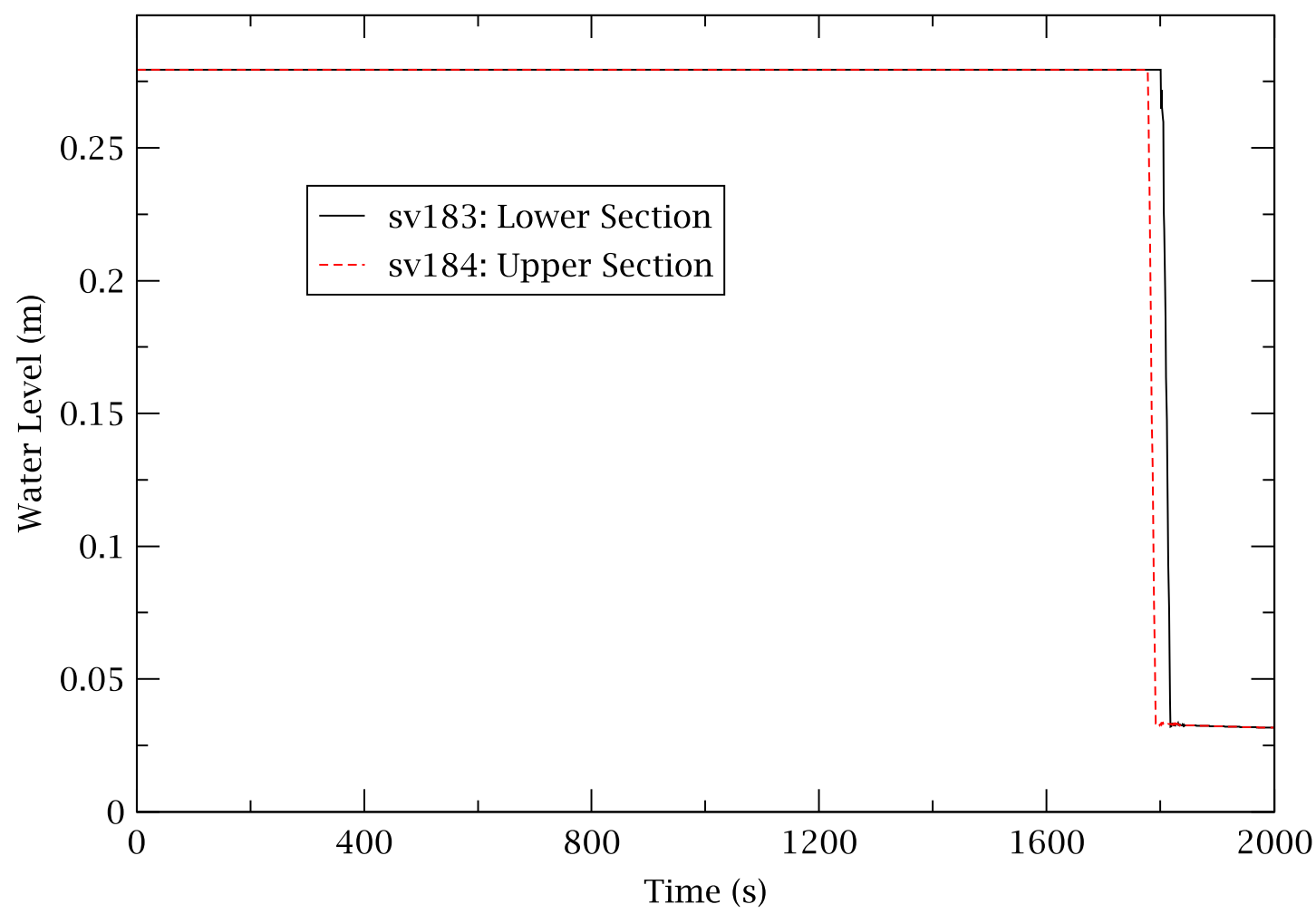

Figure 2.12 Water Level Behavior in Fuel Element after Small Break at Outer Plenum Inlet Pipe (Case 4)

The sequence of important events is shown in Table 2.6. The reactor scram signal (LOCA signal) is generated on low level at $64 \mathrm{~s}$ without any time delay. Again, the times in the parentheses are relative to the time of the LOCA signal. Figure 2.12 and Table 2.6 show that the fuel plates are completely uncovered very quickly even with such a small break size. The upper and lower fuel element sections are drained in $14 \mathrm{~s}$ and $18 \mathrm{~s}$, respectively, after the water level reaches their top. The upper fuel plate is predicted to be uncovered at around 1,780 s. 
Table 2.6 Sequence of Events after Small Break at Outer Plenum Inlet Pipe

\begin{tabular}{|c|c|}
\hline Time (s) & Event (Case 4) \\
\hline 0.0 & $\begin{array}{l}\left.\text { - A break }\left(6.77 \mathrm{~cm}^{2}\right) \text { occurs at the } 12 \text {-inch pipe (flow area of } 0.089 \mathrm{~m}^{2}\right) \\
\text { between the control valve DWV-1 and the outer plenum. } \\
\text { - Water level drops in the upper plenum. } \\
\text { - Water flows into the vessel from the IRT via the distribution pan. }\end{array}$ \\
\hline 64.0 & $\begin{array}{l}\text { - Reactor scram signal (LOCA signal) is generated due to low level }(\leq 3.56 \\
\mathrm{m}) \text {. } \\
\text { - Main } \mathrm{D}_{2} \mathrm{O} \text { pumps are tripped. } \\
\text { - Control valve DWV-2 (VALVE-70) is closed. } \\
\text { - Heavy water is supplied to the IRT from the } \mathrm{D}_{2} \mathrm{O} \text { emergency cooling tank at } \\
1.74 \mathrm{~kg} / \mathrm{s} \text {. }\end{array}$ \\
\hline 64.8 & $\begin{array}{l}\text { - Flowrate at the outer plenum inlet pipe decreases to the setpoint of low outer } \\
\text { plenum flow ( } \leq 4,700 \mathrm{gpm}) \text {. }\end{array}$ \\
\hline 67.0 & $\begin{array}{l}\text { - Valves at the outlets of the main } \mathrm{D}_{2} \mathrm{O} \text { pumps are completely closed. } \\
\text { - Control valve DWV-19 is closed. }\end{array}$ \\
\hline $1,778(1,714)$ & $\begin{array}{l}\text { - The fuel plate starts to be uncovered in the upper section of the FE (Node- } \\
\text { 407). }\end{array}$ \\
\hline $\begin{array}{l}\sim 1,792 \\
(\sim 1,728)\end{array}$ & $\begin{array}{l}\text { - The fuel plate is completely uncovered in the upper section of the FE (Node- } \\
\text { 407). }\end{array}$ \\
\hline $1,800(1,736)$ & $\begin{array}{l}\text { - The fuel plate starts to be uncovered in the lower section of the FE (Node- } \\
\text { 403). }\end{array}$ \\
\hline $\begin{array}{l}\sim 1,818 \\
(\sim 1,754)\end{array}$ & $\begin{array}{l}\text { - The fuel plate is completely uncovered in the lower section of the FE (Node- } \\
\text { 403). }\end{array}$ \\
\hline 2,000 & - Simulation ends. \\
\hline
\end{tabular}

It should be noted that in this accident the water level outside of the fuel elements doesn't drop below the top elevation of the fuel elements. In this accident the operator has enough time to shut the control valves in the primary system (DWV-1, DWV-2, and DWV-19) before the water level reaches that elevation. The coolant will be discharged through the break only via the flow channels of the fuel elements in the outer core after the control valves are closed. Figure 2.13 depicts the end-state of water distribution in this accident. In the outer core liquid film flows downward inside the flow channel at the end-state, while the flow channels are filled with heavy water in the inner core. 


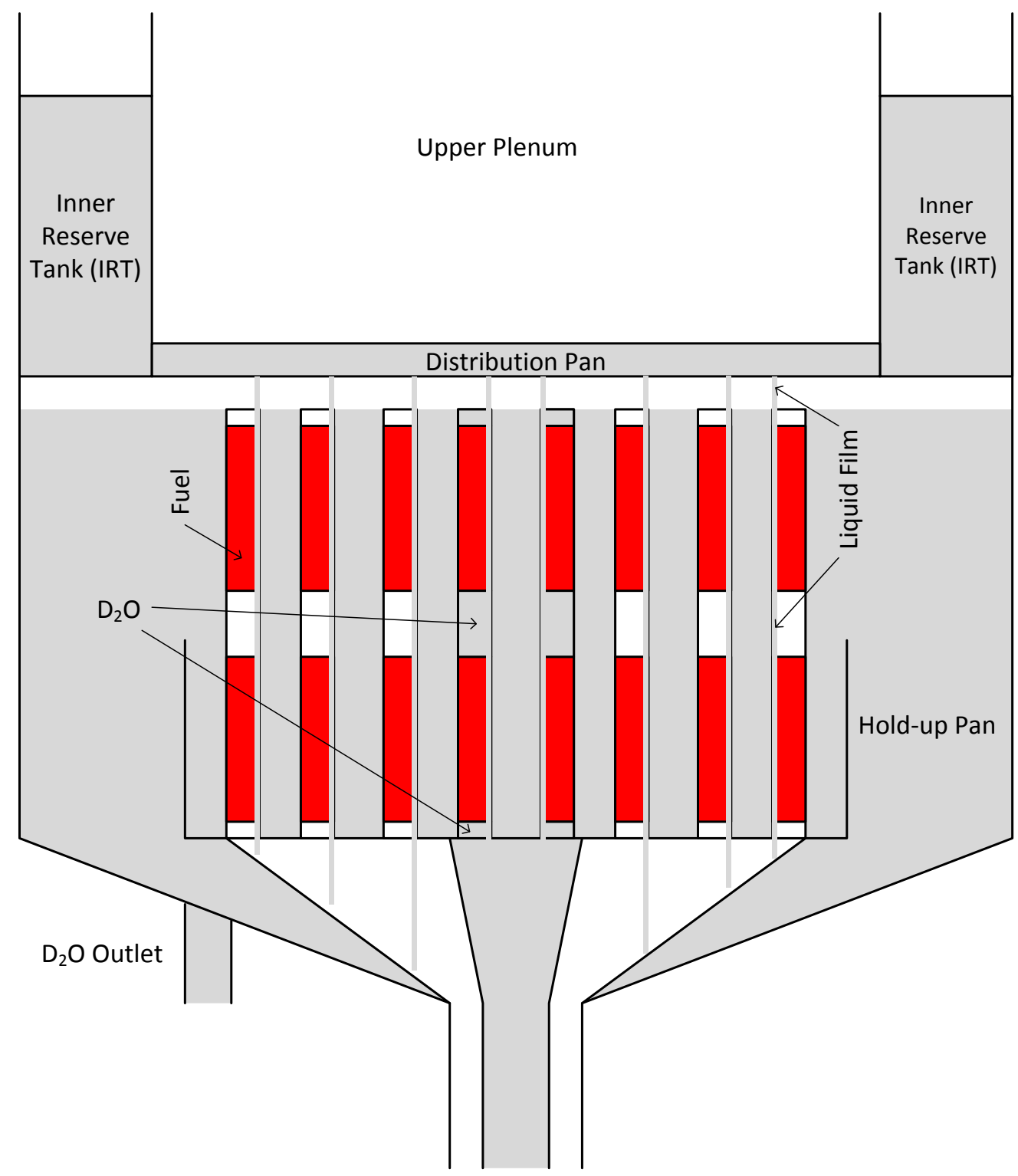

Figure 2.13 End-State of Coolant Distribution inside NBSR Vessel after Small Break at Outer Plenum Inlet Pipe (Case 4)

\subsubsection{Small Break at Inner Plenum Pipe (Case 5)}

In this accident scenario a small break of $1.33 \%\left(6.77 \mathrm{~cm}^{2}\right)$ is assumed to occur between the control valve DWV-2 and the inner plenum. This case is simulated using TRACE by opening VALVE-33 at the inner plenum inlet pipe (flow area $=0.0509 \mathrm{~m}^{2}$ ). TRACE predicts that the upper fuel plate is uncovered at around 1,780 s. The water level behavior inside the fuel element is illustrated in Figure 2.14. In the legend 'sv-185' and 'sv-186' stand for the collapsed water levels in the lower (Node-103) and upper (Node-107) sections of the fuel element in the inner core. The sequence of important events is presented in Table 2.7. The fuel plates are completely uncovered within $5 \mathrm{~s}$ in the upper section and $6 \mathrm{~s}$ in the lower section after they start to be uncovered. 


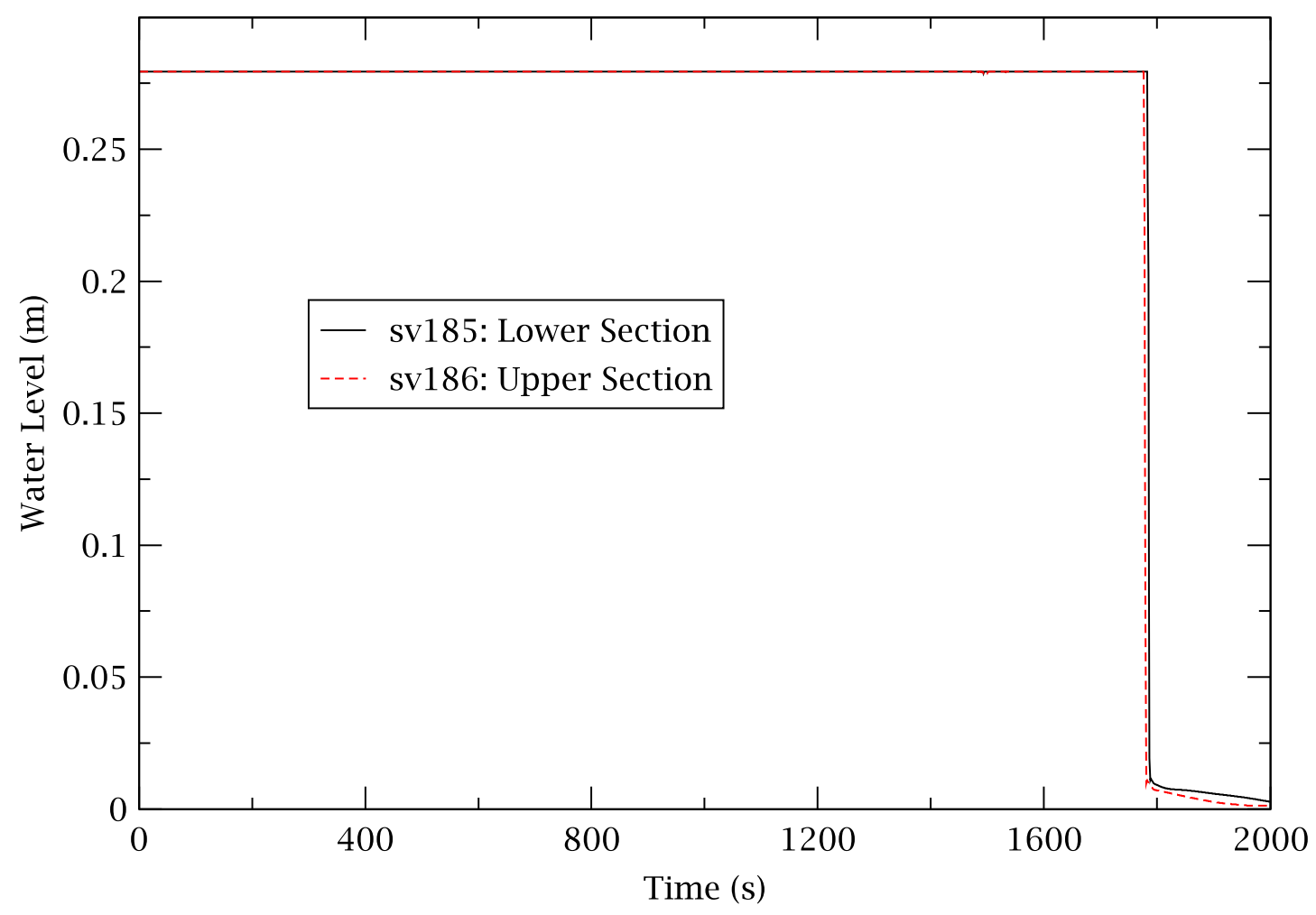

Figure 2.14 Water Level Behavior in Fuel Element after Small Break at Inner Plenum Inlet Pipe (Case 5) 
Table 2.7 Sequence of Events after Small Break at Inner Plenum Inlet Pipe

\begin{tabular}{|c|c|}
\hline Time (s) & Event (Case 5) \\
\hline 0.0 & $\begin{array}{l}\text { - A break }\left(6.77 \mathrm{~cm}^{2}\right) \text { occurs at the } 10 \text {-inch pipe (flow area of } 0.0509 \mathrm{~m}^{2} \text { ) } \\
\text { between the control valve DWV-2 and the inner plenum. } \\
\text { - Water level drops in the upper plenum. } \\
\text { - Water flows into the vessel from the IRT via the distribution pan. }\end{array}$ \\
\hline 60.6 & $\begin{array}{l}\text { - Reactor scram signal (LOCA signal) is generated due to low level ( } \leq 3.56 \\
\mathrm{~m} \text { ). } \\
\text { - Main } \mathrm{D}_{2} \mathrm{O} \text { pumps are tripped. } \\
\text { - Control Valve DWV-1 (VALVE-51) is closed. } \\
\text { - Heavy water is supplied to the IRT from the } \mathrm{D}_{2} \mathrm{O} \text { emergency cooling tank at } \\
1.74 \mathrm{~kg} / \mathrm{s} \text {. }\end{array}$ \\
\hline 61.8 & $\begin{array}{l}\text { - Flowrate at the outer plenum inlet pipe decreases to the setpoint of low outer } \\
\text { plenum flow ( } \leq 4,700 \text { gpm). }\end{array}$ \\
\hline 63.6 & $\begin{array}{l}\text { - Valves at the outlets of the main } \mathrm{D}_{2} \mathrm{O} \text { pumps are completely closed. } \\
\text { - } \quad \text { Control valve DWV-19 is closed. }\end{array}$ \\
\hline $1,776(1,715)$ & $\begin{array}{l}\text { - The fuel plate starts to be uncovered in the upper section of the FE (Node- } \\
\text { 107). }\end{array}$ \\
\hline $\begin{array}{c}\sim 1,781 \\
(\sim 1,720)\end{array}$ & $\begin{array}{l}\text { - The fuel plate is completely uncovered in the upper section of the FE (Node- } \\
\text { 107). }\end{array}$ \\
\hline $1,782(1,721)$ & $\begin{array}{l}\text { - The fuel plate starts to be uncovered in the lower section of the FE (Node- } \\
\text { 103). }\end{array}$ \\
\hline $\begin{array}{l}\sim 1,788 \\
(\sim 1,727)\end{array}$ & $\begin{array}{l}\text { - The fuel plate is completely uncovered in the lower section of the FE (Node- } \\
\text { 103). }\end{array}$ \\
\hline 2,000 & - Simulation ends. \\
\hline
\end{tabular}

An SBLOCA at the inner plenum inlet pipe will lead the NBSR to the end-state of water distribution shown in Figure 2.15. The fuel elements are completely drained in the inner core, with the falling liquid film present. The fuel and side plates are all covered by water in the outer core in this accident. 


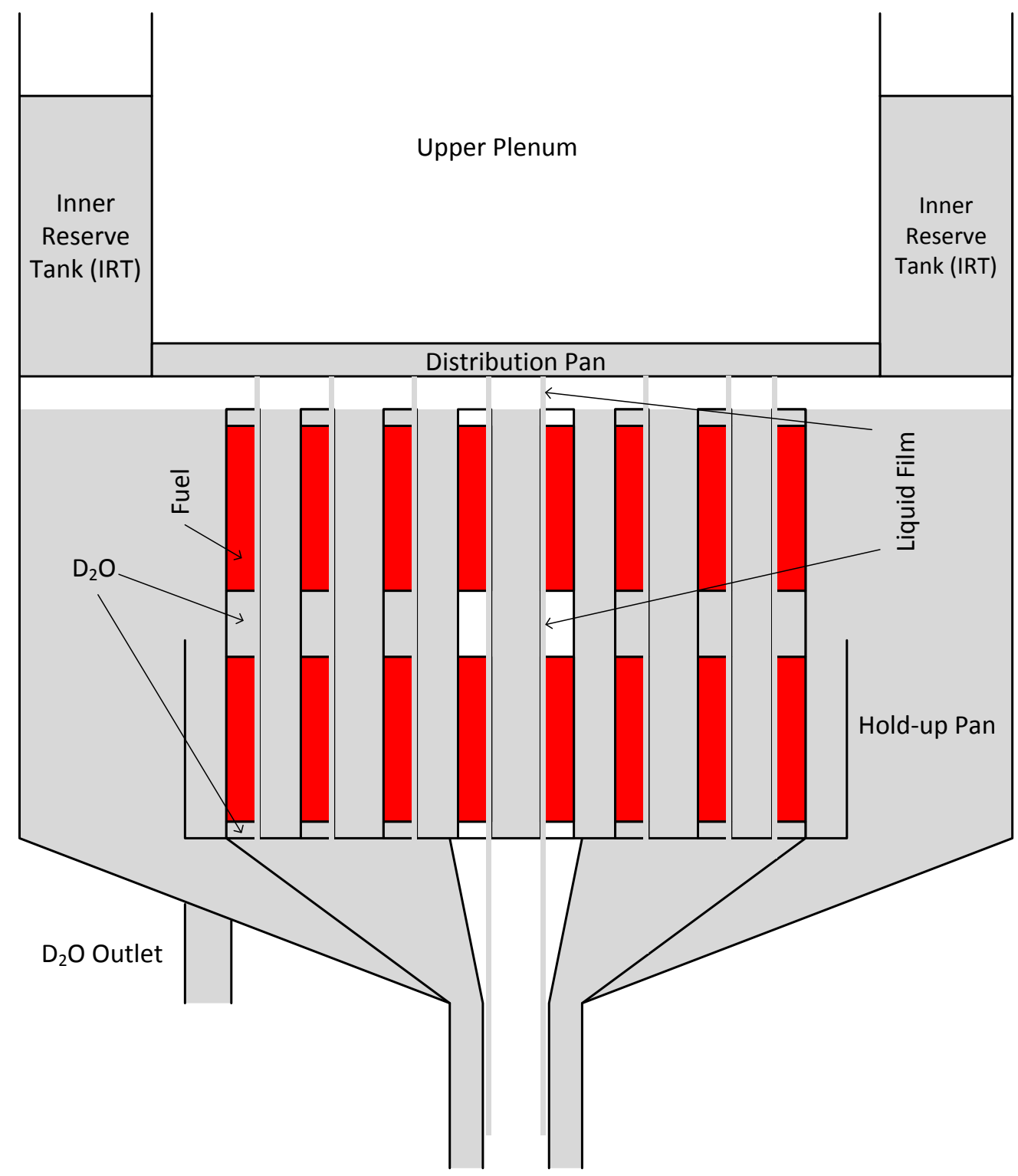

Figure 2.15 End-State of Coolant Distribution inside NBSR Vessel after Small Break at Inner Plenum Inlet Pipe (Case 5)

\subsubsection{Summary of Small Break LOCA Simulations}

Analysis of SBLOCAs with an arbitrary break size of $6.8 \mathrm{~cm}^{2}$ has been conducted using TRACE. The simulation results show that the water level inside the fuel element reaches the top elevation of the upper fuel plate around 1,700 s after the LOCA signal is generated due to low level in both SBLOCA cases;, namely, a small break at the14-inch pipe between the control valve DWV-1 and the outer plenum and at the 10-inch pipe between the control valve DWV-2 and the inner plenum. The fuel plates are drained very quickly, in $5 \mathrm{~s}$ and $14 \mathrm{~s}$ depending on the break location. 


\section{$3 \quad$ Peak Clad Temperature during LOCA}

If forced flow (delivered by the $\mathrm{D}_{2} \mathrm{O}$ main or shutdown pumps) becomes unavailable in the NBSR after a LOCA and the coolant channels drain, heat generated in the fuel elements will be transferred to the water from the IRT falling as a film on one of the side plates, and in the lower section, also by the surrounding quiescent coolant in the hold-up pan. The latter heat transfer is by natural convection, and nucleate boiling if the surface temperature is high enough. The clad and fuel temperatures may rise depending upon the decay power and the availability of the coolant.

The clad temperature on multiple fuel plates following a LOCA was calculated using the software HEATING7.3 (ORNL, 2007) to obtain the peak value spatially and then the maximum over time. HEATING7.3 solves steady-state and/or transient heat conduction problems in one-, two-, or three-dimensional Cartesian, cylindrical, or spherical coordinates. The analysis was done with different assumptions regarding the heat transfer to the falling film and to the quiescent water and taking into account the potential for a temperature discontinuity at the interface between the fuel plates and the side plates.

\subsection{Input Model for HEATING7.3}

This section describes how the fuel element is modeled in HEATING7.3, especially with respect to mesh regions, boundary conditions, the fuel plate/side plate interface, and the distribution of heat generation. A calculation notebook (Baek, 2014) discusses input data to HEATING7.3 in more detail.

\subsubsection{Mesh Regions in Fuel Element for Thin Liquid Film}

The fuel plate with the hot spot (highest local power) at end-of-cycle (to maximize decay heat) and its side plates, the eight adjacent fuel plates, the outside plate, and the fuel box above and below the heated section, are modeled in the simulation. Figure 3.1 shows the top view of a fuel plate and side plates (left and right). Figure 3.2 shows the mesh regions of the $17^{\text {th }}$ plate (the hot plate) in the X-Y plane. The figures are not to scale and the units of the dimensions are ' $\mathrm{cm}$ ' in Figure 3.2. The 13 regions that need to be considered (and other regions explained below) are listed in Table 3.1with their identification number, name, and material. The thin liquid film is taken into consideration by providing a boundary condition (heat transfer coefficient) to the outer surfaces of R-9 (facing the Y-direction) and R-10 and R-12 (facing the X-direction). 


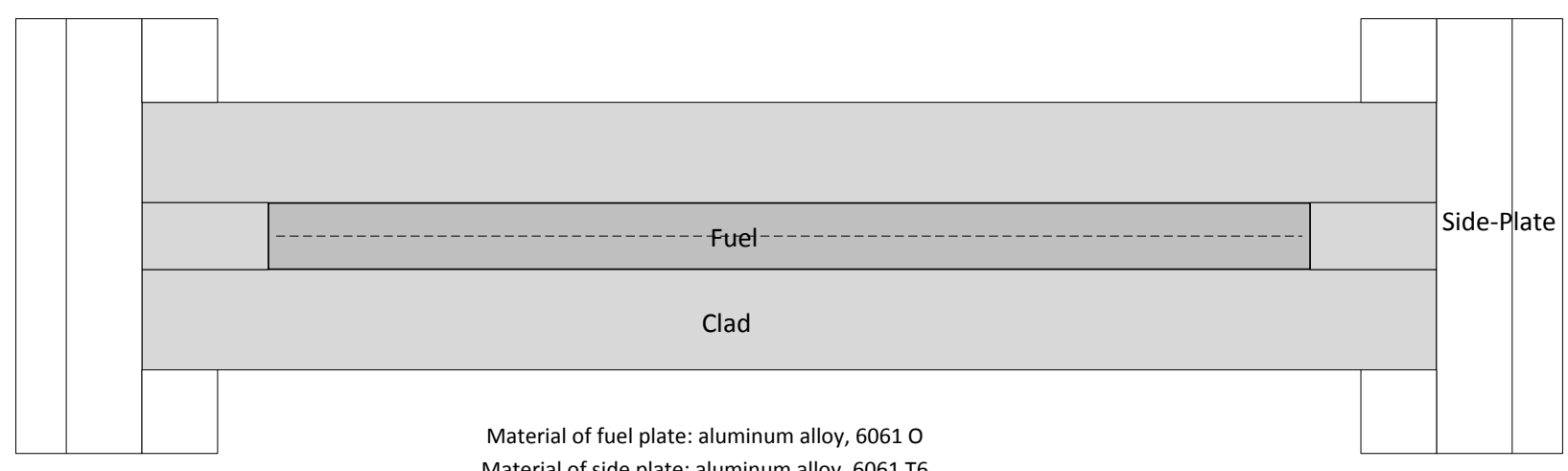

Material of side plate: aluminum alloy, 6061 T6

Figure 3.1 Fuel Plate and Side Plates (Not to Scale)

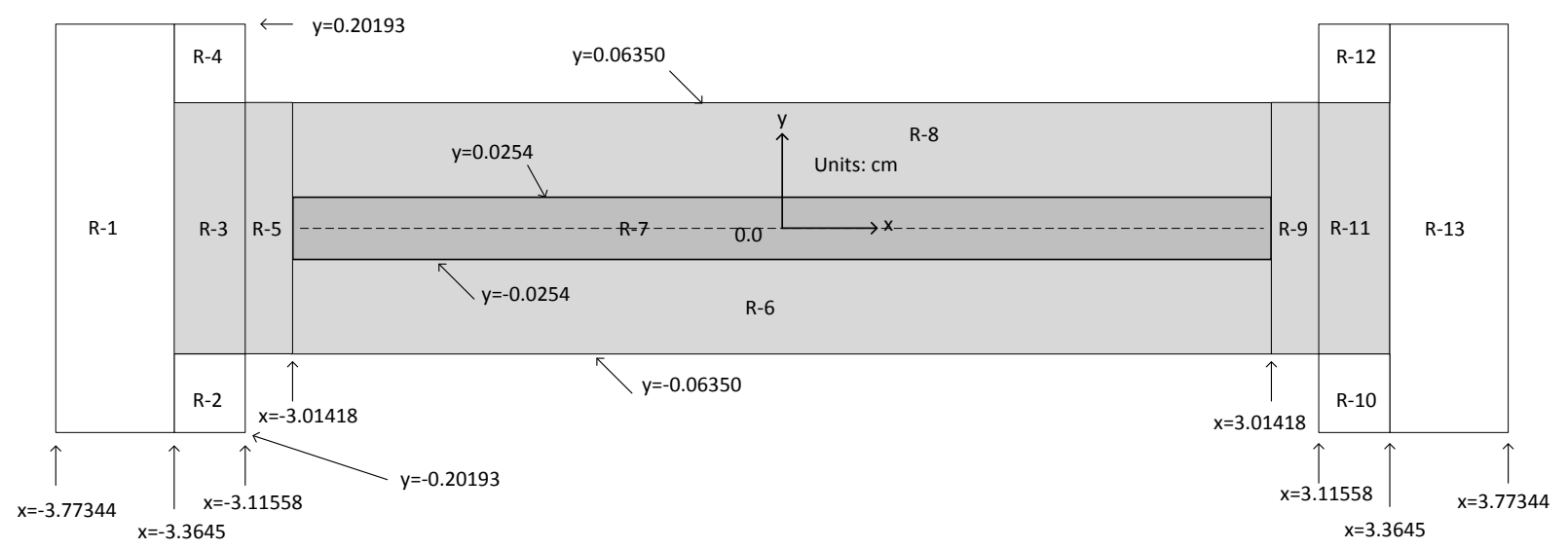

Figure 3.2 Regions of Fuel Plate and Side Plates in X-Y Plane (Not to Scale)

Table 3.1 Regions in X-Y and X-Z Plane for Thin (and Thick) Liquid Film

\begin{tabular}{|c|c|c|}
\hline Region No. & Name & Material \\
\hline $\begin{array}{c}\text { 1, 2, 4, 10, 12, 13, 2001, 2002, 2004, 2010, } \\
\text { 2012, 2013, 3001, 3002, 3004, 3010, 3012, and } \\
3013\end{array}$ & Side Plate & Aluminum alloy 6061 T6 \\
\hline $3,5,6,8,9,11,4006^{1}$, and $4008^{1}$ & Clad & Aluminum alloy 6061 O \\
\hline 7 & Fuel & $\begin{array}{c}\mathrm{U}_{3} \mathrm{O}_{8} \text { in an aluminum } \\
\text { powder dispersion }\end{array}$ \\
\hline
\end{tabular}

Note $\quad{ }^{1}$ Regions of 4006 and 4008 are used only for thick liquid film (see Section 3.1.2).

The fuel plate and side plates are also divided into regions axially as shown in Figure 3.3 for the upper section of the fuel element. Again, the figure is not to scale. The information for the regions in the X-Z plane is presented in Table 3.1. Material properties used in the analysis are summarized in Table 3.2. In the table, the region numbers in the 2000 and 3000 series represent the vertical extensions of the side plates (R-1 and R-13) and slot material (R-2, R-4, R-10, and R12), which is also considered as a part of the side plate. The 2000-regions are below the fuel 
plates and the 3000-regions are above as shown in Figure 3.3. The fuel plate axial region extends from $\mathrm{z}=0.0 \mathrm{~cm}$ to $33.02 \mathrm{~cm}$ in this model.

Table 3.2 Material Properties

\begin{tabular}{|c|c|c|c|}
\hline Material & $\begin{array}{l}\text { Density } \\
\left(\mathrm{kg} / \mathrm{cm}^{3}\right)\end{array}$ & $\begin{array}{c}\text { Heat } \\
\text { Capacity, } C_{P}, \\
(J / k g-K)\end{array}$ & $\begin{array}{c}\text { Thermal } \\
\text { Conductivity, } \\
\text { K, (W/cm-K) }\end{array}$ \\
\hline Fuel $\left(\mathrm{U}_{3} \mathrm{O}_{8}+\mathrm{Al} \text { powder }\right)^{1}$ & 0.0035955 & 660 & 1.55 \\
\hline $\begin{array}{l}\text { Clad and outside plate (Aluminum alloy } \\
6061 \text { ) }^{2}\end{array}$ & 0.0027 & 896 & 1.8 \\
\hline Side plate (Aluminum alloy $6061 \mathrm{~T} 6)^{3}$ & 0.0027 & 896 & 1.67 \\
\hline
\end{tabular}

Note ${ }^{1}$ Properties from (Baek, 2014)

${ }^{2}$ Properties from (ASM, 2014)

${ }^{3}$ Properties from (ASM, 2013)

As mentioned earlier, Figure 3.2 shows the mesh regions of the $17^{\text {th }}$ fuel plate of the fuel element "L-3" generating the highest plate power in the upper section of the 30 fuel elements. In the simulations nine fuel plates (the $9^{\text {th }}$ to $17^{\text {th }}$ plates) and one outside plate are considered as shown in Figure 3.4. The X- and Z-coordinates of the plates are the same as those shown in Figure 3.2 and Figure 3.3. A calculation notebook (Baek, 2014) provides the detailed Y-coordinates of the plates shown in Figure 3.4. 


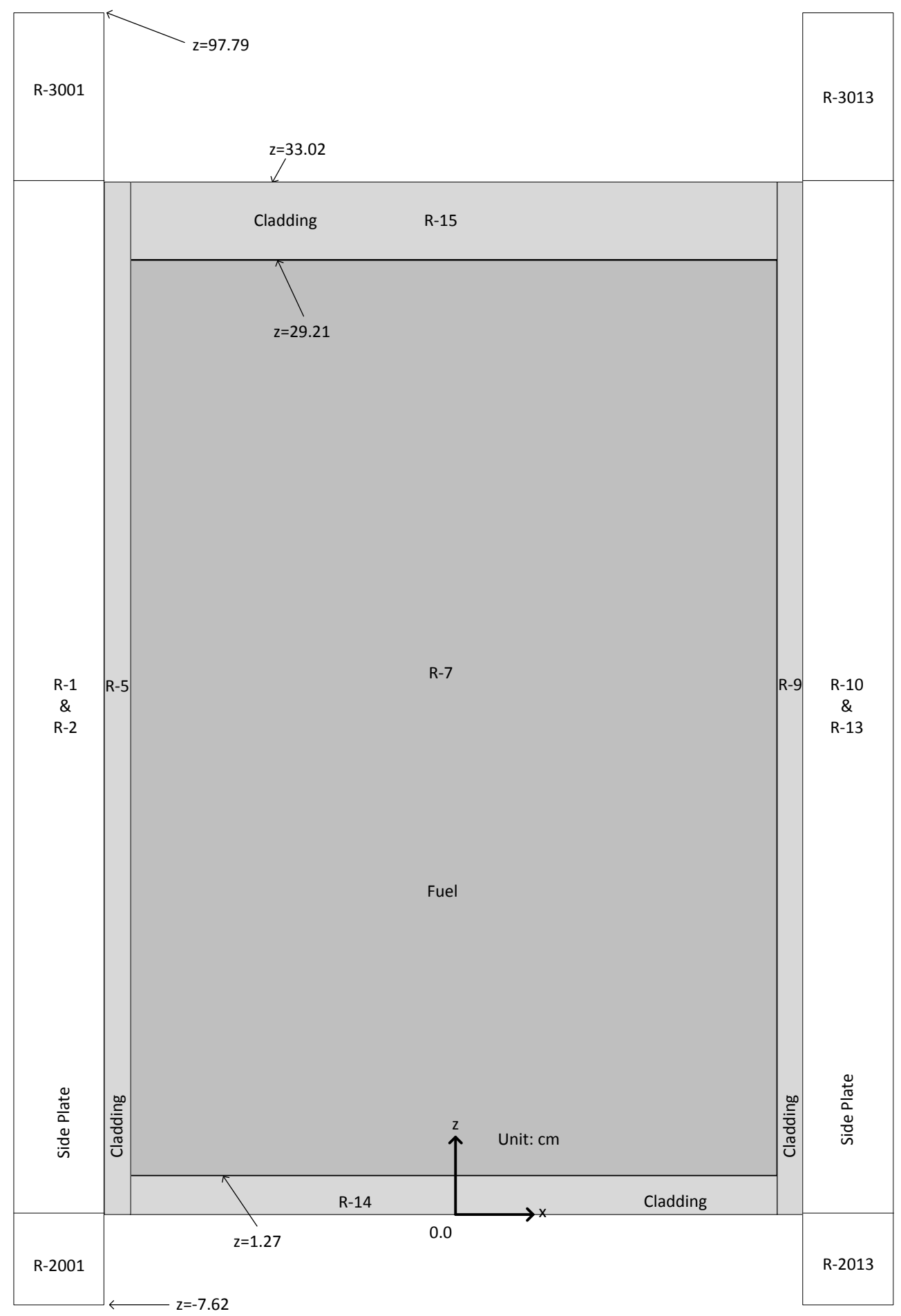

Figure 3.3 Regions of Fuel Plate and Side Plates of Upper Fuel Element in X-Z Plane (Not to Scale) 

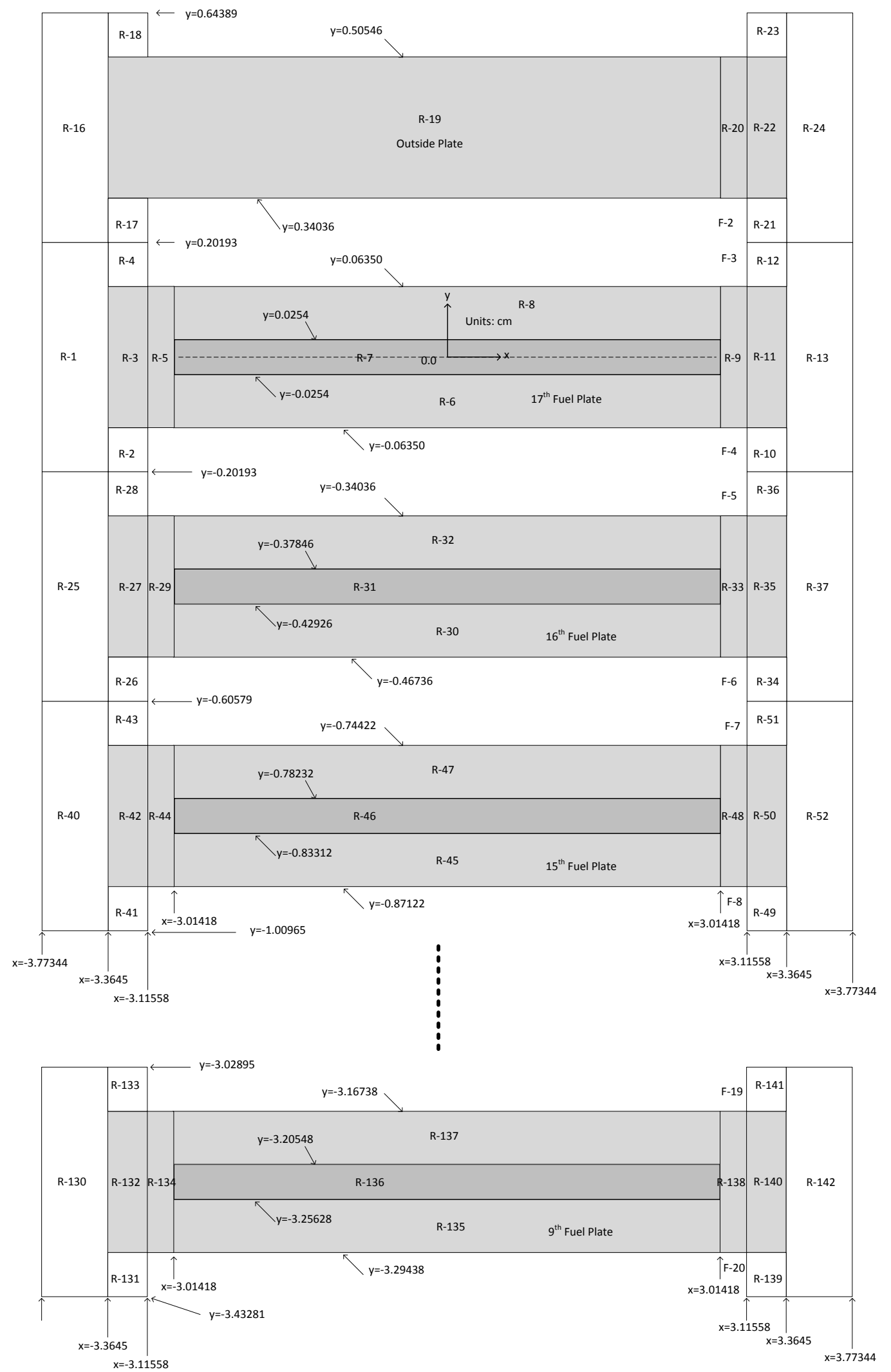

Figure 3.4 Regions of Nine Fuel, Side and Outside Plates in X-Y Plane (Not to Scale) 


\subsubsection{Mesh Regions in Fuel Element for Thick Liquid Film}

The length of R-9 is $0.0965 \mathrm{~cm}$ in the X-direction in Figure 3.2. In order to consider thicker liquid film, the mesh regions of Figure 3.2 have been modified as shown in Figure 3.5. The length of R-4006 (or R-4008) and R-9 together is $0.4 \mathrm{~cm}$ in the X-direction and these mesh regions are assumed to have a thick liquid film. The thickness of falling liquid film is simulated by applying an appropriate boundary condition (heat transfer coefficient) to the outer surfaces of R-4006, R-4008, and R-9 (facing the Y-direction), and R-10 and R-12 (facing the X-direction) while the other outer surfaces of the fuel plate and side plate are assumed to be insulated.

The mesh regions of Figure 3.3 in the axial direction remain unchanged, and the identification (region) numbers for thick liquid film are presented in Table 3.1. Figure 3.5 shows the mesh regions of the $17^{\text {th }}$ fuel plate for thick liquid film. The same mesh region scheme is applied to the other fuel plate (the $9^{\text {th }}$ through $16^{\text {th }}$ plates) to simulate a thick liquid film on the inside of one side plate in each flow channel.

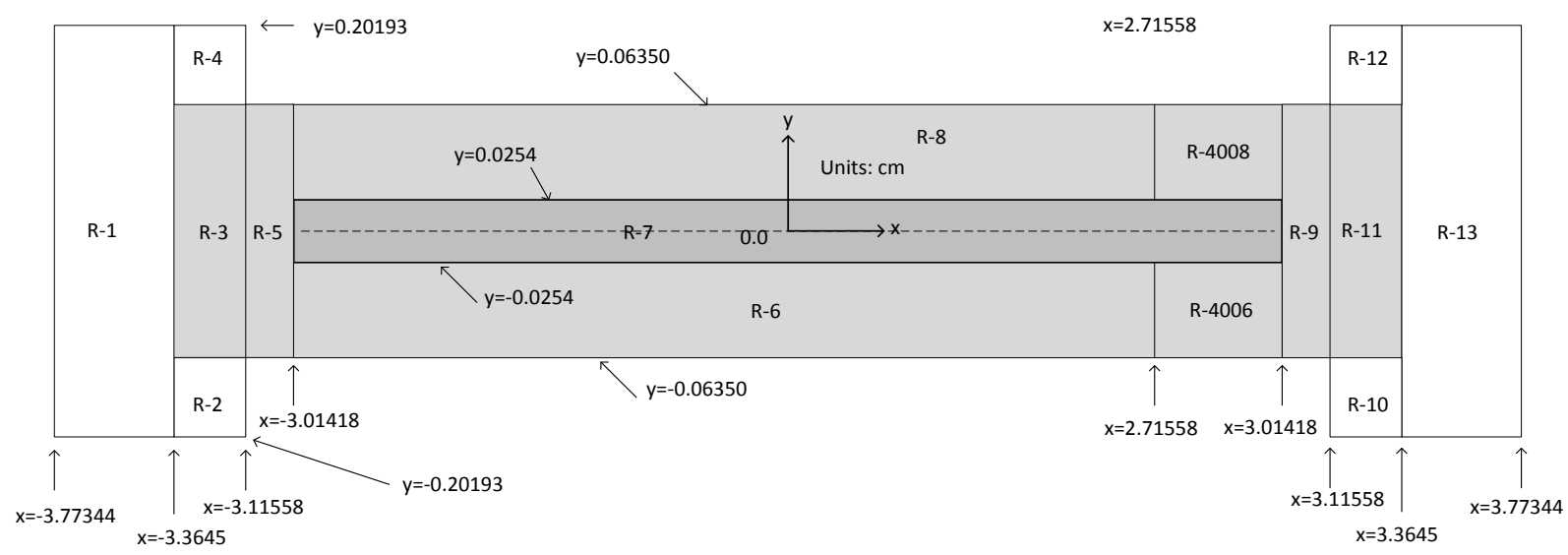

Figure 3.5 Mesh Regions to Simulate Thick Liquid Film in X-Y Plane (Not to Scale)

\subsubsection{Lower Section}

The nine fuel plates including the side plates and an outside plate in the lower section are also modeled. Their dimensions and mesh regions are identical to those in the upper fuel section as shown in Figure 3.2 through Figure 3.5 except for the dimensions in the Z-axis (because clad heights at the top and bottom are different). Figure 3.6 (not to scale) shows the Z-coordinates of the lower fuel element. 


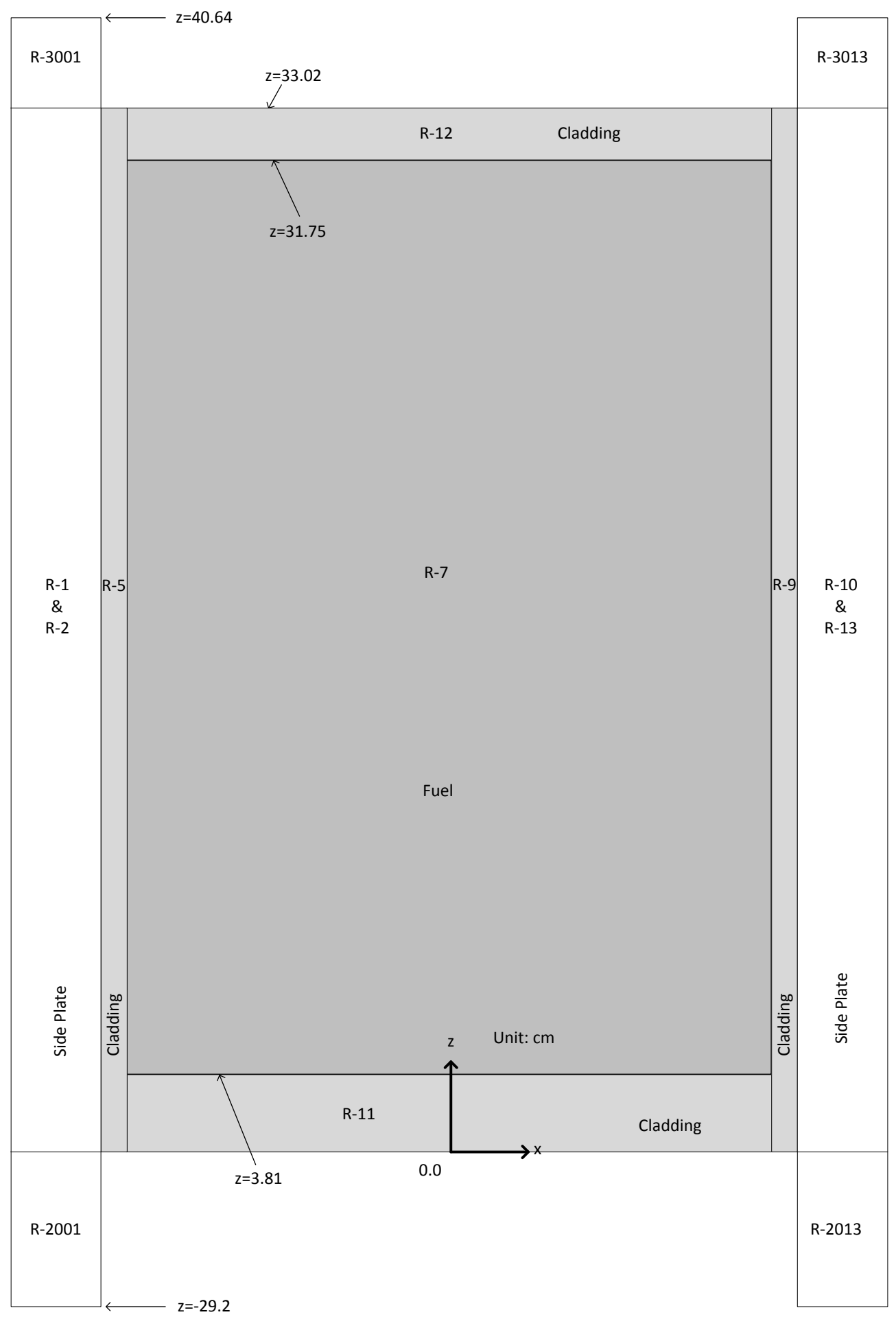

Figure 3.6 Regions of Fuel Plate and Side Plates of Lower Fuel Element in X-Z Plane (Not to Scale) 


\subsubsection{Evaluation of Film Thickness}

In the previous sections it was discussed that two types of mesh regions are used to simulate two film thicknesses, $0.1 \mathrm{~cm}$ and $0.4 \mathrm{~cm}$. The thickness of $0.1 \mathrm{~cm}$ is conservatively chosen as the base film thickness based on its evaluation under the GBLOCA conditions.

After the coolant channels are drained, the water coming from the inner reserve tank (IRT) hits one inside surface of the upper end adapter and forms a liquid film flowing downward. It is assumed that the characteristics of this film flow in the region of the fuel plates are similar to those of flow in open channels. Figure 3-7 shows flow in a rectangular open channel. In the figure $\delta$ and $W$ can represent the flow depth (film thickness) and the width of the flow channel, respectively.

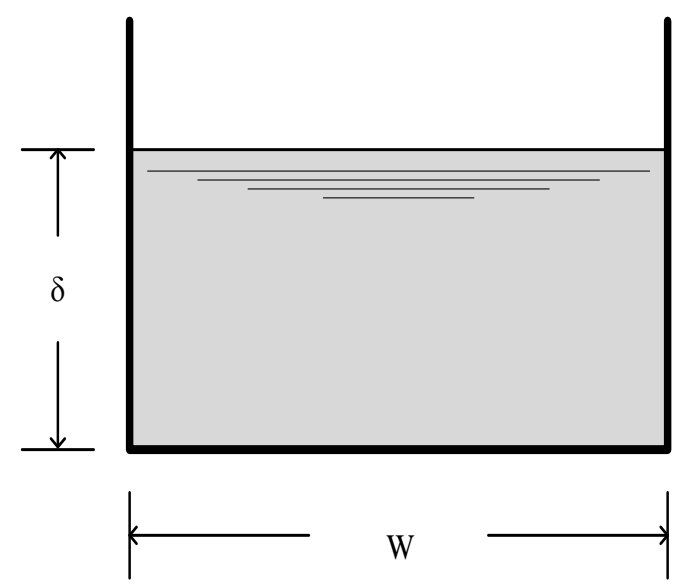

Figure 3-7 Flow in Rectangular Open Channel

If a uniform steady flow is assumed, the following relationships can be considered to evaluate the film thickness and velocity. The basic resistance equation for open channel flow is

$$
\tau_{o}=\rho \cdot g \cdot R_{H} \cdot \sin \alpha
$$

where, $\tau_{o}, \rho, g, R_{H}$, and $\alpha$ are the boundary (bed) shear stress, $\mathrm{D}_{2} \mathrm{O}$ density, gravitational acceleration, the hydraulic radius (defined later), and angle of the channel slope, respectively. The volumetric flowrate is conserved with an assumption that the density of the heavy water does not change.

$$
\dot{Q}=V_{F} \cdot \delta \cdot W
$$

where, $V_{F}$ and $\delta$ represent the average film velocity and film thickness (flow depth), respectively. The empirical equation for the relationship between flow velocity and boundary shear stress is expressed as follows (MIT, 2014).

$$
\tau_{o}=\frac{f}{8} \cdot \rho \cdot V_{F}^{2}
$$


The variable $f$ stands for the friction coefficient and is a function of the Reynolds number and the ratio of the roughness $(\varepsilon)$ of the surface to the film thickness as shown below.

$$
f=f\left(N_{R}, \frac{\varepsilon}{\delta}\right)
$$

The friction coefficient can be evaluated using the Moody-type diagram for open channel flow shown in Figure 3-8.

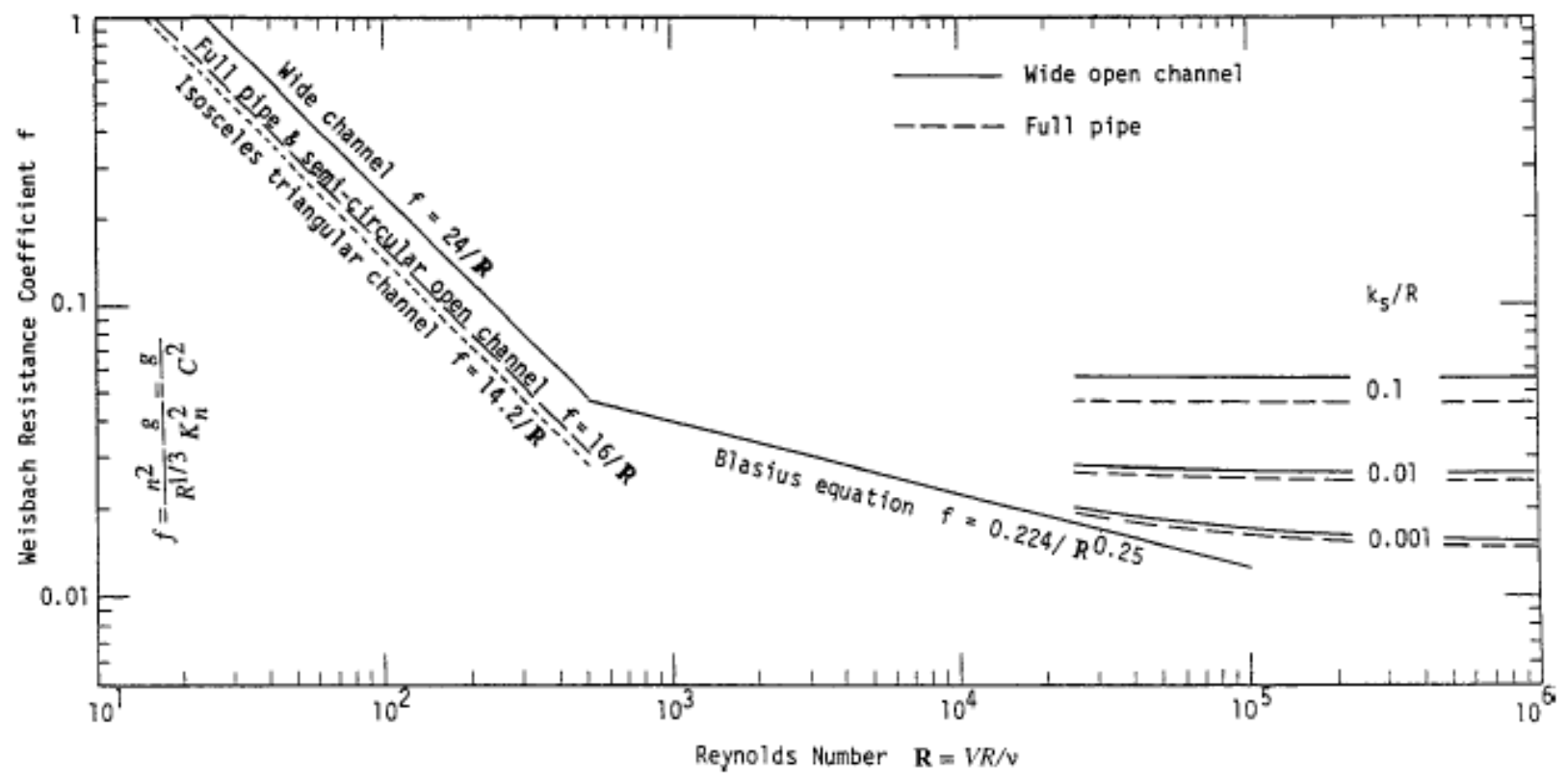

Figure 3-8 Moody Type Diagram for Open Channels with Impervious Rigid Boundary (Yen, 2002)

The mean-flow Reynolds number, $N_{R}$, and the hydraulic radius $\left(R_{H}\right)$ for the channel flow are defined as follows.

$$
N_{R}=\frac{\rho \cdot V_{F} \cdot R_{H}}{\mu}
$$

where $\mu$ is the viscosity of heavy water.

$$
R_{H}=\frac{A_{C R O S S}}{W P}
$$

In Eq. (3-6) the variables $A_{C R O S S}$ and $W P$ are the the cross section area and wetted perimeter of the channel, respectively, and they are expressed as

$$
\begin{aligned}
& A_{\text {CROSS }}=\delta \cdot W \\
& W P=2 \delta+W
\end{aligned}
$$


The volumetric flowrate of the film in one of the 18 coolant channels in the fuel element is calculated from the flowrate information. In the response to Question 14 (b) (NBS, 1966) the NIST staff stated, "The initial flow of $40 \mathrm{gpm}$ is distributed uniformly to the 37 core positions." The volumetric flowrate of liquid film in a channel becomes

$$
\dot{Q}=\frac{40 \mathrm{gpm}}{37 \times 18} \times \frac{1 \frac{\mathrm{m}^{3}}{\mathrm{~s}}}{15850.3 \mathrm{gpm}} \times \frac{10^{6} \mathrm{~cm}^{3}}{1 \mathrm{~m}^{3}}=3.789 \frac{\mathrm{cm}^{3}}{\mathrm{~s}}
$$

The heavy water density is $1104.4 \frac{\mathrm{kg}}{\mathrm{m}^{3}}$ at $25^{\circ} \mathrm{C}$. The average width of a flow channel is $0.295 \mathrm{~cm}$ (0.116 in). Using Eq. (3-1) through Eq. (3-8), the thickness and velocity of the falling film are evaluated to be $0.118 \mathrm{~cm}$ and $109 \mathrm{~cm} / \mathrm{s}$, respectively, under the NBSR LOCA conditions.

$$
\begin{aligned}
& V_{F}=109 \frac{\mathrm{cm}}{\mathrm{s}} \\
& \delta=0.118 \mathrm{~cm}
\end{aligned}
$$

\subsubsection{Representation of Joint Between Fuel Plate and Side Plate}

\subsubsection{Thermal Contact between Fuel Plates and Side Plates}

For the HEATING7.3 models discussed in the previous sections it was assumed that contact between the fuel plates and side plates is perfect on all sides. In reality, some portion of the plates may not be touching and in some portion where the plates touch, thermal contact may not be perfect. The latter situation is because of tiny random gaps between the two metallic surfaces as shown (exaggerated) in Figure 3.9. Heat transfer by conduction becomes less efficient because of these gaps, and a discontinuity in temperature is expected at the interface as shown in the figure. The added thermal resistance at the interface is represented by a contact conductance (see Section 3.1.5.2). In the other situation there is clearance between the plates due to the fabrication process. As explained below, this is the result of the deliberate clearance at the edge of the fuel plate that is left when the fuel plate is inserted into the slots in the side plate and the result of the swaging process. These clearances are conservatively assumed to be large enough so that there is no heat transfer.

HEATING7.3 input models were developed to simulate the different thermal contacts. Figure 3.10 shows the input model for the $17^{\text {th }}$ plate. There is about 0.5 or $1 \mathrm{~mm}$ gap, or clearance, between the side plates and the ends of the fuel plate (O'Kelly, 2014) as shown in Figure 3.11, which depicts the left-upper part of Figure 2.5. This means that the edge of the fuel plate (the surface normal to the $\mathrm{X}$-axis) doesn't physically touch the side plate. This clearance is modeled between the side plates (R-1 and R-13) and the fuel plate (R-3 and R-11) as shown in Figure 3.10 . 


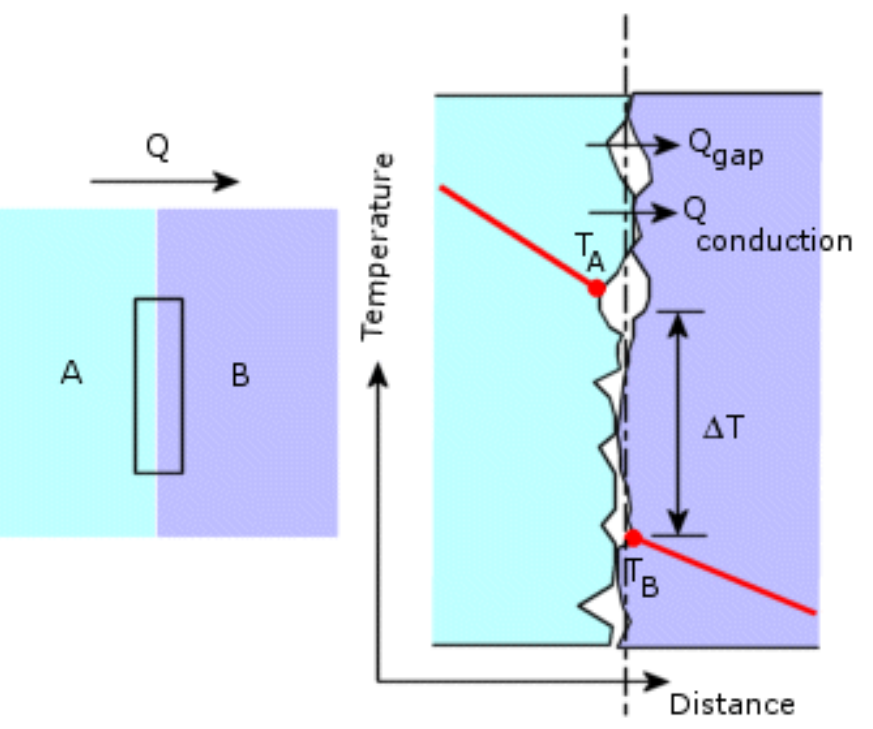

Figure 3.9 Thermal Contact of Two Plates (Dassault, 2014)
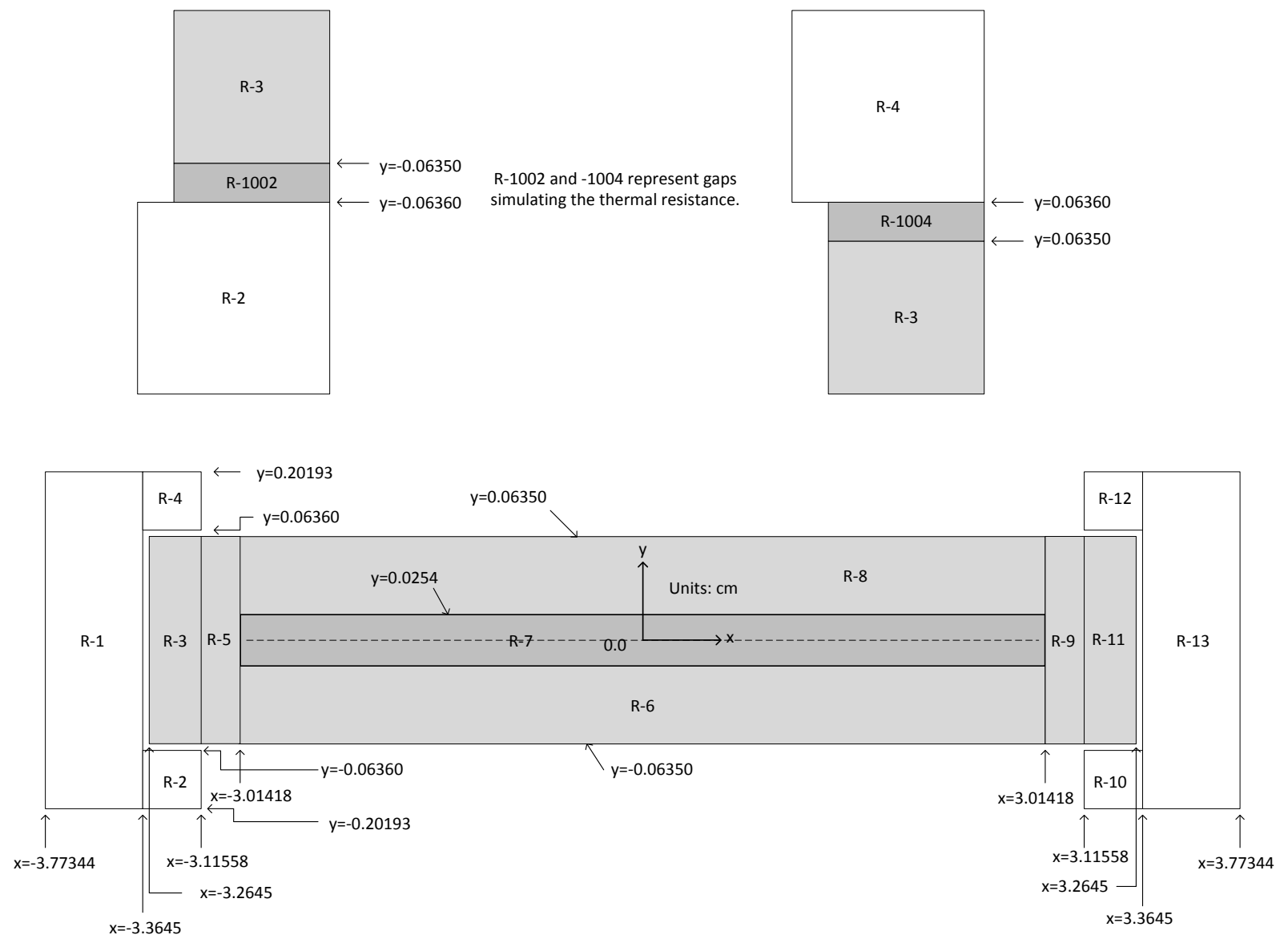

Figure 3.10 Mesh Regions to Simulate Imperfect Thermal Contact with Complete (100\%) Contact Area (Not to Scale) 


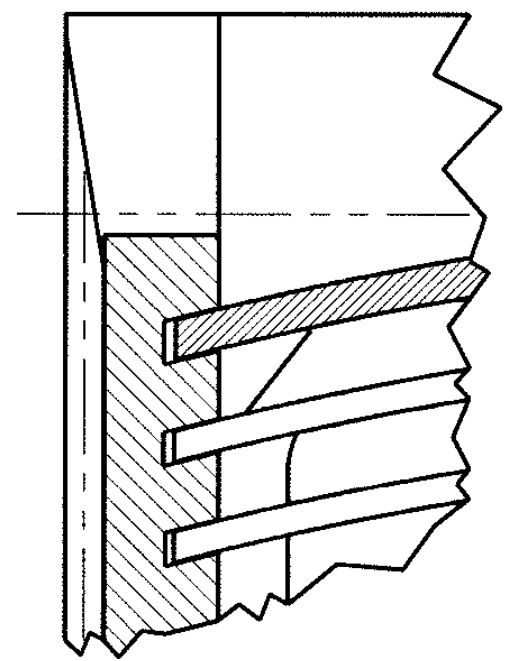

Figure 3.11 Fuel Plates and Side Plate (NIST, 2012)

In addition, the thermal resistance caused by the imperfect thermal contact due to the random gaps at the interface between the slot material (R-2 or R-4) and the fuel plate (R-3) is modeled by considering a gap (R-1002 or R-1004) between them and applying a "surface-to-surface" boundary to the gap. There are additional gaps R-1010 between R-10 and R-11 and R-1012 between R-11 and R-12. The clearance and imperfect thermal contact in the other fuel plates (the $9^{\text {th }}$ through the $16^{\text {th }}$ plates) are modeled in the same way shown in Figure 3.10. The thermal resistance due to imperfect contact is input as "contact conductance" of the gap regions.

Figure 3.10 and Figure 3.11 show complete (100\%) contact area between the side plate (the slot material) and the fuel plate in the Y-direction. However, some portion of the joint may not be in contact at all. Figure 3.12 depicts how the swaging was done for the fuel element of the Advanced Test Reactor (ATR). The lower-right part of the figure shows that the slot material and fuel element were not completely touching (incomplete contact) after swaging. The white and black colors in that enlarged view stand for the solid material and void, respectively. A similar situation for the similar joints in the NBSR fuel elements is assumed possible after swaging.

In the simulations a 50\% incomplete contact area is modeled as shown in Figure 3.13. In this case the thermal resistance caused by the incomplete contact between the slot material (R-2 or R4) and the fuel plate (R-3) is modeled by considering a gap (R-1002 or R-1004) touching only half of them. Again, a "surface-to-surface” boundary is applied to the gap. Similarly, gaps R1010 between R-10 and R-11 and R-1012 between R-11 and R-12 touch half of the metal surfaces. For the $9^{\text {th }}$ plate to $16^{\text {th }}$ plate and the outside plate, the incomplete $(50 \%)$ physical contact is modeled in the same way done for the $17^{\text {th }}$ plate shown in Figure 3.13. 


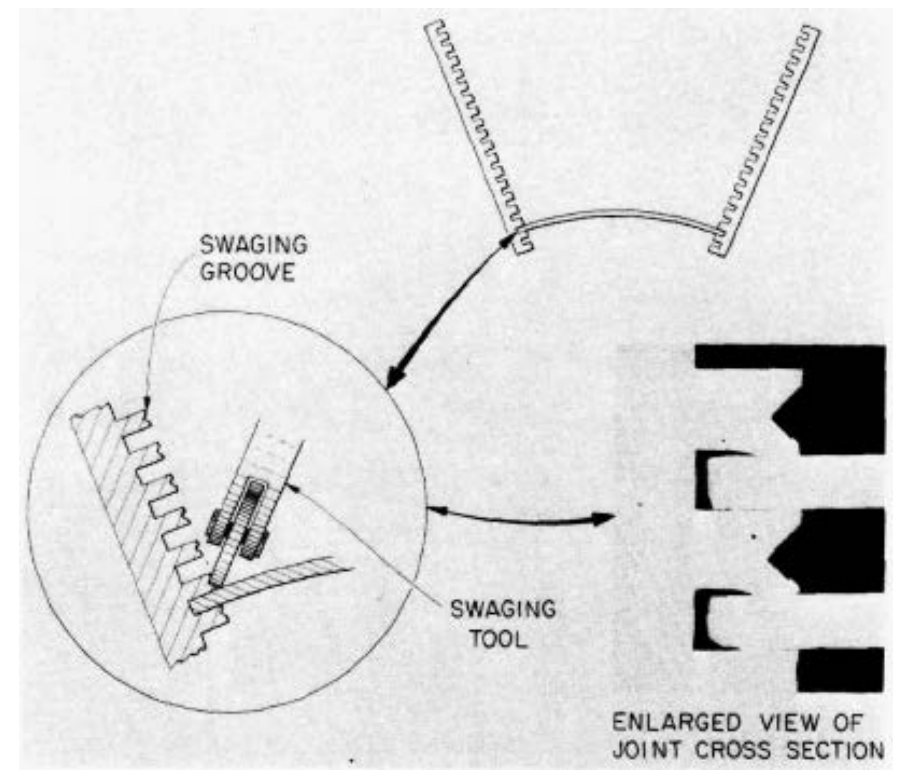

Figure 3.12 Technique Used to Fabricate Roll Swaged Joint for Advance Test Reactor Fuel Element (Adamson, 1968)
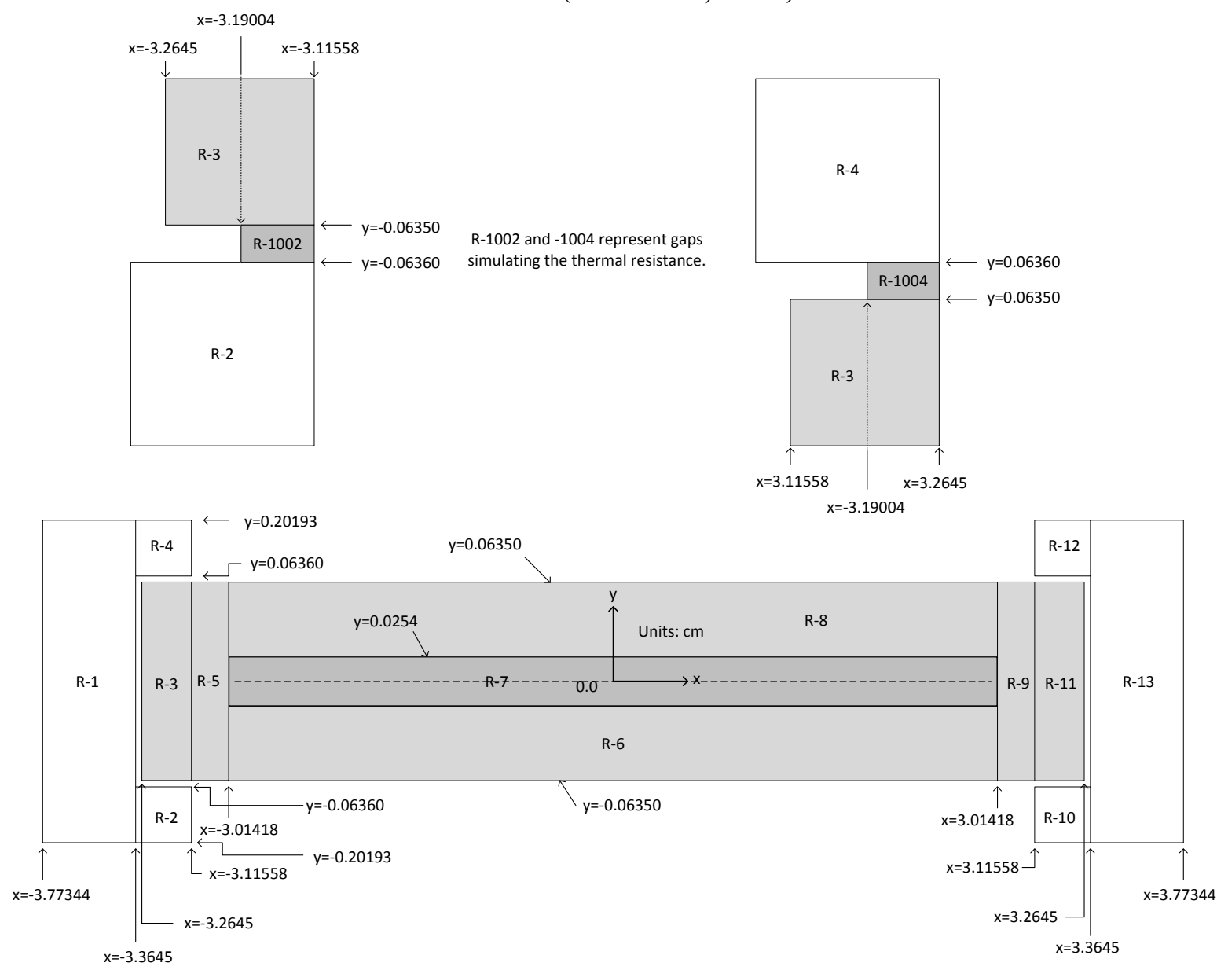

$x=-3.19004$

Figure 3.13 Mesh Regions to Simulate Imperfect Thermal Contact with Incomplete (50\%) Contact Area (Not to Scale) 


\subsubsection{Conductance for Imperfect Thermal Contact}

(Yovanovich, 2014) discussed how to evaluate contact conductance for clamped joints, which are assumed to be a first approximation to swaged joints. The thermal joint conductance, $h_{j}$, of the interface formed by two conform, rough surfaces is given as follows:

$$
h_{j}=h_{c}+h_{g}
$$

where, $h_{c}$ and $h_{g}$ are the contact conductance and gap conductance, respectively. The gap conductance is very small compared to the contact conductance in the simulation cases discussed in the later sections, so Eq. (3-9) can be expressed as

$$
h_{j} \approx h_{c}
$$

The contact conductance is given by:

$$
h_{c}=1.25 k_{s} \frac{m}{\sigma}\left(\frac{P}{H_{c}}\right)^{0.95}
$$

where, $k_{s}, m$, and $\sigma$ represent the harmonic mean thermal conductivity of the interface, the effective mean absolute asperity slope of the interface, and the effective root-mean-square (RMS) surface roughness of the contacting asperities, respectively. They are expressed as follows:

$$
\begin{aligned}
& k_{s}=\frac{2 k_{1} k_{2}}{k_{1}+k_{2}} \\
& m=\sqrt{m_{1}^{2}+m_{2}^{2}} \\
& m_{i}=0.125\left(\sigma_{i} \times 10^{6}\right)^{0.402} \\
& \sigma=\sqrt{\sigma_{1}^{2}+\sigma_{2}^{2}}
\end{aligned}
$$

In Eq. (3-11) $P$ and $H_{c}$ are the contact pressure and the surface microhardness of the softer of the two contacting solids, respectively. Table 3.3 shows the properties of Al 6061 associated with the contact conductance.

Section 4.2.1.3 of (NIST 2004) says, "The efficiency of the roll swaging assembly technique is tested by determining the force which is necessary to fail test sections. A minimum joint strength of $150 \mathrm{lbs}$ per linear inch (26.8 $\mathrm{kg}$ per linear $\mathrm{cm}$ ) of roll swaged joint is required." The contact pressure corresponding to a joint strength of $26.8 \frac{\mathrm{kg}_{\mathrm{f}}}{\mathrm{cm}}$ can be evaluated by considering the relationship between friction and normal forces shown in Figure 3.14. 
Table 3.3 Thermal and Surface Properties of Al 6061 (Yovanovich, 2014)

\begin{tabular}{|c|c|}
\hline Property & Value \\
\hline Thermal conductivity, $k_{s}$ & $180 \frac{\mathrm{W}}{\mathrm{m} \cdot \mathrm{K}}$ \\
\hline Microhardness, $H_{c}$ & $705 \mathrm{MPa}$ \\
\hline Surface roughness, $\sigma_{A l}$ & $0.7 \mu \mathrm{m}$ \\
\hline Effective mean absolute asperity slope, $m_{A l}$ & $m_{A l}=0.125(0.7)^{0.402}=0.1083$ \\
\hline $\begin{array}{l}\text { Effective mean absolute asperity slope of the } \\
\text { interface, } m\end{array}$ & $m=\sqrt{2} \cdot m_{A l}=\sqrt{2} \times 0.1083=0.1532$ \\
\hline Effective RMS surface roughness, $\sigma$ & $\sigma=\sqrt{2} \cdot \sigma_{A l}=\sqrt{2} \times 0.7 \mu \mathrm{m}=0.9899 \mu \mathrm{m}$ \\
\hline
\end{tabular}

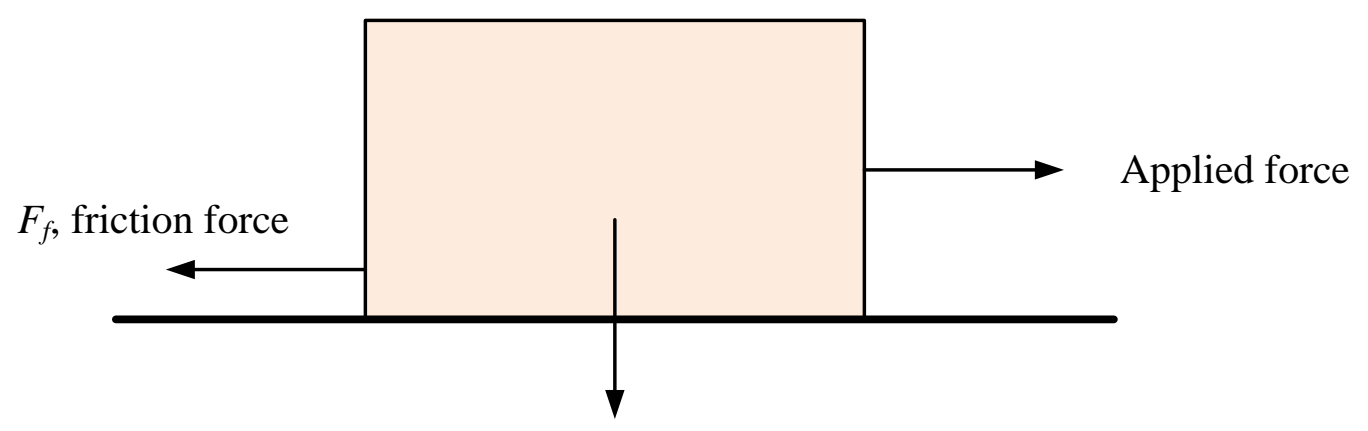

$F_{N}$, normal force

Figure 3.14 Friction and Normal Forces

The friction force can be expressed as

$$
F_{f}=\mu \cdot F_{N}
$$

where, $\mu$ is the static frictional coefficient and it is 1.05 to 1.35 for clean and dry aluminum-andaluminum surface (Engineeringtoolbox, 2014). By considering that the friction force is the joint strength of $26.8 \frac{\mathrm{kg}_{\mathrm{f}}}{\mathrm{cm}}$, the normal force can be calculated using Eq. (3-16).

$$
F_{N}=\frac{F_{f} \cdot L_{F E}}{\mu}=\frac{26.8 \frac{\mathrm{kg}_{\mathrm{f}}}{\mathrm{cm}} \times 9.81 \frac{\mathrm{N}}{\mathrm{kg}_{\mathrm{f}}} \times 33.02 \mathrm{~cm}}{1.05}=8263.8 \mathrm{~N}
$$

where, $L_{F E}$, the length of a fuel plate, is $33.02 \mathrm{~cm}$. Then, the contact pressure can be evaluated by dividing the normal force by the contact area between the side plate and fuel plate. From Figure 3-2 the contact area per interface is evaluated as

$$
A_{C T-1}=w_{F E} \cdot L_{F E}=(3.3645-3.1158) \mathrm{cm} \times 33.02 \mathrm{~cm}=8.2 \mathrm{~cm}^{2}
$$


where, $w_{F E}$ stands for the width of the contact area. Because there are two sides of the physical contact after the roll swaging, the total contact area which needs to be considered for the test becomes

$$
A_{C T-T O T A L}=2 \cdot A_{C T-1}=2 \times 8.2 \mathrm{~cm}^{2}=16.4 \mathrm{~cm}^{2}
$$

The contact pressure can be obtained as

$$
P_{C T-100 \%}=\frac{F_{N}}{A_{C T-T O T A L}}=\frac{8263.8 \mathrm{~N}}{16.4 \mathrm{~cm}^{2}} \times \frac{10000 \mathrm{~cm}^{2}}{1 \mathrm{~m}^{2}} \times \frac{1 \mathrm{kPa}}{1000 \mathrm{~Pa}}=5031.5 \mathrm{kPa}
$$

With a contact pressure of $5031.5 \mathrm{kPa}$ the contact conductance is evaluated using Eq. (3-11) and the properties of Table 3-3 as below.

$$
\begin{aligned}
h_{c-100 \%}= & 1.25 \times 180 \frac{\mathrm{W}}{\mathrm{m} \cdot \mathrm{K}} \times \frac{0.1532}{0.9899 \mu \mathrm{m}} \times \frac{10^{6} \mu \mathrm{m}}{1 \mathrm{~m}} \times \frac{1 \mathrm{~m}^{2}}{10000 \mathrm{~cm}^{2}} \times\left(\frac{5.0315 \mathrm{MPa}}{705 \mathrm{MPa}}\right)^{0.95} \\
= & 31.81 \frac{\mathrm{W}}{\mathrm{cm}^{2} \cdot \mathrm{K}}
\end{aligned}
$$

The contact conductance evaluated above is for the complete (100\%) physical contact area as shown in Figure 3.10. When the contact area is $50 \%$ of the full area (see Figure 3.13), the contact pressure needs to be re-calculated as

$$
P_{C T-50 \%}=\frac{F_{N}}{A_{C T-50 \%}}=\frac{8263.8 \mathrm{~N}}{\frac{16.4}{2} \mathrm{~cm}^{2}} \times \frac{10000 \mathrm{~cm}^{2}}{1 \mathrm{~m}^{2}} \times \frac{1 \mathrm{kPa}}{1000 \mathrm{~Pa}}=10063.0 \mathrm{kPa}
$$

Then the contact conductance becomes

$$
\begin{aligned}
& h_{c-50 \%}= 1.25 \times 180 \frac{\mathrm{W}}{\mathrm{m} \cdot \mathrm{K}} \times \frac{0.1532}{0.9899 \mu \mathrm{m}} \times \frac{10^{6} \mu \mathrm{m}}{1 \mathrm{~m}} \times \frac{1 \mathrm{~m}^{2}}{10000 \mathrm{~cm}^{2}} \times\left(\frac{10.063 \mathrm{MPa}}{705 \mathrm{MPa}}\right)^{0.95} \\
&=61.45 \frac{\mathrm{W}}{\mathrm{cm}^{2} \cdot \mathrm{K}}
\end{aligned}
$$

In summary, the contact conductance of $31.81 \frac{\mathrm{W}}{\mathrm{cm}^{2} \cdot \mathrm{K}}$ and Figure 3.10 are considered for the complete (100\%) contact area and $h_{c}$ of $61.45 \frac{\mathrm{W}}{\mathrm{cm}^{2} \cdot \mathrm{K}}$ and Figure 3.13 are used to simulate the incomplete (50\%) contact area in the HEATING7.3 runs. These values are based on the minimum acceptable joint strength; a conservative assumption as the actual strength is expected to be higher.

\subsubsection{Boundary Conditions}

Boundary conditions in transient runs are applied to the appropriate outer surfaces of the fuel plate and side plates using either a heat transfer coefficient (HTC) or a heat flux. For the heat flux from the outside of the side plate, the heat transfer coefficients are first evaluated using the 
Churchill and Chu correlation (Incropera, 1996) which is appropriate for natural convection from a vertical surface and Gorenflo correlation (Wolverine, 2006) for nucleate boiling. The former and latter correlations depend upon the difference between the surface temperature $\left(T_{s}\right)$ and the surrounding water temperature $\left(T_{b}\right)$ and the difference between the surface temperature and the liquid saturation temperature $\left(\mathrm{T}_{\text {sat }}\right)$, respectively. Heat flux from the surface of the side plate is calculated using the heat transfer coefficients and the temperature differences. The evaluated heat flux as a function of temperature difference is depicted in Figure 3.15.

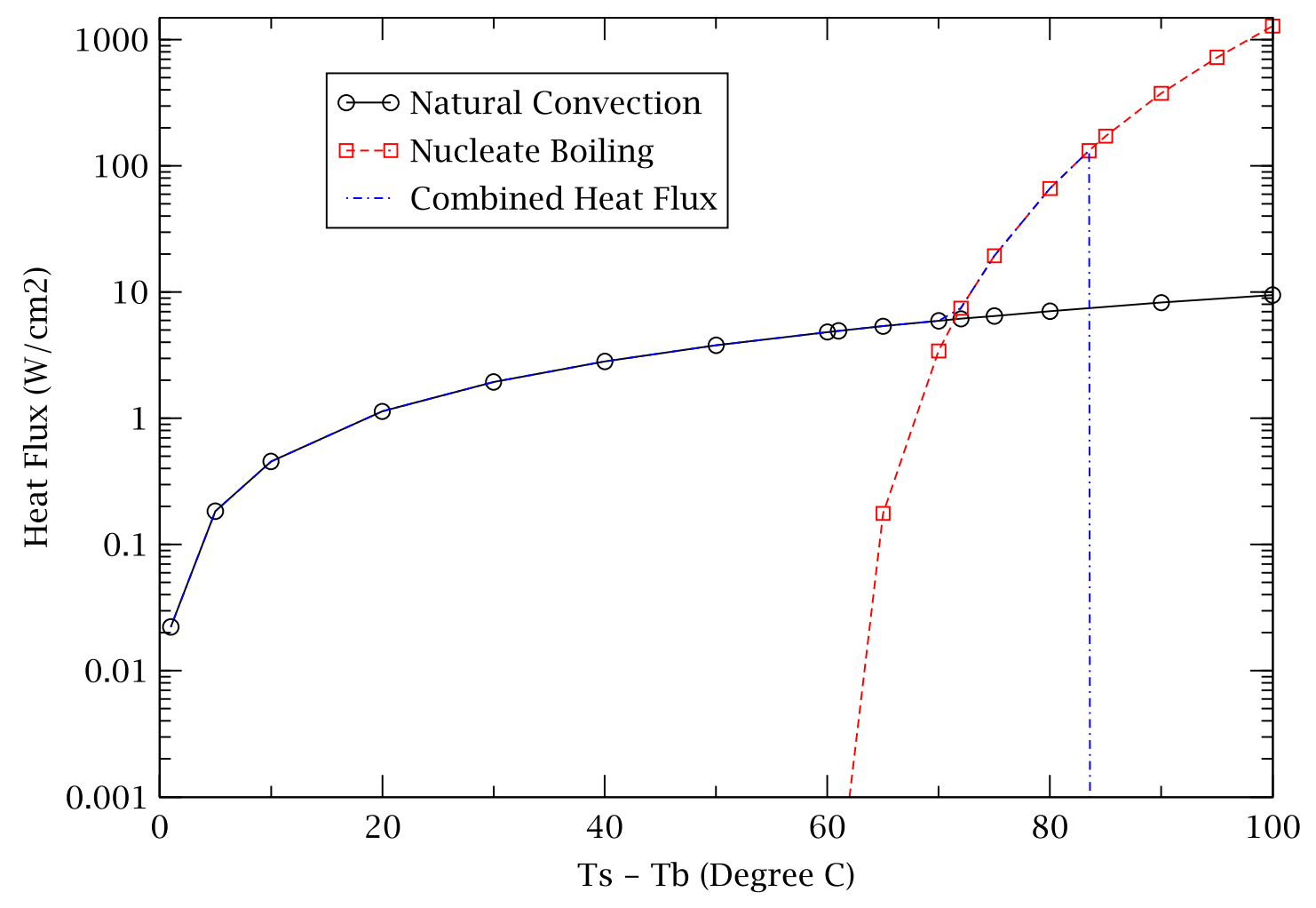

Figure 3.15 Heat Flux Applied to Outer Surface of Side plate

In Figure 3.15 the "Combined Heat Flux" indicates the larger of the heat fluxes due to natural convection and nucleate boiling. It is assumed that the water temperature in the hold-up pan is $41^{\circ} \mathrm{C}$ and that nucleate boiling starts when the side plate surface temperature becomes $101^{\circ} \mathrm{C}$ (saturation temperature of heavy water). In the HEATING7.3 simulation the boundary temperature is considered to be $0^{\circ} \mathrm{C}$ so that nucleate boiling is assumed to occur when the predicted temperature of the side plate surface is $60^{\circ} \mathrm{C}$. The "Combined Heat Flux" is applied to the side plate surface as the boundary condition. In Figure 3.15 the heat flux becomes zero when the surface temperature is $83.6^{\circ} \mathrm{C}$. This implies reaching boiling crisis with a critical heat flux of $q_{C H F}^{\prime \prime}=132.2 \frac{\mathrm{W}}{\mathrm{cm}^{2}}$ and a surface temperature of $83.5^{\circ} \mathrm{C}$. (Mourgues, 2013) presents experimental results for the critical heat flux $\left(\sim 130 \mathrm{~W} / \mathrm{cm}^{2}\right)$ on a vertical plate with water. 
The Wilke correlation (Wolverine, 2001), shown in Eq. (3-17) for turbulent film flow, is used to calculate the HTC of the falling film by assuming that a subcooled film is flowing downward on the inside of one side plate.

$$
h\left(\frac{\mu^{2}}{k^{3} \rho^{2} g}\right)^{\frac{1}{3}}=0.0087\left(\frac{4 \Gamma}{\mu}\right)^{0.4}\left(\frac{c \mu}{k}\right)^{0.34}
$$

where, $\mu, k, \rho, g, \Gamma$, and $c$ represent the dynamic viscosity, thermal conductivity, density, gravitational acceleration, mass flowrate per length, and specific heat, respectively, of the fluid. The evaluated HTC is $0.7041 \mathrm{~W} / \mathrm{cm}^{2}-^{\circ} \mathrm{C}$ under the NBSR guillotine break LOCA conditions.

\subsubsection{Decay Power and Power Distribution among Fuel Plates}

As shown in Table 2.5, the GBLOCAs cause the upper fuel plate to be uncovered from around 5 $\mathrm{s}$ to $10 \mathrm{~s}$ after the first reactor scram, depending on the break location. The decay power at $5 \mathrm{~s}$ is conservatively chosen as the initial power in the simulations. Figure 3.16 shows the decay power fraction used in the analysis for the fuel at end-of-cycle from $5 \mathrm{~s}$ after a reactor scram. The curve is from the decay heat model in RELAP5 (ISL, 2001); known to be conservative (Brown, 2013). The abscissa is

$$
t_{\text {HEATING7.3 }}=t_{\text {Decay }}-5 \mathrm{~s}
$$

where the variable $t_{\text {Decay }}$ is the time after reactor scram. Power fraction is the current decay power divided by the operating power of 20.4 MW (conservative to account for uncertainties).

$$
P_{\text {Fraction }}=\frac{\text { Current Decay Power }}{20.4 \mathrm{MW}}
$$




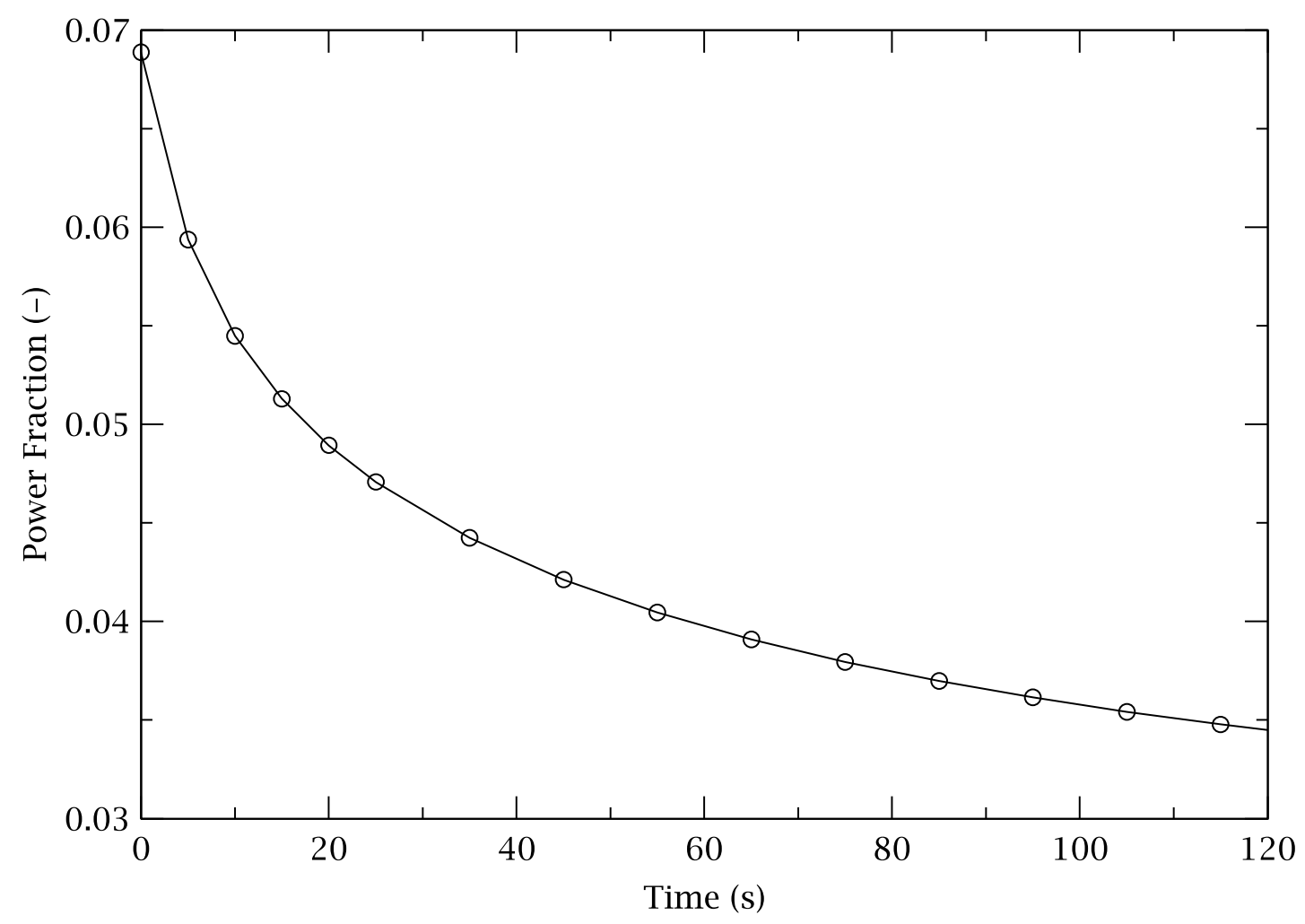

Figure 3.16 Power Fraction as Function of Time in GBLOCA Simulations

The decay power at time zero on the graph must be obtained as a function of location in the fuel element. It is obtained for the fuel element with the hottest location in the core at end-of-cycle conditions when decay heat is expected to be largest (and closest to the infinite irradiation condition utilized in obtaining Figure 3.16). Approximately 50\% of the decay power is due to alpha and beta radiation which can be assumed to be deposited in the fuel at the site at which it originated. Hence, the steady-state power distribution (the source of the fission products) is used to determine the energy deposition distribution for that portion of the decay heat.

The gamma energy deposition, the other $50 \%$ of decay power, could be assumed to also follow that source distribution. However, since calculations of gamma transport using a Monte Carlo method were available [(Williams, 2014a) and (Williams, 2014b)], credit was taken for the actual distribution of gamma energy deposition in the fuel meat, clad, and other parts of the fuel element. Figure 3.17 shows a comparison of the steady state power distribution (photon emission) and the calculated energy deposition (photon absorption) on a platewise basis. The values in the figure are the normalized values in the upper section of the fuel element L-3. The resulting total energy deposition is shown in Table 3.4 not only for the fuel plates, but for all other materials in the element. For the axial direction as well as the transverse direction in the fuel plates, the steady-state power distribution was used for all components of the decay power while uniform power distribution is assumed in the other materials.

The power densities in the fuel plates and other materials decrease from their initial values given in Table 3.4 according to the relative decay power fraction of Figure 3.16 as the HEATING7.3 simulation time progresses. 


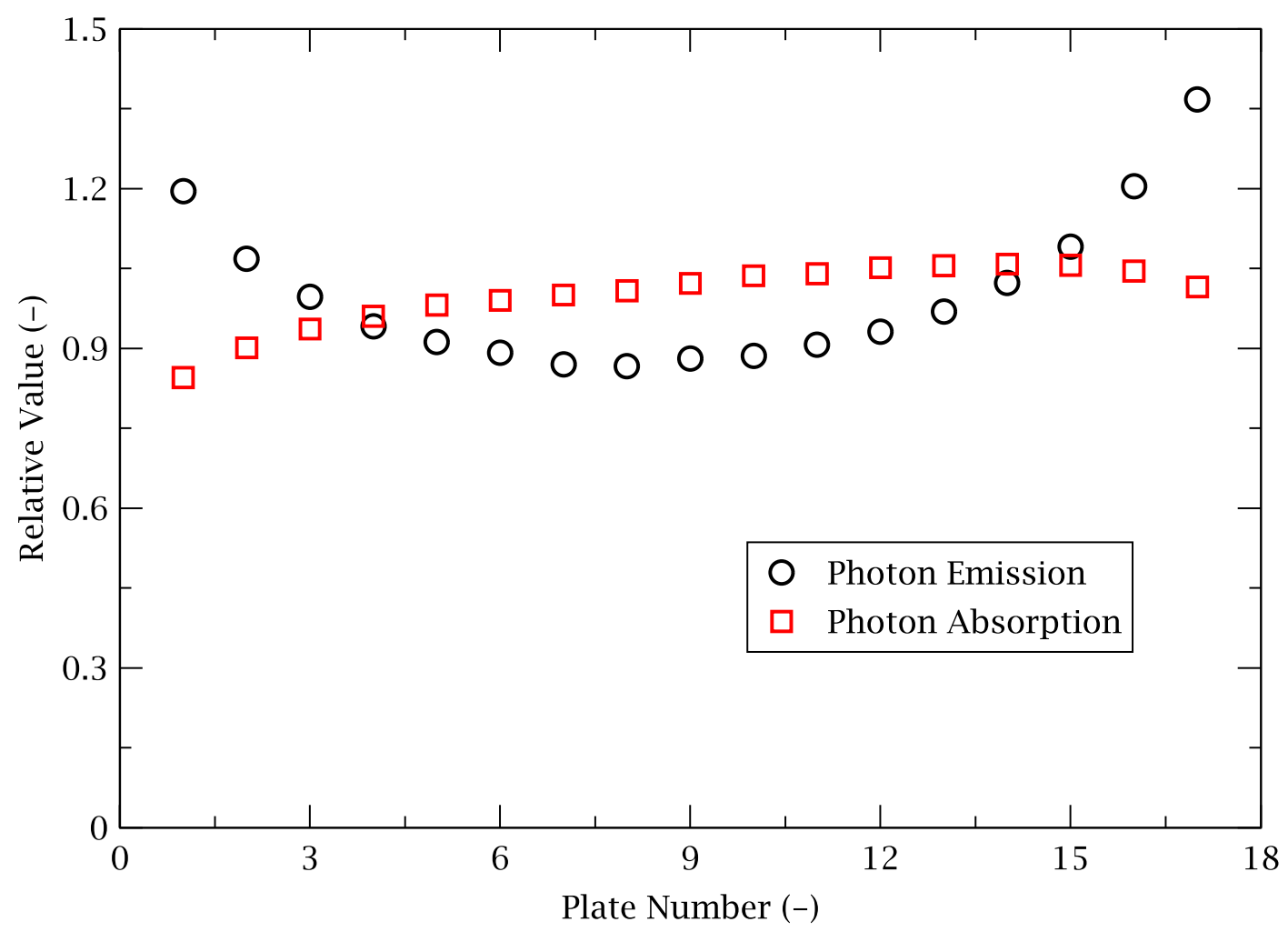

Figure 3.17 Normalized Photon Emission and Absorption Rates in Fuel Element L-3 (Williams, 2014b)

Table 3.4 Power Densities in Fuel Element L-3

\begin{tabular}{|c|c|c|}
\hline \multirow[t]{2}{*}{ Plate No. or Name } & \multicolumn{2}{|c|}{ Initial Power Density $\left(\mathrm{W} / \mathrm{cm}^{3}\right)$} \\
\hline & Upper Section & Lower Section \\
\hline 17 & 134.93 & 120.47 \\
\hline 16 & 121.28 & 108.45 \\
\hline 15 & 112.90 & 100.85 \\
\hline 14 & 105.72 & 94.94 \\
\hline 13 & 101.54 & 90.74 \\
\hline 12 & 98.18 & 87.72 \\
\hline 11 & 95.46 & 85.57 \\
\hline 10 & 93.43 & 84.05 \\
\hline 9 & 92.51 & 82.75 \\
\hline Clad in fuel plates & 2.94 & 2.52 \\
\hline $\begin{array}{l}\text { Side and outside plates } \\
\text { adjacent to fuel plates }\end{array}$ & 2.18 & 2.18 \\
\hline Upper side plates & 0.39 & 1.28 \\
\hline Lower side plates & 1.28 & 0.39 \\
\hline
\end{tabular}




\subsection{GBLOCA Simulations}

The GBLOCA end-state of Figure 2.7 is considered for the HEATING 7.3 simulations. In this scenario the fuel plates are uncovered. The outside of the upper fuel element is also dry while the outside of the lower section is submerged in the water of the hold-up pan. The thickness of the falling liquid film on the inside of one side plate will depend on the coolant mass flowrate and its velocity. Analysis has been conducted with two film thicknesses, $0.1 \mathrm{~cm}$ and $0.4 \mathrm{~cm}$. The former $(0.1 \mathrm{~cm})$ is conservatively chosen to represent the film thickness covering only the non-heated region (R-9 in Figure 3.2). The latter $(0.4 \mathrm{~cm})$ is used for a thicker falling film to examine its effect on the clad temperature.

\subsubsection{Steady-State}

HEATING7.3 transient runs begin when the upper or lower fuel plates start to be uncovered with an assumption that the fuel plates are totally uncovered instantaneously because the drainage occurs in a very short time as discussed in Section 2.2.1. It is assumed that the temperatures in the fuel element don't change from normal operating conditions until the heated section is uncovered. To obtain the steady state temperatures, HEATING7.3 has been run with a heat transfer coefficient (as a boundary condition) commensurate with the flowrate in a flow channel under normal operating conditions. The heat transfer coefficient is applied to all outer surfaces of the mesh regions (see Figure 3.4). The hot spot is located in the bottom of the upper fuel plates and in the top of the lower plates. Reactor inlet and outlet temperatures are $38^{\circ} \mathrm{C}$ and $46^{\circ} \mathrm{C}$, respectively, during normal operation (NIST, 2010a).

The steady-state average temperatures are predicted as shown in Table 3.5. $\Delta \mathrm{T}_{\mathrm{AVG}}$ is the difference between the material temperature and the reference bulk temperature, which is taken to be zero in the HEATING7.3 calculations. The steady state bulk (coolant) temperature varies between $38^{\circ} \mathrm{C}$ and $46^{\circ} \mathrm{C}$ and therefore, the highest initial average clad temperature (in plate 17 upper section) is $81^{\circ} \mathrm{C}\left(46^{\circ} \mathrm{C}+35^{\circ} \mathrm{C}\right)$. 
Table 3.5 Steady-State Average Temperatures in Upper and Lower Sections

\begin{tabular}{|c|c|c|c|c|c|c|c|}
\hline \multirow[b]{2}{*}{ Plate } & \multirow[b]{2}{*}{ Name } & \multicolumn{2}{|c|}{$\Delta \mathrm{T}_{\mathrm{AVG}}\left({ }^{\circ} \mathrm{C}\right)$} & \multirow[b]{2}{*}{ Plate } & \multirow[b]{2}{*}{ Name } & \multicolumn{2}{|c|}{$\Delta T_{\text {AVG }}\left({ }^{\circ} \mathrm{C}\right)$} \\
\hline & & $\begin{array}{l}\text { Upper } \\
\text { Section }\end{array}$ & $\begin{array}{c}\text { Lower } \\
\text { Section }\end{array}$ & & & $\begin{array}{c}\text { Upper } \\
\text { Section }\end{array}$ & $\begin{array}{l}\text { Lower } \\
\text { Section }\end{array}$ \\
\hline \multirow{3}{*}{ Outside } & Clad & 0.71 & 0.0 & \multirow{3}{*}{$13^{\text {th }}$} & Clad & 23.53 & 22.66 \\
\hline & Fuel meat & NA & NA & & Fuel meat & 32.23 & 29.0 \\
\hline & Side plate & 5.07 & 0.25 & & Side plate & 8.63 & 0.45 \\
\hline \multirow{3}{*}{$17^{\text {th }}$} & Clad & 34.53 & 31.35 & \multirow{3}{*}{$12^{\text {th }}$} & Clad & 22.67 & 21.82 \\
\hline & Fuel meat & 44.14 & 40.06 & & Fuel meat & 31.05 & 27.91 \\
\hline & Side plate & 7.77 & 0.39 & & Side plate & 8.35 & 0.43 \\
\hline \multirow{3}{*}{$16^{\text {th }}$} & Clad & 28.41 & 27.68 & \multirow{3}{*}{$11^{\text {th }}$} & Clad & 22.01 & 21.24 \\
\hline & Fuel meat & 39.3 & 35.53 & & Fuel meat & 30.11 & 27.17 \\
\hline & Side plate & 9.01 & 0.47 & & Side plate & 8.12 & 0.42 \\
\hline \multirow{3}{*}{$15^{\text {th }}$} & Clad & 26.36 & 25.5 & \multirow{3}{*}{$10^{\text {th }}$} & Clad & 21.5 & 20.82 \\
\hline & Fuel meat & 36.29 & 32.71 & & Fuel meat & 29.39 & 26.62 \\
\hline & Side plate & 9.16 & 0.47 & & Side plate & 7.96 & 0.41 \\
\hline \multirow{3}{*}{$14^{\text {th }}$} & Clad & 24.58 & 23.82 & \multirow{3}{*}{$9^{\text {th }}$} & Clad & 21.29 & 20.50 \\
\hline & Fuel meat & 33.73 & 30.55 & & Fuel meat & 29.12 & 26.2 \\
\hline & Side plate & 8.93 & 0.46 & & Side plate & 7.88 & 0.41 \\
\hline \multirow{3}{*}{$\begin{array}{l}\text { Extended } \\
\text { lower } \\
\text { region }\end{array}$} & Clad & 0.1 & 0.0 & \multirow{3}{*}{$\begin{array}{c}\text { Extended } \\
\text { upper } \\
\text { region }\end{array}$} & Clad & 0.0 & 0.0 \\
\hline & Fuel meat & NA & NA & & Fuel meat & NA & NA \\
\hline & Side plate & 0.01 & 0.0 & & Side plate & 0.0 & 0.0 \\
\hline
\end{tabular}

\subsubsection{Base Case - Perfect Thermal Contact}

In this section the analysis assumes that the fuel plates and the side plates are in perfect contact thermally. The simulation results are presented for the upper and lower sections separately.

\subsubsection{Upper Section of Fuel Element}

Figure 2.7 shows that the upper section of the fuel element is exposed to the gas (air and/or helium) and liquid films flow downward on the inside of one side plate (the slot material) in each flow channel. Only the falling films remove heat generated in the fuel element as the heat transfer to the gas is negligible. The results for the peak clad temperature (PCT) are depicted in Figure 3.18. In the figure the abscissa and ordinate represent the temperature difference between the clad surface and the falling liquid film and the time after the fuel plate is uncovered, respectively. The symbols represent the predicted values and are connected using straight lines. The maximum temperature difference is $284^{\circ} \mathrm{C}$ at $~ 90 \mathrm{~s}$ with a film thickness of $0.1 \mathrm{~cm}$ and $250^{\circ} \mathrm{C}$ at $\sim 80 \mathrm{~s}$ with a film thickness of $0.4 \mathrm{~cm}$. Since the liquid temperature is expected to be less than saturation (and more than $\sim 41^{\circ} \mathrm{C}$ ), the coolant exit temperature during operation, the maximum PCT is lower than the blister temperature of $450^{\circ} \mathrm{C}$. 


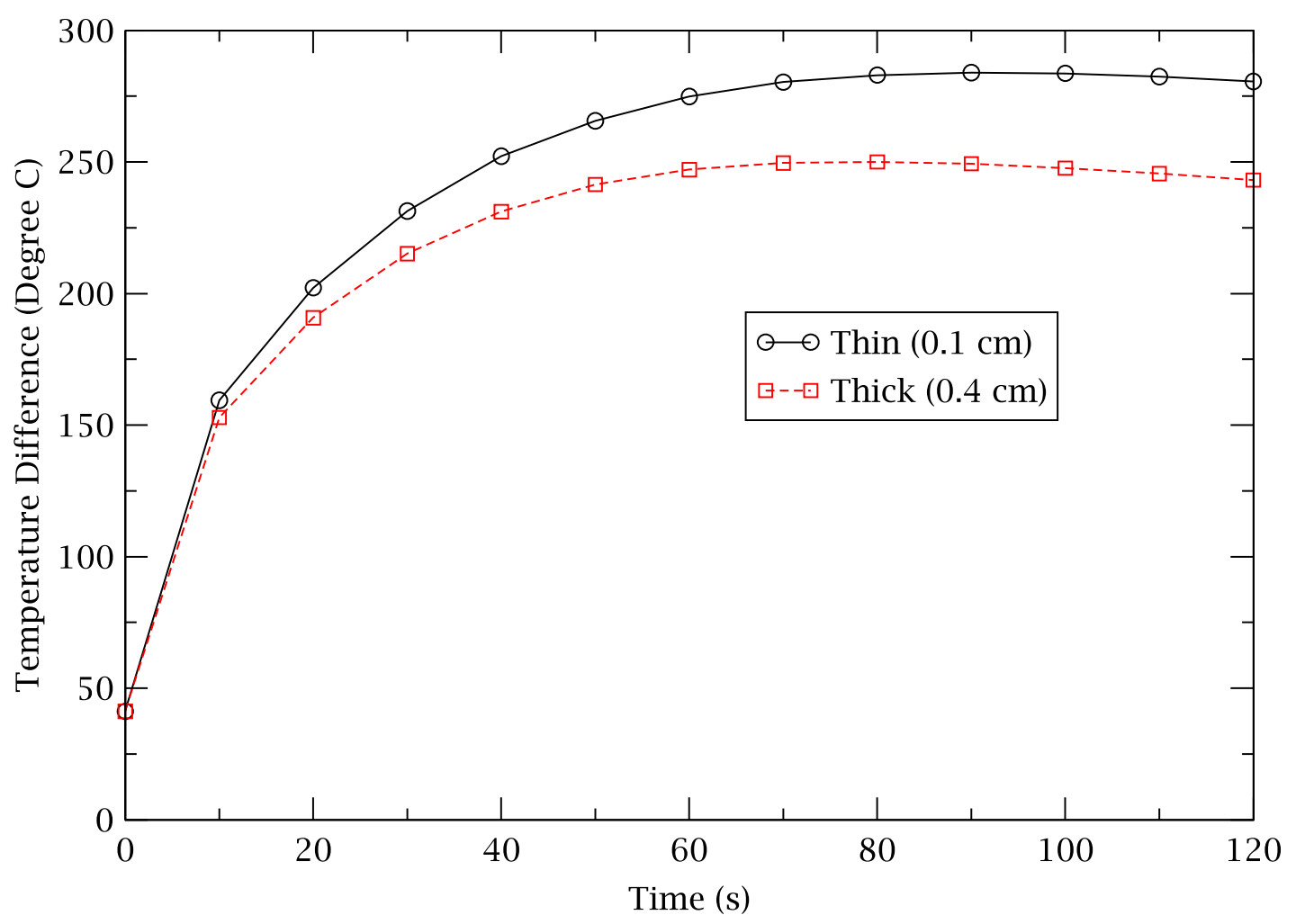

Figure 3.18 Peak Clad Temperature of Upper Fuel Plates after GBLOCA

Figure 3.19 shows the temperature on the surface of the $17^{\text {th }}$ plate on which the thin $(0.1 \mathrm{~cm})$ film flows downwardly. Figure 3.2 and Figure 3.3 show the $\mathrm{X}, \mathrm{Y}$, and $\mathrm{Z}$ coordinates given in Figure 3.19. If the water temperature is assumed to be $41^{\circ} \mathrm{C}$ in the IRT, the surface temperature reaches the boiling temperature of $101^{\circ} \mathrm{C}$ at $\sim 80 \mathrm{~s}$ because the temperature difference becomes $\sim 60^{\circ} \mathrm{C}$ at $\mathrm{X}=3.01 \mathrm{~cm}$ at that time. (Actually it will happen earlier than $80 \mathrm{~s}$ because the film temperature will increase as it flows downward.) At that point subcooled boiling may occur on the surface. 


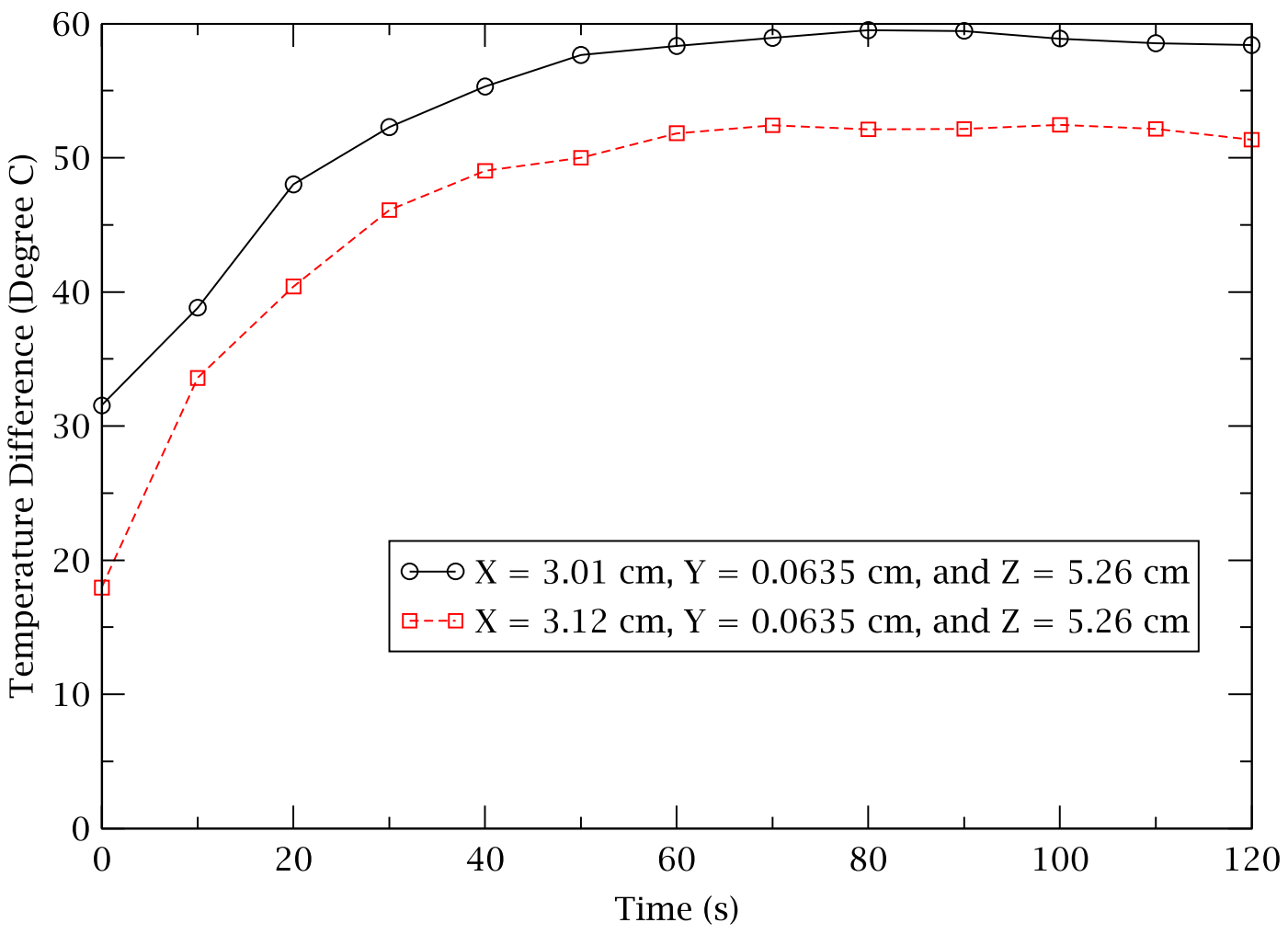

Figure 3.19 Temperature of Surface with Thin Film after GBLOCA

Fujita and Ueda suggested the heat transfer coefficient for nucleate boiling in falling film on a vertical plate (Fujita, 1978):

$$
h=0.006\left(\frac{\mu^{2}}{k^{3} \rho^{2} g}\right)^{-\frac{1}{3}}\left(\frac{4 \Gamma}{\mu}\right)^{0.4}
$$

where, $\mu, k, \rho, g$, and $\Gamma$ represent the dynamic viscosity, thermal conductivity, density, gravitational acceleration, and mass flowrate per length, respectively, of the fluid. The heat transfer coefficient with nucleate boiling becomes $0.5617 \mathrm{~W} / \mathrm{cm}^{2}-{ }^{\circ} \mathrm{C}$ with the initial mass flowrate of $2.8 \mathrm{~kg} / \mathrm{s}$ from the IRT at the saturation temperature of $101^{\circ} \mathrm{C}$. This HTC for nucleate boiling is smaller than the one used in the simulation $\left(0.7041 \mathrm{~W} / \mathrm{cm}^{2}-{ }^{\circ} \mathrm{C}\right)$ by considering subcooled turbulent film flow without evaporation. This means that if nucleate boiling occurs in the falling film on the side plate, it will result in a higher PCT than the one in Figure 3.18.

When the film is thicker $(0.4 \mathrm{~cm})$, the surface temperature is not so high $\left(\Delta \mathrm{T}<40^{\circ} \mathrm{C}\right)$ as shown in Figure 3.20, and nucleate boiling is not expected. The lower surface temperature in this case is because of the larger heat transfer area. The X, Y, and Z coordinates in Figure 3.20 are given in Figure 3.3 and Figure 3.5. The lower surface temperature at $X=3.12 \mathrm{~cm}$ at $10 \mathrm{~s}$ relative to time zero seems to be because the initial tempeature is a little high under this condition. As the energy accumulates, the surface temperature starts increasing. 


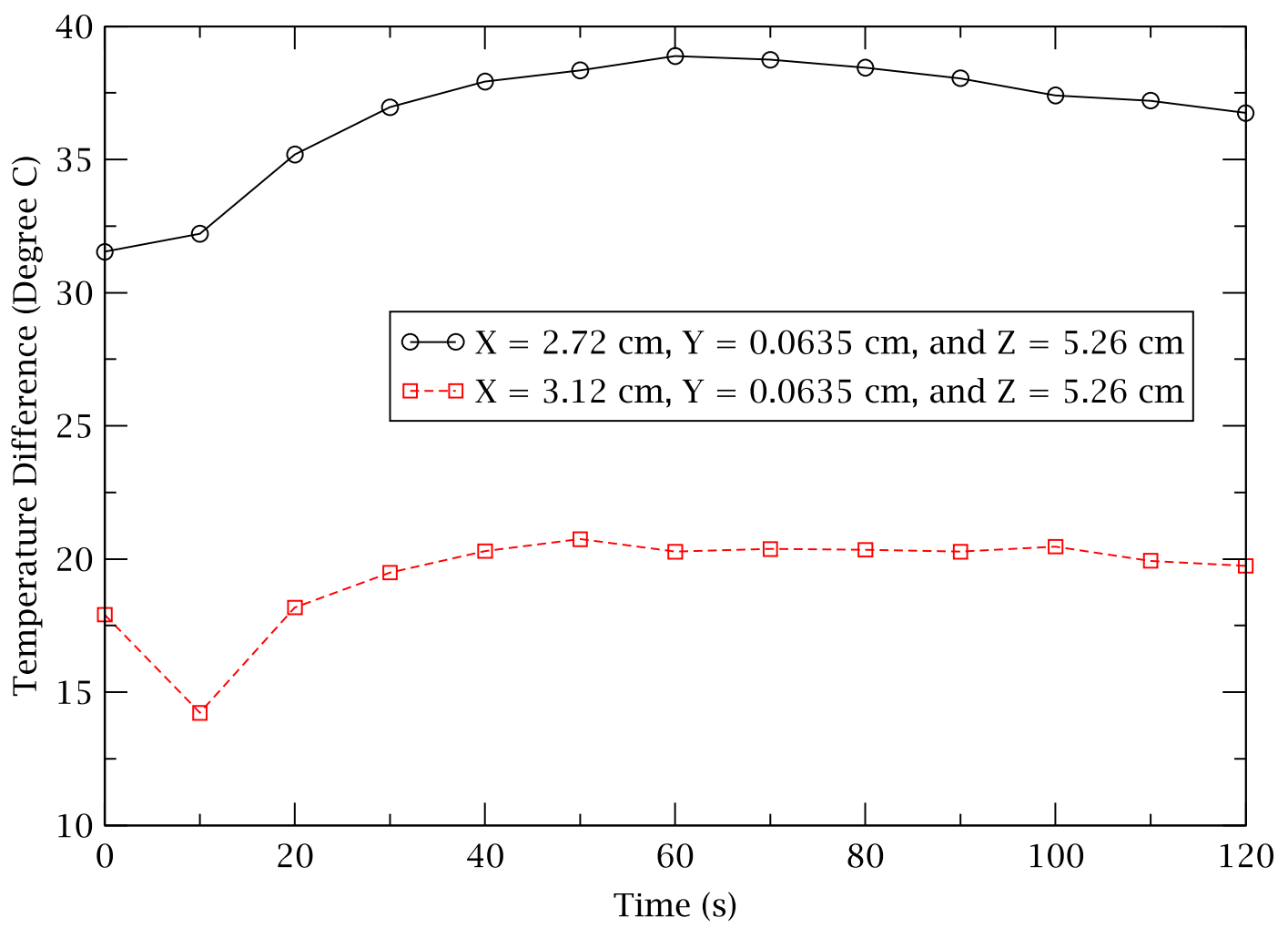

Figure 3.20 Temperature of Surface with Thick Film after GBLOCA

\subsubsection{Lower Section of Fuel Element}

The lower section of the fuel element is submerged in the hold-up pan water as shown in Figure 2.7. The outside of the side plates are in contact with quiescent water and the liquid film flows downward on the inside of one side plate (the slot material). The results of HEATING7.3 runs for the lower fuel plates are shown in Figure 3.21. The maximum PCT (temperature difference between the clad and the liquid in the hold-up pan) is $154^{\circ} \mathrm{C}$ at $\sim 20 \mathrm{~s}$ with the thin liquid film $(0.1 \mathrm{~cm})$. In this case the maximum PCT is much lower than the blister temperature of $450^{\circ} \mathrm{C}$. 


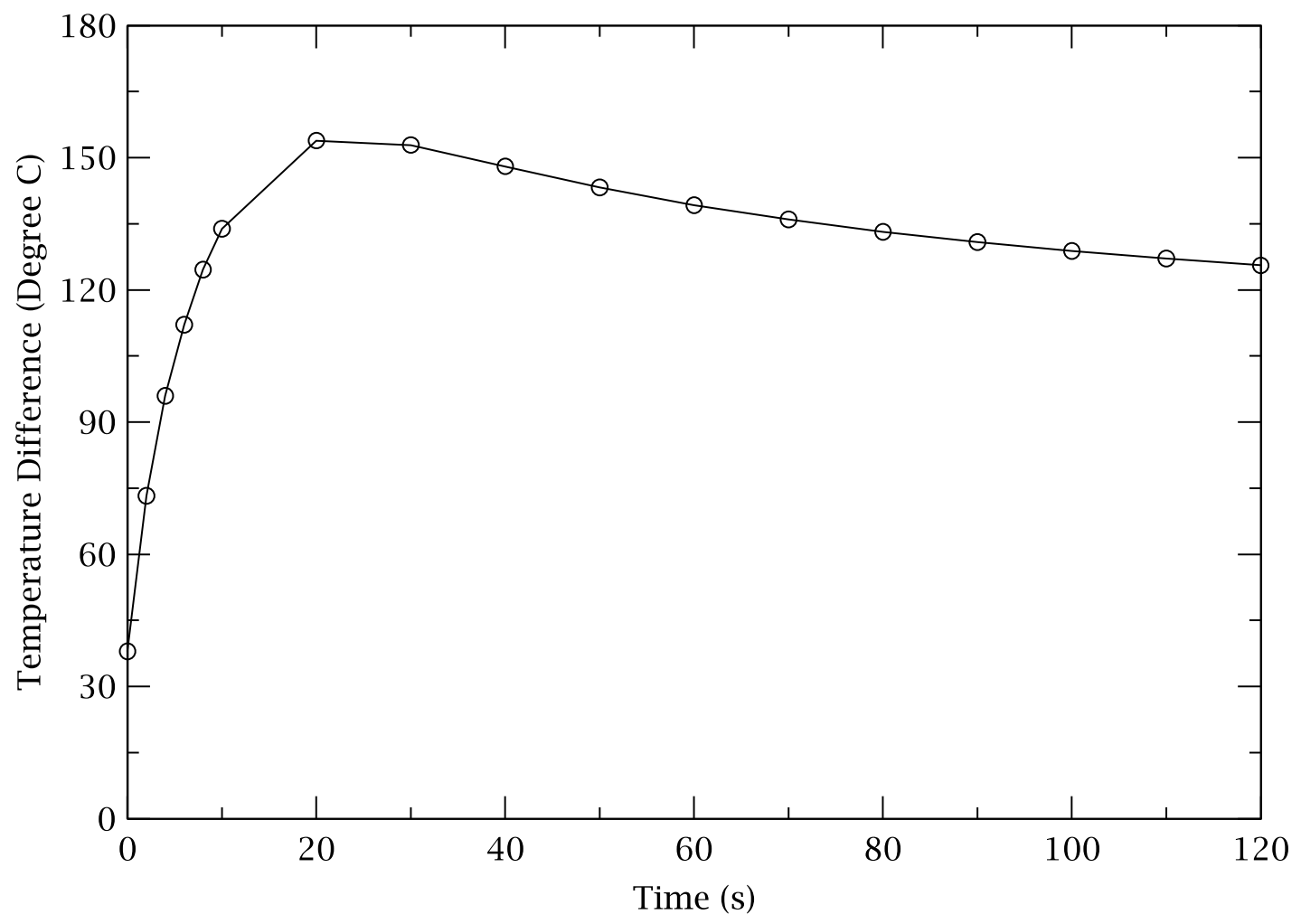

Figure 3.21 PCT in Lower Fuel Plates with Thin Liquid Film after GBLOCA

\subsubsection{Imperfect Thermal Contact}

The clad temperature behavior has been investigated when the thermal contact is not perfect between the fuel plates and side plates. In the analysis two cases with different contact areas are considered; a complete (100\%) contact (see Figure 3.10) and an incomplete (50\%) one (see Figure 3.13). The contact conductance of the former and the latter is evaluated to be $31.81 \frac{\mathrm{W}}{\mathrm{cm}^{2} \cdot \mathrm{K}}$ and $61.45 \frac{\mathrm{W}}{\mathrm{cm}^{2} \cdot \mathrm{K}}$ with the minimum joint strength of $26.8 \frac{\mathrm{kg}_{\mathrm{f}}}{\mathrm{cm}}\left(150 \frac{\mathrm{lb}_{\mathrm{f}}}{\mathrm{in}}\right)$ of roll swaged joint as discussed in Section 3.1.5.2. Only the upper section of the fuel element is analyzed with respect to the imperfect thermal contact.

The case with imperfect thermal contact and 100\% contact area have been analyzed by running HEATING7.3 with the input model of Figure 3.3, Figure 3.4, and Figure 3.10. The incomplete (50\%) contact area between the fuel plates and side plates is simulated using the input model of Figure 3.3, Figure 3.4, and Figure 3.13 with a contact conductance of $61.45 \frac{\mathrm{W}}{\mathrm{cm}^{2} \cdot \mathrm{K}}$. In both cases a film thickness of $0.1 \mathrm{~cm}$ is considered. Figure 3.22 compares the predicted PCTs to the one with perfect thermal contact and complete contact area. As shown in the figure, the effect of imperfect thermal contact and incomplete contact area on the PCT is almost negligible. This is because the contact conductance increases to $61.45 \frac{\mathrm{W}}{\mathrm{cm}^{2} \cdot \mathrm{K}}$ from $31.81 \frac{\mathrm{W}}{\mathrm{cm}^{2} \cdot \mathrm{K}}$ when the contact area is reduced by $50 \%$ and the conductance of $31.81 \frac{\mathrm{W}}{\mathrm{cm}^{2} \cdot \mathrm{K}}$ is already very high resulting in 
almost identical PCT behavior as with perfect thermal contact. The highest PCTs are all lower than the blister temperature of $450^{\circ} \mathrm{C}$ even when the film temperature is $101^{\circ} \mathrm{C}$ (saturation temperature).

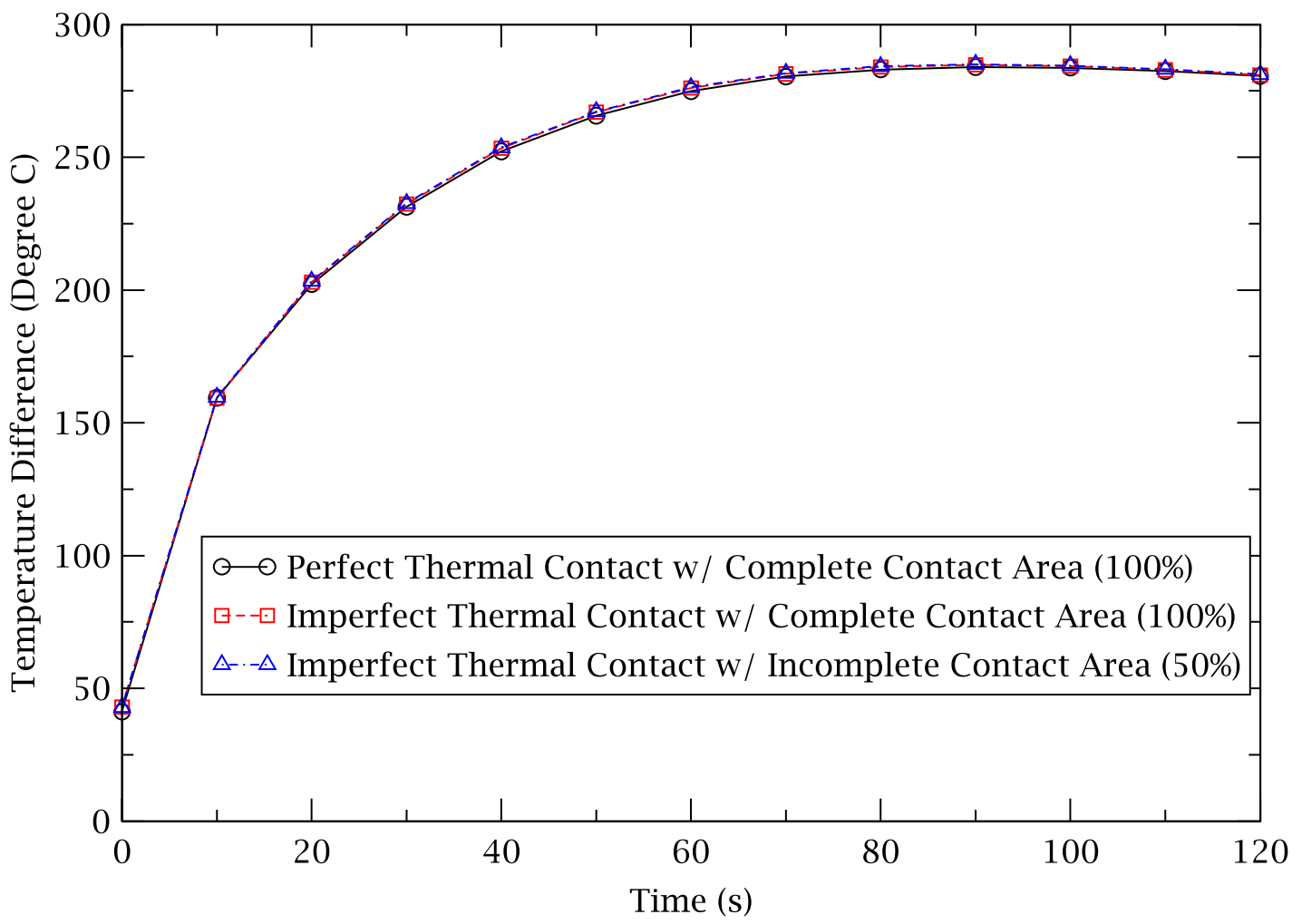

Figure 3.22 Effect of Thermal Contact and Contact Area on PCT

\subsubsection{Other Considerations}

\subsubsection{Uncertainty in Correlation for Contact Conductance}

No information was available on the uncertainty in the correlation, Eq. (3-11), used to evaluate the thermal contact conductance. By assuming that the correlation has an uncertainty range of $\pm 25 \%$, a contact conductance of $23.86 \frac{\mathrm{W}}{\mathrm{cm}^{2} \cdot \mathrm{K}}$ has been obtained as a low limit. When $100 \%$ contact area is considered, HEATING7.3 predicts the PCT behavior as shown in Figure 3.23. The difference between the PCT and liquid film temperature is predicted to be $285^{\circ} \mathrm{C}$ at $\sim 90 \mathrm{~s}$ in the both cases. 


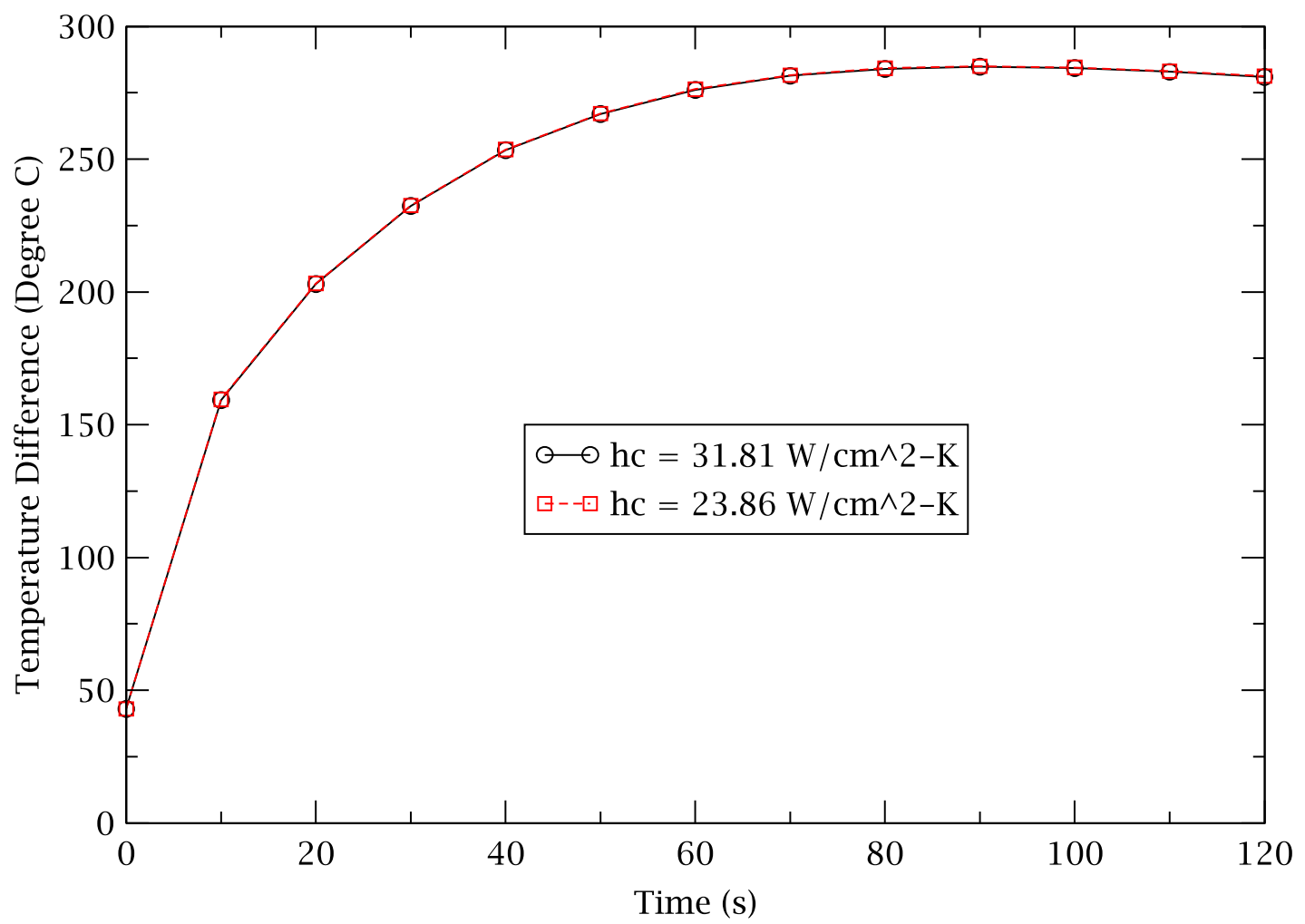

Figure 3.23 Effect of Smaller Contact Conductance on PCT

Again, as shown in Figure 3.23, the clad temperature behavior is very similar in the both cases. A smaller contact conductance (by 25\%) has almost negligible effect on the PCT with the contact pressure of $5.03 \mathrm{MPa}$ discussed in Section 3.1.5.2. Based on the discussions in this and previous sections, it can be concluded that when the swaged joint strength is $26.8 \frac{\mathrm{kg}_{\mathrm{f}}}{\mathrm{cm}}\left(150 \frac{\mathrm{lb}_{\mathrm{f}}}{\mathrm{in}}\right)$, the contact pressure between the fuel plates and side plates is so high that the contact conductance is very large and variation of its value up to $25 \%$ doesn't significantly affect the PCT .

\subsubsection{Thinner Liquid Film}

In the HEATING7.3 simulations discussed in the previous sections, it was assumed that the water is evenly distributed among the 18 flow channels at the level of the fuel plates in a fuel element. The film thickness is evaluated to be $0.118 \mathrm{~cm}$ (Section 3.1.4) but conservatively assumed to be about $0.1 \mathrm{~cm}$ in the simulations. However, it is expected, and was observed in simple demonstrations that after the water from the distribution pan impinges on the top of the fuel element, especially under GBLOCA conditions, most of the water falls down the side of the side plate where the water impinges. This would be the left region of the side plate shown in Figure 3.24 and would be caused by the internal structures (the center metal bar, latch bars, and windows) that interrupt the spread of the film. Figure 3.24 shows the water impingement in a mockup with the upper part of the fuel element including the upper end adapter. 


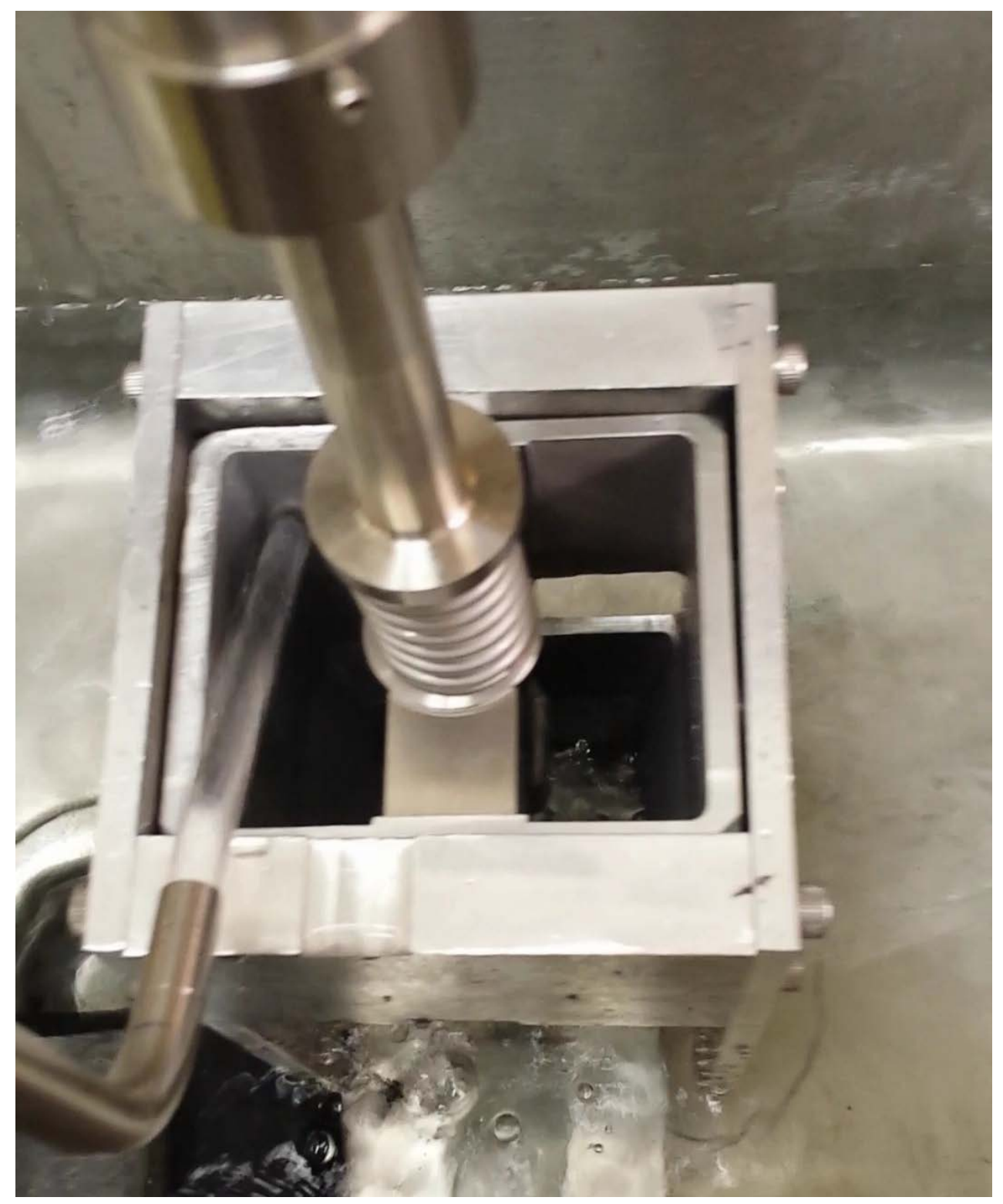

Figure 3.24 Water Impingement in Mockup Test with Upper Part of Fuel Element

No measurements have been made of the film thickness and mass flowrate in the partial mockup shown in the figure and no demonstrations have been done with an entire fuel element. Hence, the film thickness in each of the 18 coolant channels is estimated. In the calculations in Section 3.1.4, the thickness was assumed to be uniform across the side plate. In the following it is assumed that the thickness is considerably less along the side of the side plate being modeled in HEATING7.3 with another assumption that the nine fuel plates are located in the right hand side of Figure 3.24. Two small film mass flowrates, $1 / 4$ (1.05 g/s per fuel channel) and 1/5 (0.84 g/s per fuel channel) of the average film flowrate, are considered in the right region in the analysis. The heat transfer coefficients of the film are $0.4044 \mathrm{~W} / \mathrm{cm}^{2}-\mathrm{K}$ at $1.05 \mathrm{~g} / \mathrm{s}$ and $0.3699 \mathrm{~W} / \mathrm{cm}^{2}-\mathrm{K}$ at $0.84 \mathrm{~g} / \mathrm{s}$. The method discussed in Section 3.1.4 is applied to calculate the film thicknesses that are $0.046 \mathrm{~cm}$ with the former and $0.04 \mathrm{~cm}$ with the latter. However, thinner (about a half) 
thicknesses of $0.025 \mathrm{~cm}$ for $1.05 \mathrm{~g} / \mathrm{s}$ and $0.02 \mathrm{~cm}$ for $0.84 \mathrm{~g} / \mathrm{s}$ are conservatively used in the simulations.

Figure 3.25 shows the PCT behavior with the smaller mass flowrates. The highest PCTs are $340^{\circ} \mathrm{C}$ and $351^{\circ}$ at $120 \mathrm{~s}$ with the mass flowrates of $1.05 \mathrm{~g} / \mathrm{s}$ and $0.84 \mathrm{~g} / \mathrm{s}$. While the former mass flowrate results in a lower PCT than the blister temperature of $450^{\circ} \mathrm{C}$, the latter one would cause the PCT to reach $450^{\circ} \mathrm{C}$ if the film temperature is close to its saturation temperature of $101^{\circ} \mathrm{C}$.

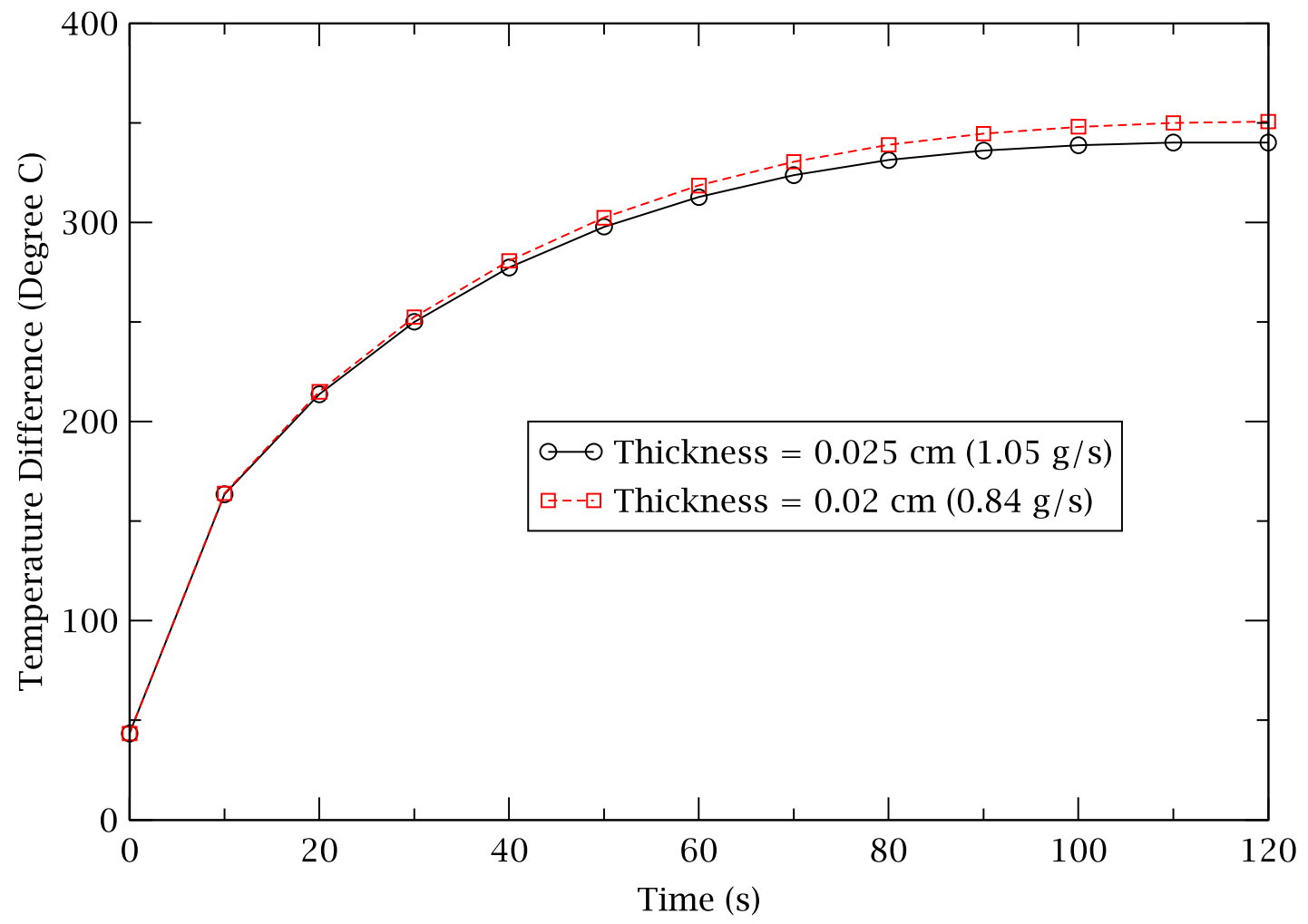

Figure 3.25 PCT Behavior with Smaller Mass Flowrates

However, the reality is that a significant amount of water is dripping down vertically from the center bar and latch bars and it contacts some fuel plates directly. Hence, another case is simulated by assuming that the film thickness is $0.02 \mathrm{~cm}$ in a flow channel and the dripping water flowrate is about $1 / 4$ of the total flow $(0.7 \mathrm{~kg} / \mathrm{s})$ and covers half of one clad surface (the mesh region R-135 in Figure 3.4) from $0.0 \mathrm{~cm}$ to $3.0 \mathrm{~cm}$ in the X-direction. For this liquid film due to the water dripping, the heat transfer coefficient is evaluated to be $0.4945 \mathrm{~W} / \mathrm{cm}^{2}-\mathrm{K}$.

Figure 3.26 shows the effect of the dripping water on the PCT. The maximum PCT is $316^{\circ} \mathrm{C}$ at $100 \mathrm{~s}$ when the $9^{\text {th }}$ plate is also cooled by the dripping water. In reality, there are eight more fuel plates (plus another end plate) that are present but not modeled in HEATING7.3 and they are cooled more effectively because more water is available for them than for the plates being simulated. This fact will lead to a lower PCT than calculated for Figure 3.25 and Figure 3.26 and hence, the maximum PCT is expected to be less than the blister temperature of $450^{\circ} \mathrm{C}$ under GBLOCA conditions. 


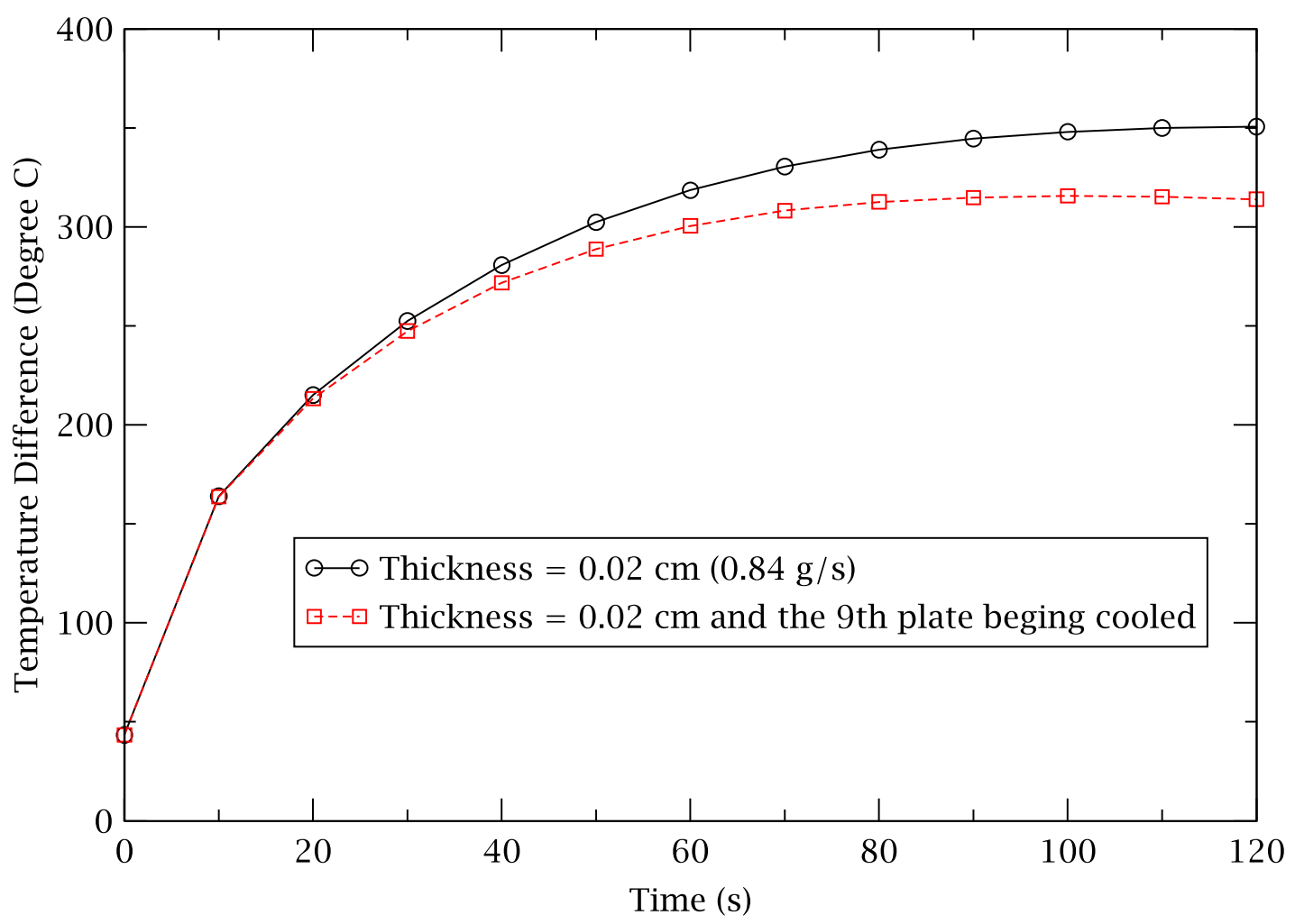

Figure 3.26 Effect of the $9^{\text {th }}$ Plate Being Cooled by Dripping Water

Although very small film mass flowrates resulting in thinner film thicknesses are arbitrarily considered in this analysis, if the actual mass flowrate after impingement was known and found to be less than $0.84 \mathrm{~g} / \mathrm{s}$ per flow channel in the right hand side of Figure 3.24, additional calculations with HEATING7.3 would need to be run to simulate the case and verify that there is no damage to the integrity of the fuel plates.

\subsubsection{Summary of GBLOCA Simulations}

If a guillotine break occurs in the NBSR primary system, the maximum PCT is expected to be lower than the blister temperature of $450^{\circ} \mathrm{C}$. The uncertainty in the thermal contact resistance at the joint between the fuel plates and the side plate has negligible effect on the prediction of the PCT as does the contact area at that location.

Table 3.7 shows the maximum PCTs with an initial transient power corresponding to the decay power level at $5 \mathrm{~s}$ after reactor scram. The values in the $6^{\text {th }}$ column of Table 3.7 are the maximum temperature difference between the clad and the surrounding water, so the actual PCT depends on the surrounding coolant temperature.

Table 3.6 Maximum PCTs after Guillotine Break 


\begin{tabular}{|c|c|c|c|c|c|}
\hline $\begin{array}{l}\text { Fuel plate } \\
\text { location }\end{array}$ & $\begin{array}{c}\text { Contact } \\
\text { conductance } \\
\left(\mathrm{W} / \mathrm{cm}^{2}-\mathrm{K}\right)\end{array}$ & $\begin{array}{c}\text { Contact } \\
\text { Area (\%) }\end{array}$ & $\begin{array}{c}\text { Film } \\
\text { thickness } \\
\text { (cm) }\end{array}$ & $\Delta \mathrm{T}_{\text {MAX }}\left({ }^{\circ} \mathrm{C}\right)$ & Time (s) \\
\hline \multirow{2}{*}{ Upper section } & \multirow{2}{*}{$\begin{array}{l}\text { Perfect } \\
\text { contact }\end{array}$} & \multirow{2}{*}{100} & 0.1 & 284 & 90 \\
\hline & & & 0.4 & 250 & 80 \\
\hline $\begin{array}{l}\text { Lower } \\
\text { section }\end{array}$ & $\begin{array}{l}\text { Perfect } \\
\text { contact }\end{array}$ & 100 & 0.1 & 154 & 20 \\
\hline \multirow{6}{*}{ Upper section } & $\begin{array}{c}31.81 \\
\text { (Imperfect } \\
\text { contact) }\end{array}$ & 100 & 0.1 & 285 & 90 \\
\hline & $\begin{array}{c}61.45 \\
\text { (Imperfect } \\
\text { contact) }\end{array}$ & 50 & 0.1 & 285 & 90 \\
\hline & $\begin{array}{c}23.86^{1} \\
\text { (Imperfect } \\
\text { contact) }\end{array}$ & 100 & 0.1 & 285 & 90 \\
\hline & \multirow{3}{*}{$\begin{array}{c}31.81 \\
\text { (Imperfect } \\
\text { contact) }\end{array}$} & \multirow{3}{*}{100} & 0.025 & 340 & 120 \\
\hline & & & 0.02 & 351 & 120 \\
\hline & & & $0.02^{2}$ & 316 & 90 \\
\hline
\end{tabular}

Note ${ }^{1}$ The contact conductance of $23.86 \frac{\mathrm{W}}{\mathrm{cm}^{2} \cdot \mathrm{K}}$ was evaluated with an uncertainty of $25 \%$.

${ }^{2} \mathrm{Half}$ of one clad surface of the $9^{\text {th }}$ fuel plate is additionally being cooled by water.

\subsection{SBLOCA Simulations}

As discussed in Section 2.2.2, SBLOCAs at the outer and inner plenum inlet pipes will cause the NBSR to reach the conditions shown in Figure 2.13 and Figure 2.15, in which the outside of the side plates are in contact with the coolant in both the upper and lower sections of the fuel elements. In addition, the inner or outer flow channels are filled with water depending upon the break location while the other flow channels are filled with gas (air and/or helium).

If the flow channels are completely drained, falling liquid film may be available on the inside of one side plate (the slot material). For the SBLOCA analysis, however, two arbitrarily extreme conditions are considered in the simulations. The initial decay power level is assumed to be the one at $5 \mathrm{~s}$ after reactor scram, which is the same as the initial power level used in the GBLOCA simulations. Another conservative assumption is that the falling film is not available in all flow channels, i.e., the fuel plates are cooled only by the quiescent water on the outside of the side plates. Figure 3.27 shows the simulation results with the contact conductance of $31.81 \frac{\mathrm{W}}{\mathrm{cm}^{2} \cdot \mathrm{K}}$ and $23.86 \frac{\mathrm{W}}{\mathrm{cm}^{2} \cdot \mathrm{K}}$. 


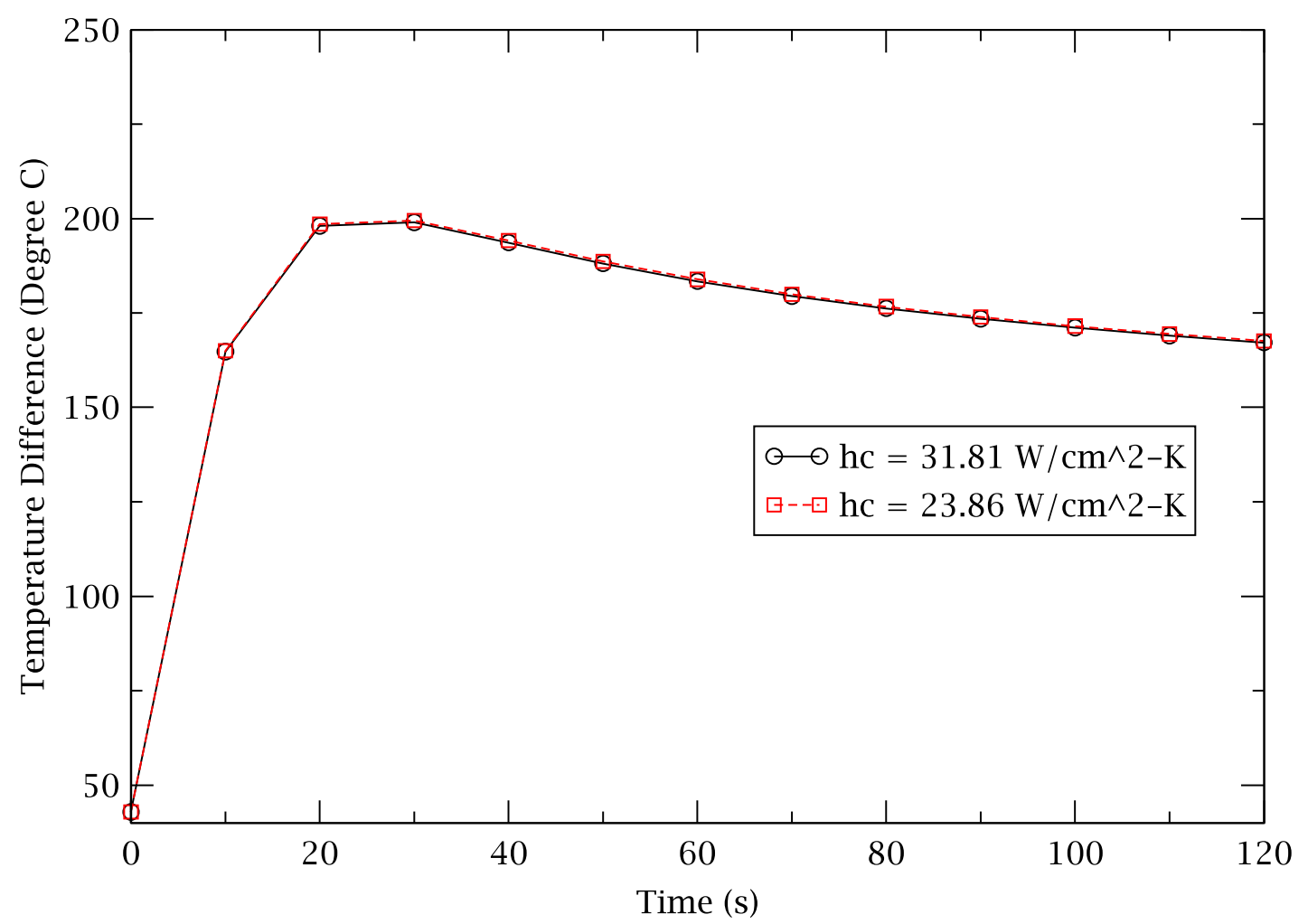

Figure 3.27 PCT in Upper Plates under Extreme SBLOCA Conditions

HEATING7.3 predicts the maximum temperature difference between the clad and the surrounding water to be $199.0^{\circ} \mathrm{C}$ at $\sim 30 \mathrm{~s}$ with $h_{c}=31.81 \frac{\mathrm{w}}{\mathrm{cm}^{2} \cdot \mathrm{K}}$ and $199.5^{\circ} \mathrm{C}$ at $\sim 30 \mathrm{~s}$ with $h_{c}=23.86 \frac{\mathrm{w}}{\mathrm{cm}^{2} \cdot \mathrm{K}}$. This indicates that the maximum PCTs are much lower than the blister temperature of $450^{\circ} \mathrm{C}$ even under arbitrarily assumed extreme SBLOCA conditions. From these results it can be deduced that the clad temperature will not reach its blister temperature after a typical SBLOCA, or even after a GBLOCA, as long as the side plates are in contact with quiescent water.

\section{Summary and Conclusions}

Analysis has been performed to investigate the NBSR response to pipe breaks at different locations. Guillotine break LOCAs and small break LOCAs were considered. Three break locations are taken into account: (1) the 18-inch pipe between the reactor vessel outlet and the control valve DWV-19; (2) the 14-inch pipe between the control valve DWV-1 and the outer plenum; and (3) the 10-inch pipe between the control valve DWV-2 and the inner plenum.

TRACE has been run to investigate the hydrodynamic behavior, especially the water level inside the NBSR following LOCAs. HEATING7.3 has been used to examine the clad temperature in the top and bottom fuel plates of the hottest fuel element given the coolant available after the fuel elements drain. The coolant available is from the inner reserve tank and the quiescent water in the hold-up pan. 
For a guillotine break LOCA in the primary system the analysis results are summarized below.

1. The fuel plates are uncovered at a very early stage of the accident: starting at $4.5 \mathrm{~s}$ with the break at the outer plenum inlet pipe; $6.3 \mathrm{~s}$ with the break at the vessel outlet pipe; and $9.0 \mathrm{~s}$ with the break at the inner plenum inlet pipe, after a LOCA signal on low level.

2. It takes only $0.7 \mathrm{~s}, 1.5 \mathrm{~s}$, or $2.2 \mathrm{~s}$ (depending upon the break location) for the upper fuel plates to be completely uncovered after their tops start to be uncovered.

3. Assuming that it takes more than $7 \mathrm{~s}$ to $22 \mathrm{~s}$ (depending on the break location) for the operator to stop the shutdown pump and shut the control valves (DWV-1, DWV-2, and DWV-19) in the primary system, the upper sections of the fuel elements are exposed to gas (helium) while the lower sections remain submerged (on the outside of the element) in the hold-up pan water.

4. Based on photographs showing the water from the IRT as it exits the distribution pan, it can be assumed that the emergency cooling water flows as a film down the inside of the fuel elements along one of the side plates.

5. Heat conduction is very effective between the fuel plates and side plates even with imperfect thermal contact between them; as effective as with perfect thermal contact, and the maximum PCT is lower than the blister temperature of $450^{\circ} \mathrm{C}$ in the upper fuel plates. The clad temperature of the lower fuel plates is predicted to be much lower than this conservative limit.

6. Even with smaller mass flowrate in flow channels, as small as $1 / 5$ of the one obtained by assuming that the water is evenly distributed among the 18 flow channels in a fuel element after the impingement, the highest PCT is predicted to be lower than the blister temperature.

As breaks of decreasing size (relative to a guillotine break) are considered, the behavior is expected to be similar to that for a guillotine break, but with lower temperatures, until there is sufficient time for operator actions. Operator actions lead to changes in the way the reactor drains.

Small break LOCA analysis has been performed with an arbitrary break size of $6.8 \mathrm{~cm}^{2}$ in the primary system to investigate the drainage behavior of the fuel plates in the fuel element. Two very conservative assumptions are made to examine the clad temperature behavior. The SBLOCAs allow for operator actions to take place. The analysis results are:

1. The fuel plates are drained very quickly in both the upper and lower sections after their top becomes uncovered. For the $6.8 \mathrm{~cm}^{2}$ break, this occurs at approximately $1700 \mathrm{~s}$ into the event.

2. The clad temperature does not reach its blister temperature after a typical SBLOCA regardless of the availability of liquid films as long as the outside of the side plates are 
cooled by the quiescent water. This is also true for a GBLOCA in spite of the fact that the decay energy that must be removed is higher because the fuel element drains earlier than in the SBLOCA case.

There are several factors that affect the results of the HEATING7.3 simulations for all break sizes:

1. Imperfect thermal contact is expected between the fuel plates and side plates. The simulation results depend on the contact conductance used to model the interface. However, because the contact conductance is very large when the swaged joint strength is as big as $26.8 \mathrm{~kg}_{\mathrm{f}} / \mathrm{cm}\left(150 \mathrm{lb}_{\mathrm{f}} / \mathrm{in}\right)$, the effect of uncertainty in the thermal contact resistance is small and the PCT behavior does not depend much on whether the contact area the joint is uniform or if only $50 \%$ of the area is in contact.

2. The water temperature is assumed to be constant during the transient runs. This assumption should be valid for the water outside of the fuel elements because of the large inventory in the vessel. However, the liquid film temperature inside the fuel elements is expected to increase as it flows downward, and the heat transfer coefficient to the subcooled falling film increases (slightly) with the film temperature based on the Wilke correlation. The change in coefficient will result in a slightly lower PCT.

3. A constant heat transfer coefficient $\left(0.7041 \mathrm{~W} / \mathrm{cm}^{2}-\mathrm{K}\right.$ based on a high flow rate $)$ is used for the falling liquid film in the simulations. As time passes, the film flow rate may decrease initially due to a reduction in the water column height in the inner reserve tank (although eventually operators will assure that more water gets into the IRT from the storage tank). Since the heat transfer coefficient depends on the falling liquid film flowrate, the coefficient may decrease as the IRT water level drops. This will result in a slightly higher PCT.

4. If the heat transfer regime changes from falling film convection to nucleate boiling on the surface of the side plate, the heat transfer coefficient decreases according to the Fujita and Ueda correlation. This will cause a slightly higher PCT at the bottom of the fuel plate where the film temperature is highest and when the film mass flowrate is small.

5. If the film mass flowrate is known to be very small on part of the side plate, smaller than $0.84 \mathrm{~g} / \mathrm{s}$ per flow channel in some channels, additional analysis would be needed to determine the maximum PCT after a GBLOCA. 


\section{References}

Adamson, G. M. Jr., “Fabrication of Research Fuel Elements,” Oak Ridge National Laboratory, ORNL-TM-2197, June 1968

ASM Material (Aerospace Specification Metals Inc.), Aluminum 6061-O, http://asm.matweb.com/search/SpecificMaterial.asp?bassnum=MA60610, as of January 2014

ASM (Aerospace Specification Metals Inc.), Aluminum 6061-T6, http://asm.matweb.com/search/SpecificMaterial.asp?bassnum=MA6061t6, as of December 2013.

Baek, J.S., "HEATING7.3 Model of NBSR Fuel Element,” Brookhaven National Laboratory, April 2014.

Baek, J.S., Cuadra, A., Hanson, A.L., Cheng, L-Y, Brown, N.R., and Diamond, D.J., “Accident Analysis for the NIST Research Reactor Before and After Fuel Conversion - Revision 1,” BNL9852-2012-IR-R1, Brookhaven National Laboratory, June 25, 2013.

Brown, N. and Cuadra, A., "Calculation of Short-Time Decay Power in the NBSR,” BNL memorandum, Brookhaven National Laboratory, January 3, 2014.

Cheng, L., Hanson, A., Diamond, D., Xu, J., Carew, J., and Rorer, D., "Physics and Safety Analysis for the NIST Research Reactor,” BNL-NIST-0803, Rev. 1, Brookhaven National Laboratory, April 2004.

Dassault Systèmes, “Thermal Contact Resistance,”, Solidworks Website, http://help.solidworks.com/2012/English/SolidWorks/cworks/thermal_contact_resistance.htm?fo rmat=P, 2012, as of February 2014.

Fujita, T. and Ueda, T., "Heat Transfer to Falling Liquid Films and Film Breakdown - II: Saturated Liquid Films with Nucleate Boiling,” International Journal of Heat and Mass Transfer, Vol. 21, pp. 109-118, 1978.

Incropera, F.P. and DeWitt, D.P., Fundamentals of Heat and Mass Transfer, Fourth Edition, John Wiley and Son, 1996.

ISL, "RELAP5/MOD3.3 Code Manual,” NUREG/CR-5535/Rev1, Information Systems Laboratories, Inc., Rockville, MD and Idaho Falls, ID, December 2001.

MIT Lecture Notes, “Chapter 5 Open-Channel Flow - MIT Open CourseWare,” http://ocw.mit.edu/courses/earth-atmospheric-and-planetary-sciences/12-090-special-topics-anintroduction-to-fluid-motions-sediment-transport-and-current-generated-sedimentary-structuresfall-2006/lecture-notes/ch5.pdf, As of April 2014. 
Mourgues, A., Hourtane, V., Muller, T., and Caron-Charles, M., “Boiling Behavior and Critical Heat Flux on a Horizontal and Vertical Plate in Saturated Pool Boiling with and without ZnO Nanofluid," International Journal of Heat and Mass Transfer, Vol. 57, pp. 595 - 607, 2013.

NBS, "Final Safety Analysis Report on the National Bureau of Standards Reactor," Supplement B, NBS 9B, National Bureau of Standards (NBS), December 16, 1966.

NIST, “NIST Assembled Fuel Element,” Drawing No. E-04-016, Rev. 4, Sheet No. 2 of 8, March 2012.

NIST, “NBSR Annunciator Procedures,” National Institute of Standards and Technology (NIST), 2011.

NIST, "Safety Analysis Report (SAR) for License Renewal for the National Institute of Standards and Technology Reactor - NBSR; NBSR 14, Rev 4,” National Institute of Standards and Technology (NIST), 2010a.

NIST, “Technical Specifications for the NIST Test Reactor (NBSR),” Appendix A to License No. TR-5, National Institute of Standards and Technology (NIST), 2010b.

NRC, “TRACE V5.0 Theory Manual,” U.S. Nuclear Regulatory Commission (NRC), June 4, 2010.

NRC, "Guidelines for Preparing and Reviewing Applications for the Licensing of Non-Power Reactors; Format and Content,” NUREG/CR-1537, Part 1, U.S. Nuclear Regulatory Commission, February, 1996.

ORNL, "Multidimensional, Finite-Difference Heat Conduction Analysis Code System, Versions 7.2i and 7.3,” RSICC Code Package PSR-199, Oak Ridge National Laboratory, August 2007.

O’Kelly, S., "RE: heat distribution in LOCA calculations,” Email to BNL, NIST Center for Neutron Research, March 05, 2014.

Stahl, D., “Fuels for Research and Test Reactors, Status Review: July 1982,” ANL-83-5, Argonne National Laboratory, December 1982.

Yen, B. C., “Open Channel Flow Resistance,” Journal of Hydraulic Engineering, January 2002

Yovanovich, M. M., Culham, J. R., and Teertstra, P., “Calculating Interface Resistance,” Microelectronics Heat Transfer Laboratory Department of mechanical Engineering university of Waterloo, http://www.mhtl.uwaterloo.ca/pdf_papers/mhtl97-4.pdf, as of March 2014. 
Williams, R., "Heat Distribution in LOCA Calculations - Continued," NIST Center for Neutron Research, March 21, 2014a.

Williams, R., “Gamma Ray Heating in Fuel Element L-3,” NIST Center for Neutron Research, March 11, 2014b.

Wolverine Tube Inc., “Wolverine Engineering Data Book II,” Chapter 5, 2001.

Wolverine Tube Inc., “Wolverine Engineering Data Book III,” Chapter 9, 2006. 